\title{
THE IMPACTS OF ARTERIAL OCCLUSION, SEX, AND EXERCISE ON ARTERIOGENESIS AND FUNCTIONAL VASODILATION
}

\author{
A Thesis \\ presented to \\ the Faculty of California Polytechnic State University, \\ San Luis Obispo
}

\author{
In Partial Fulfillment \\ of the Requirements for the Degree \\ Master of Science in Biomedical Engineering
}

by

Megan Tze-Mei Chu

December 2016 
(C) 2016

Megan Tze-Mei Chu

\section{ALL RIGHTS RESERVED}




\section{COMMITTEE MEMBERSHIP}

TITLE:

AUTHOR:

DATE SUBMITTED:

COMMITTEE CHAIR:

COMMITTEE CHATR:
The Impacts of Arterial Occlusion, Sex, and Exercise on Arteriogenesis and Functional Vasodilation

Megan Tze-Mei Chu

December 2016

COMMITTEE MEMBER: Jason Blank, Ph.D.

Associate Professor of Biology

COMMITTEE MEMBER: $\quad$ Lily Laiho, Ph.D.

Associate Professor of Biomedical Engineering 


\begin{abstract}
The Impacts of Arterial Occlusion, Sex, and Exercise on Arteriogenesis and Functional Vasodilation Megan Tze-Mei Chu
\end{abstract}

The most frequent clinical presentation of peripheral arterial occlusive disease (PAOD) is intermittent claudication, which may be caused by impaired vasodilation. Patients demonstrate both local and systemic impairments in vasodilation, but as the collateral circulation is the primary site of resistance to the ischemic zone, impaired collateral vasodilation would have the greatest potential to induce claudication. Collateral function following arterial occlusion is not well defined, but immature collaterals may demonstrate impaired vasodilation in animal models, although this is potentially improved with exercise training. Furthermore, as females exhibit poorer physical function with ischemia and less improvement with therapeutic exercise, there appears to be a sexually dimorphic response to PAOD, warranting a comparison in collateral vasodilation between sexes. In this study, the femoral artery was ligated to induce chronic ischemia in sedentary and exercise-trained mice, and at 7 or 28 days postsurgery, the diameter of the gracilis collateral arteriole was measured at rest and after gracilis muscle contraction using intravital microscopy. No major sex differences were observed in any group. At day 7 , both the resting and dilated diameters were increased, while vascular reactivity was minimal. By day 28 , resting diameter decreased while maximal diameter was unchanged, causing an increase in functional vasodilation. Exercise training also improved vasodilation by decreasing collateral resting diameter. These results are consistent with reported trends in endothelium-dependent and smooth muscle-dependent vasodilation, which are impaired in immature vessels and improved with maturation and exercise, but the significance of the observed variations in resting diameter remains unclear. Large resting diameters at day 7 could be due to a loss of sympathetic tone or the proliferative and non-contractile state of smooth muscle cells, while decreased resting diameters at day 28 could indicate that a smooth muscle contractile phenotype has been restored, or that the gracilis collateral is no longer the primary collateral. However, the further research is required to determine the functional relevance of collateral resting diameter and its importance in the ischemic limb circulation.

Keywords: collateral circulation, exercise training, ischemia, sexual dimorphism, vasodilation 


\section{ACKNOWLEDGMENTS}

I would like to thank Dr. Cardinal for his guidance throughout the duration of this project, and for always letting me tag along on his walks between classes to bombard him with questions.

Then, many thanks to the rest of the MaVR lab for their help and support, for always letting me vent, and for pretending to laugh at my nerdy science humor. You guys are awesome.

Finally, I would like to thank my parents for showing me their continued love and patience while also pushing me to achieve my potential (even when I don't want to hear it). Love you both so much.

"Somewhere, something incredible is waiting to be known."

- Carl Sagan 


\section{TABLE OF CONTENTS}

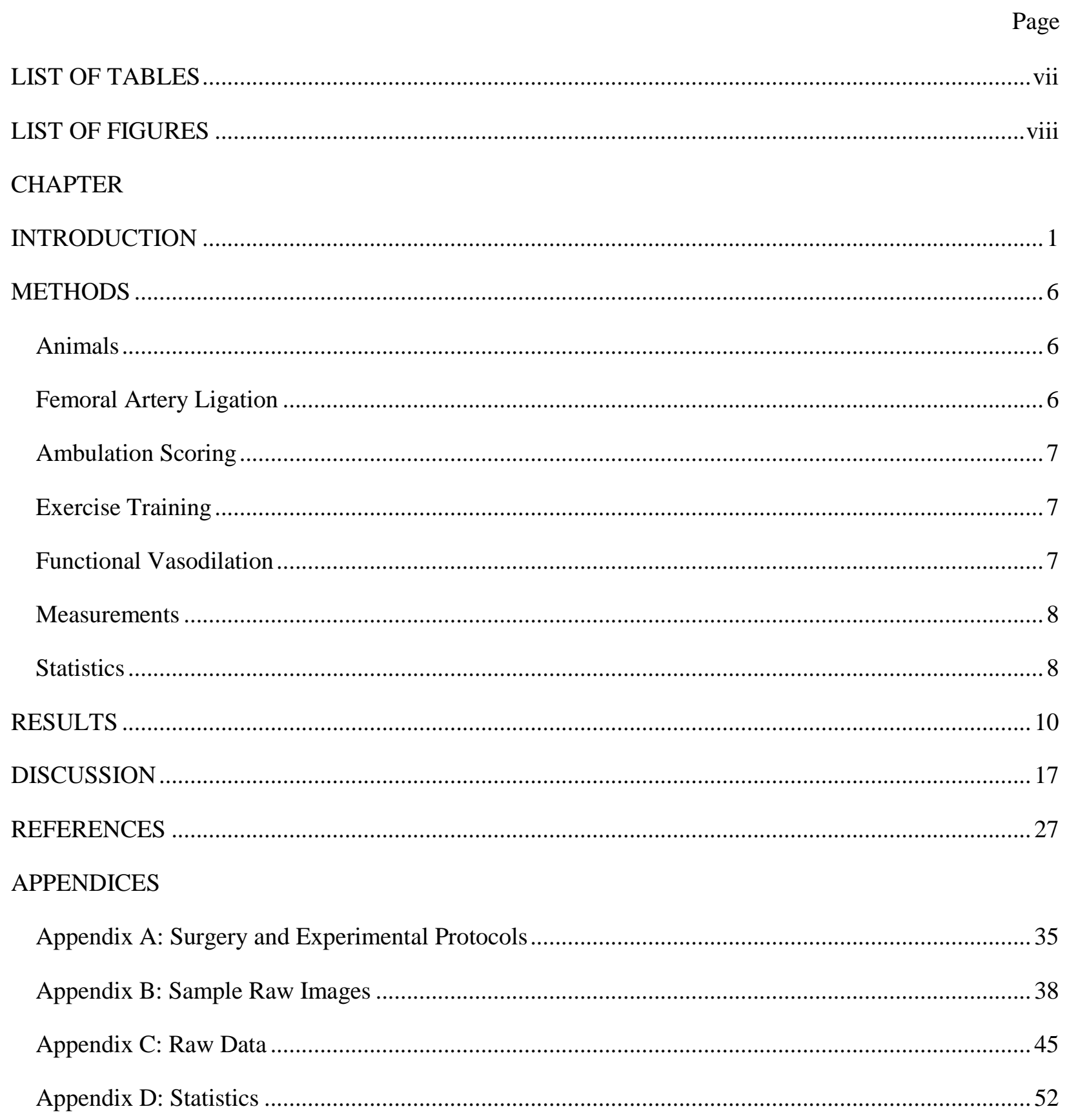




\section{LIST OF TABLES}

Page

Table 1. Comparisons made between experimental groups using Kruskal-Wallis tests............................ 9 


\section{LIST OF FIGURES}

Page

Figure 1. Collateral functional vasodilation is impaired at day 7 and restored at day $28 \ldots \ldots \ldots \ldots \ldots \ldots \ldots \ldots . . . . . . . . .11$

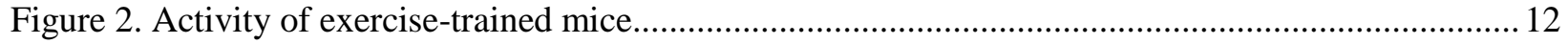

Figure 3. Collateral functional vasodilation is improved with exercise training. ................................... 13

Figure 4. Relationship between access to exercise and collateral resting diameter. ................................ 14

Figure 5. Balb/c collateral functional vasodilation is impaired at day 7 but improved with exercise. ....... 15

Figure 6. Activity and ambulation of exercise-trained Balb/c mice. ..................................................... 16 


\section{INTRODUCTION}

The most frequent clinical presentation of peripheral arterial occlusive disease (PAOD) is intermittent claudication, which is characterized by pain with exercise that is relieved at rest $[1,2,3,4]$. A common explanation for intermittent claudication and other complications arising from PAOD, such as chronic ulceration, is poor collateralization $[3,4,5]$. Because of this, there have been many attempts to define the mechanism of and develop therapies to stimulate collateral arteriogenesis, which is triggered by increased shear stress and aided by many pro-angiogenic and pro-inflammatory cytokines [6]. Potential therapies in this area include the delivery of growth factors, such as VEGF and FGF, which increase collateraldependent blood flow by increasing vascular remodeling following occlusion [7]. In addition to gene or protein therapies, cells can be transplanted to the ischemic or peri-ischemic zones [8], presumably to produce the cytokines and growth factors necessary for collateral enlargement, although these actions are not well-described [9]. In clinical studies, transplanting bone marrow-derived mononuclear cells or endothelial progenitor cells improved ankle-brachial index (ABI) [8,9]. However, poor collateralization as an explanation for PAOD pathophysiology does not take into account the disparity between ABI and performance [10]. Specifically, long-term supervised exercise training increases pain-free walking distance without increasing the $\mathrm{ABI}$ or number of arteries as measured by magnetic resonance angiography [11], suggesting that claudication and its resolution are due to processes other than collateralization.

An alternative explanation for intermittent claudication in patients with peripheral atherosclerosis is impaired vasodilation in the resistance vessels [12]. Vasodilation is impaired in both the upper [13] and lower [14] extremities but also in the collateral circulation, highlighted by the correlation between exercise blood flow and flow reserve to the ischemic zone with disease severity [15]. Furthermore, vasoconstrictor administration for the treatment of headaches aggravates claudication symptoms in patients with PAOD $[16,17]$, indicating that a restricted ability to increase blood flow contributes to symptomatic disease presentation. Because the collateral circulation is the primary site of vascular 
resistance following arterial occlusion $[18,19,20]$, impaired vasodilation of collaterals is most likely to have greatest potential impact on intermittent claudication. Indeed, decreased vasodilatory reserve in myocardium perfused by collateral flow correlated with more prevalent ischemic symptoms during exercise [21], highlighting the contribution of impaired collateral vasodilation to the pathophysiology of ischemic disease.

As arteriogenesis occurs with collateral recruitment following arterial occlusion, it is possible that the remodeling process may negatively influence reactivity in the collateral vessels during development. However, because reports regarding endothelium-dependent and smooth muscle-dependent collateral vasodilation are somewhat inconsistent, it is unclear which component of arteriogenesis is the cause of this impaired reactivity. In animal models, vasodilation to endothelium-dependent agents is impaired in immature collaterals [22,23,24,25,26] but is either completely restored [25] or still noticeably impaired [26] after maturation. This is potentially due to endothelial dysfunction induced as a result of either a chronic increase in collateral flow [27] or inflammatory conditions during remodeling [28]. However, as endothelium-dependent mechanisms of vasodilation are contingent upon smooth muscle cell function, these observations do not necessarily implicate the endothelium as the cause of impairment. For example, both endothelium-dependent and endothelium-independent dilation responses are attenuated in immature feed arteries and restored after maturation [29], indicating smooth muscle dysfunction. Although remodeling processes differ between feed arteries and collaterals, endothelium-independent vasodilation is also impaired in collateral vessels throughout maturation [26,30,31]. In collaterals, smooth muscle dysfunction could be the result of the change in smooth muscle cell phenotype from contractile to synthetic that occurs during proliferation $[32,33]$. The structural increase in vessel size is nearly complete [34] in immature collaterals, but smooth muscle cells are actively proliferating [35], whereas in mature collaterals, smooth muscle proliferation has ceased [35] and structural enlargement is maintained [34]. Because both endothelium-dependent and smooth muscle-dependent reactivity are impaired during collateral development, smooth muscle proliferation and differentiation to a synthetic phenotype during 
arteriogenesis is likely the cause of vasodilatory impairment and subsequent improvement. Regardless, studying collateral functional vasodilation following arterial occlusion will elucidate the impact of arteriogenesis on the overall ability to increase blood flow.

Sex appears to influence the vascular response to chronic ischemia, as functional claudication symptoms, potentially brought on by impaired vasodilation, are generally more severe in females [36,37]. Women experienced a sharper rise in PAOD-related death and disability over the past two decades [38,39], a trend that is expected to continue [40,41]. Although reports of overall sex differences in PAOD prevalence and outcomes are conflicting [42], women with the disease generally experience poorer physical function and a lower quality of life $[43,44,45]$. For example, women have a higher prevalence of critical limb ischemia, which is the most severe form of the disease $[46,47]$. Functional parameters that decline with intermittent claudication such as walking performance and ambulatory activity $[48,49,50]$ are also more impaired in women than in men with symptomatic PAOD, accompanied by decreased microcirculatory function and increased circulating inflammatory markers [51]. There is also a sexually dimorphic response to chronic ischemia in animal models, as female mice have more impaired limb use and blood flow recovery [52]. In addition, females exhibited higher hindlimb vascular resistance in the ischemic hindlimb, which could result from either less revascularization or decreased vasodilation [52]. If females exhibit a greater impairment in function after occlusion, and these symptoms may be explained by impaired vasodilation, then there may be underlying sex differences in vasodilation following an ischemic event that are responsible for some of the sexually dimorphic response to PAOD.

Exercise training is the most effective claudication therapy, equivalent to [53] or more functionally beneficial than [54] endovascular revascularization; therefore, it is recommended as a primary treatment for PAOD [55]. Because exercise improves claudication symptoms, the impact of intermittent claudication on vascular function may provide insight into the mechanisms of PAOD pathophysiology. Following occlusion, exercise training amplifies arteriogenic stimuli to increase collateral enlargement [56]. Additionally, regular exercise prior to arterial occlusion increases post-occlusive collateral- 
dependent hindlimb blood flow in rats [57], but it is unclear whether this is the result of enhanced arteriogenesis or improved vasodilation. Increased arteriogenesis is beneficial in that it allows greater blood flow to the ischemic zone. However, since different components of arteriogenesis may result in a transient impairment in vasodilation, which may be the cause of intermittent claudication, it is potentially more important for an effective treatment for PAOD to enhance functional hyperemia rather than augmenting post-occlusive structural adaptations. In non-ischemic animals, regular exercise increases functional vasodilation in skeletal muscle collateral arterioles, while only leading to a slight increase in vascular density [58], suggesting that the functional benefits of exercise may outweigh the structural adaptations. Furthermore, exercise training either pre- or post-occlusion improves endothelium-mediated collateral vasodilation [30,59], while simulation of exercise by chronic electrical stimulation enhances exercise performance [60]. These responses indicate that exercise training improves collateral function, given that collateral resistance is almost solely responsible for determining downstream blood flow during exercise $[59,61]$. However, functional vasodilation must be directly assessed in the collaterals to fully determine the therapeutic effects of exercise training.

Although the treatment of PAOD and intermittent claudication with exercise is well documented, there is a lack of data concerning female patients, as only a small number of patients enrolled in exercise rehabilitation clinical trials have been women [62]. However, based on existing data, women with PAOD appear to be less responsive to therapeutic exercise training [63]. This diminished response to exercise could be attributed to the poorer baseline physical function observed in women with PAOD, including reduced daily ambulatory activity and hemoglobin oxygen saturation in the calf muscle $[36,62]$. Women also responded less efficaciously to exercise despite a similar ABI between sexes [37,64], suggesting that the difference between males and females is not an impairment in resting blood flow to the ischemic zone, but rather an impairment in the ability to increase blood flow as needed during exercise. Further comparison is necessary to determine sex differences in collateral vasodilation in response to ischemia 
and exercise, as a reduction in both exercise performance and response to exercise therapy may be the result of impaired vascular reactivity.

Impaired vasodilation is a potential explanation for intermittent claudication, and because the collateral circulation is the primary site of vascular resistance to the ischemic zone, impaired vasodilation in collaterals would have the greatest potential to induce claudication. Exercise training increases blood flow to the ischemic zone in male animal models, but it is unclear if this is a result of enhanced arteriogenesis or improved collateral vasodilation, while female patients respond more poorly to ischemia and may not experience the same therapeutic effects of exercise training. Because of these observations, we tested the hypotheses that functional vasodilation following femoral artery ligation is impaired in the immature gracilis collateral arteriole of mice and restored after maturation, that functional vasodilation is impaired more in females, and that exercise training improves functional vasodilation to a greater extent in males. 


\section{METHODS}

\section{Animals}

All procedures were performed according to protocols approved by the California Polytechnic State University Institutional Animal Care and Use Committee. Male and female C57B1/6 mice (Taconic Farms; Oxnard, CA) and male Balb/c mice (The Jackson Laboratory; Sacramento, CA) between 2 and 4 months of age were used for all experiments. Mice were divided into sedentary and exercise-trained groups. C57Bl/6 mice were further divided into day 7 and day 28 groups ( $\mathrm{n}=8$ males, $\mathrm{n}=8$ females each). For Balb/c mice, only the day 7 time-point was assessed for exercised and sedentary groups ( $\mathrm{n}=6$ males each). All mice were maintained on a 12-hour light/dark cycle and were given feed and water ad libitum. Mice were housed in microisolator cages and provided enrichment (nesting material, 'house', and plastic tube). In-cage running wheels (Columbus Instruments; Columbus, $\mathrm{OH}$ ) were also provided for the exercise group immediately following surgery.

\section{Femoral Artery Ligation}

Chronic hindlimb ischemia was induced by ligating the femoral artery between the epigastric and popliteal branches, as described previously [65]. Animals were anesthetized in an induction chamber with $5 \%$ isofluorane in oxygen flowing at $0.8-1.01 \cdot \mathrm{min}^{-1}$. Following induction, isofluorane was decreased to 2-3\%. Hair was removed from the ventral aspect of both hindlimbs using depilatory cream, and skin was disinfected using chlorhexidine diacetate. Veterinary ophthalmic ointment was placed over the eyes to prevent corneal desiccation, and mice were given pre- and post-surgical buprenorphine analgesic $(0.075$ $\mathrm{mg} \cdot \mathrm{kg}^{-1}$, subcutaneous). Body temperature was maintained at $35^{\circ} \mathrm{C}$ with a temperature-controlled heat pad and a rectal thermistor probe (CWE, Inc.; Ardmore, PA). The left femoral artery was separated from the adjacent nerve and vein and ligated with 6-0 silk suture, and the skin incision was closed with 7-0 polypropylene suture. A sham surgery was performed in the right hindlimb, in which the connective tissue overlying the femoral neurovascular bundle was gently blunt dissected before skin closure. Mice were allowed to recover on a heat pad until ambulatory. 


\section{Ambulation Scoring}

Beginning after surgery, visual assessment of ambulation was conducted daily. Each mouse was given a score between 0 and 3 ( 3 = dragging hindpaw, 2 = dorsiflexion but no plantar flexion, $1=$ some plantar flexion, and $0=$ normal ambulation) until normal ambulation was observed for two consecutive days.

\section{Exercise Training}

Access to an exercise wheel (Columbus Instruments 8 Station Home Cage Running Wheel System) was provided post-surgery for mice in the exercise group. Wheel revolutions were detected using a magnetic indicator on the wheel and a Hall Effect sensor. Revolutions were counted using data acquisition software (Columbus Instruments Multi-Device Interface), and cumulative counts for each cage were recorded manually. The estimated distance run by each animal was calculated as the total distance run for the entire cage divided by the number of mice in the cage, and this number was divided by the number of days of observation to provide an estimate for the average distance run by each animal per day.

\section{Functional Vasodilation}

At day 7 or day 28 following surgery, animals were anesthetized as described above. Hair was removed from both the dorsal and ventral aspects of the hindlimbs using clippers and depilatory cream. The gracilis muscles were exposed via skin incision and resection of the epigastric fat pad; overlying fascia was removed by gentle blunt dissection. A custom trans-illuminating LED probe was placed under the hindlimb to allow visualization of the gracilis collateral arteriole, and two tungsten microelectrodes (FHC; Bowdoin, ME) were placed near the motor-end plates of the gracilis anterior, halfway between the profunda femoris artery and the saphenous artery. A stimulus isolator and data acquisition system (ADInstruments; Colorado Springs, CO, USA) were used to stimulate muscle contractions with $1 \mathrm{~mA}$ square waves of $0.2 \mathrm{~ms}$ duration at $1 \mathrm{~Hz}$ to confirm proper electrode placement. The preparation was irrigated with PBS, covered with plastic wrap, and given 30 minutes to equilibrate. After equilibration, the gracilis muscles were stimulated for 90 seconds with $1 \mathrm{~mA}$ square waves of $0.2 \mathrm{~ms}$ duration at $8 \mathrm{~Hz}$. Images of the collateral midzone and the profunda femoris artery were captured before and immediately 
after stimulation using an intravital microscope (Olympus BXFM) with a 10X objective (Olympus LMPlanFL N) and digital imaging software (QCapture Pro). The entire procedure was repeated for the contralateral hindlimb, after which mice were euthanized by cervical dislocation under general anesthesia.

\section{Measurements}

Vessel diameters were measured with ImageJ software. To examine any retest error introduced by this method of measurement, diameters were measured three separate times in the same day and then three times on a different day for a subset of images $(n=6)$. The average standard deviation of the measurements for each image was $2.6 \mu \mathrm{m}$, while the average range was $7.3 \mu \mathrm{m}$. The intraclass correlation coefficient (ICC) was calculated to assess the reliability of these measurements, and was found to be 0.99 , indicating a high retest correlation. Additionally, using a subset of the images that were not as clear $(n=16)$, which tended to be those of the sham limb at rest, maximum and minimum possible diameters were measured. To determine potential measurement error resulting from variations in image quality, the average range between these values was calculated at $11.1 \mu \mathrm{m}$, causing the group average for this subset of images to have a lowest possible value of $24.3 \mu \mathrm{m}$ or a highest possible value of $35.5 \mu \mathrm{m}$.

\section{Statistics}

Differences between resting and dilated diameters were assessed using paired t-tests. Percent changes in diameter were calculated as the difference between the dilated and resting diameters divided by the resting diameter and multiplied by $100 \%$. Then, differences in resting diameter, dilated diameter, and percent change in diameter between males and females, operated and sham limbs, and day 7 and day 28 time points were determined using either ANOVA and Tukey post-hoc comparisons for normal data or Kruskal-Wallis tests and Games-Howell comparisons for data that violated the ANOVA normality assumption (Table 1). Data are presented as mean \pm SE. 
Table 1. Comparisons made between experimental groups using Kruskal-Wallis tests. Each row contains two different experimental groups to be compared. Because at least one data set in each comparison listed violated the ANOVA normality assumption, non-parametric Kruskal-Wallis tests were used to compare median values.

\begin{tabular}{cccc}
\hline Experimental Group 1 & Group 1 & Experimental Group 2 & Group 2 \\
Normal? & Normal? \\
\hline C57 Male Sedentary Operated Day 7 & Yes & C57 Male Sedentary Sham Day 7 & No \\
C57 Female Sedentary Sham Day 7 & Yes & C57 Male Sedentary Sham Day 7 & No \\
C57 Male Sedentary Sham Day 28 & Yes & C57 Male Sedentary Sham Day 7 & No \\
C57 Male Exercised Sham Day 7 & Yes & C57 Male Sedentary Sham Day 7 & No \\
C57 Female Exercised Operated Day 7 & No & C57 Female Exercised Sham Day 7 & Yes \\
C57 Female Exercised Operated Day 7 & No & C57 Male Exercised Operated Day 7 & Yes \\
C57 Female Exercised Operated Day 7 & No & C57 Female Sedentary Operated Day 7 & Yes \\
C57 Female Exercised Operated Day 28 & Yes & C57 Female Exercised Operated Day 7 & No \\
Balb/c Male Sedentary Sham Day 7 & No & C57 Male Sedentary Sham Day 7 & No \\
Balb/c Male Sedentary Operated Day 7 & No & Balb/c Male Sedentary Sham Day 7 & No \\
Balb/c Male Sedentary Operated Day 7 & No & C57 Male Sedentary Operated Day 7 & Yes \\
Balb/c Male Exercised Sham Day 7 & Yes & Balb/c Male Sedentary Sham Day 7 & No \\
Balb/c Male Exercised Operated Day 7 & No & Balb/c Male Exercised Sham Day 7 & Yes \\
Balb/c Male Exercised Operated Day 7 & No & Balb/c Male Sedentary Operated Day 7 & No \\
Balb/c Male Exercised Operated Day 7 & No & C57 Male Exercised Operated Day 7 & Yes \\
\hline
\end{tabular}




\section{RESULTS}

To test the hypothesis that arteriogenesis transiently impairs functional vasodilation, we used intravital microscopy to assess functional vasodilation in the collateral midzone 7 or 28 days following femoral artery ligation (Figure 1A, 1B). By day 7, the collateral arterioles had enlarged by arteriogenesis, as evidenced by dilated diameters in the operated limb ( $85 \pm 4 \mu \mathrm{m}$ in males; $83 \pm 5 \mu \mathrm{m}$ in females) that were greater than in the sham limb $(62 \pm 5 \mu \mathrm{m}$ in males; $51 \pm 3 \mu \mathrm{m}$ in females) (Figure 1C). Operated limb resting diameters ( $75 \pm 5 \mu \mathrm{m}$ in males; $71 \pm 6 \mu \mathrm{m}$ in females) were also greater than in the sham limb (41 $\pm 4 \mu \mathrm{m}$ in males; $32 \pm 4 \mu \mathrm{m}$ in females). Arteriogenesis was associated with a reduction in the dynamic range of the vessel, as the percent change in diameter in the operated limb was $16 \pm 4 \%$ for males and 18 $\pm 4 \%$ for females, versus $55 \pm 11 \%$ for males and $64 \pm 11 \%$ for females in the sham limb (Figure 1D). Surprisingly, there were no differences in diameters between males and females at day 7.

As expected, dilated diameter remained elevated in the operated limb at day 28 (88 $\pm 5 \mu \mathrm{m}$ in males; $84 \pm$ $5 \mu \mathrm{m}$ in females) in comparison to the sham ( $55 \pm 4 \mu \mathrm{m}$ in males; $58 \pm 4 \mu \mathrm{m}$ in females), reflecting the structural enlargement induced by arteriogenesis (Figure 1E). Interestingly, resting diameter in the operated limb was smaller at day 28 ( $55 \pm 6 \mu \mathrm{m}$ in males; $34 \pm 3 \mu \mathrm{m}$ in females) than at day 7 , and was closer to sham values ( $33 \pm 3 \mu \mathrm{m}$ in males; $34 \pm 3 \mu \mathrm{m}$ in females). Because of this, functional vasodilation as measured by percent change in diameter ( $71 \pm 17 \%$ in males; $150 \pm 16 \%$ in females) was greater than at day 7 and no longer lower than in the sham limb (75 $\pm 14 \%$ in males; $81 \pm 22 \%$ in

females) (Figure 1F). Unexpectedly, operated limb resting diameter was smaller in females than in males, causing female percent change in diameter to be larger than the percent change in both males and the female sham. 
Day 7
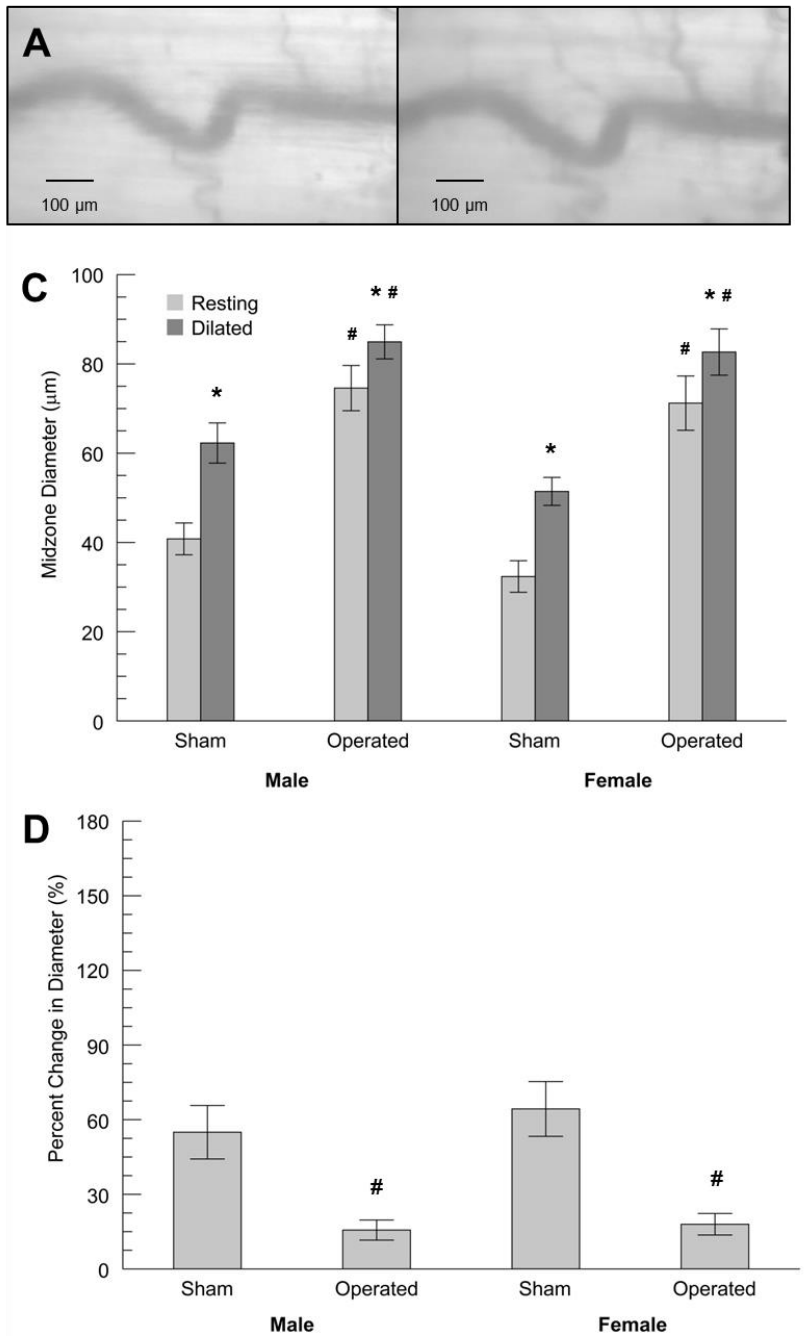

Day 28
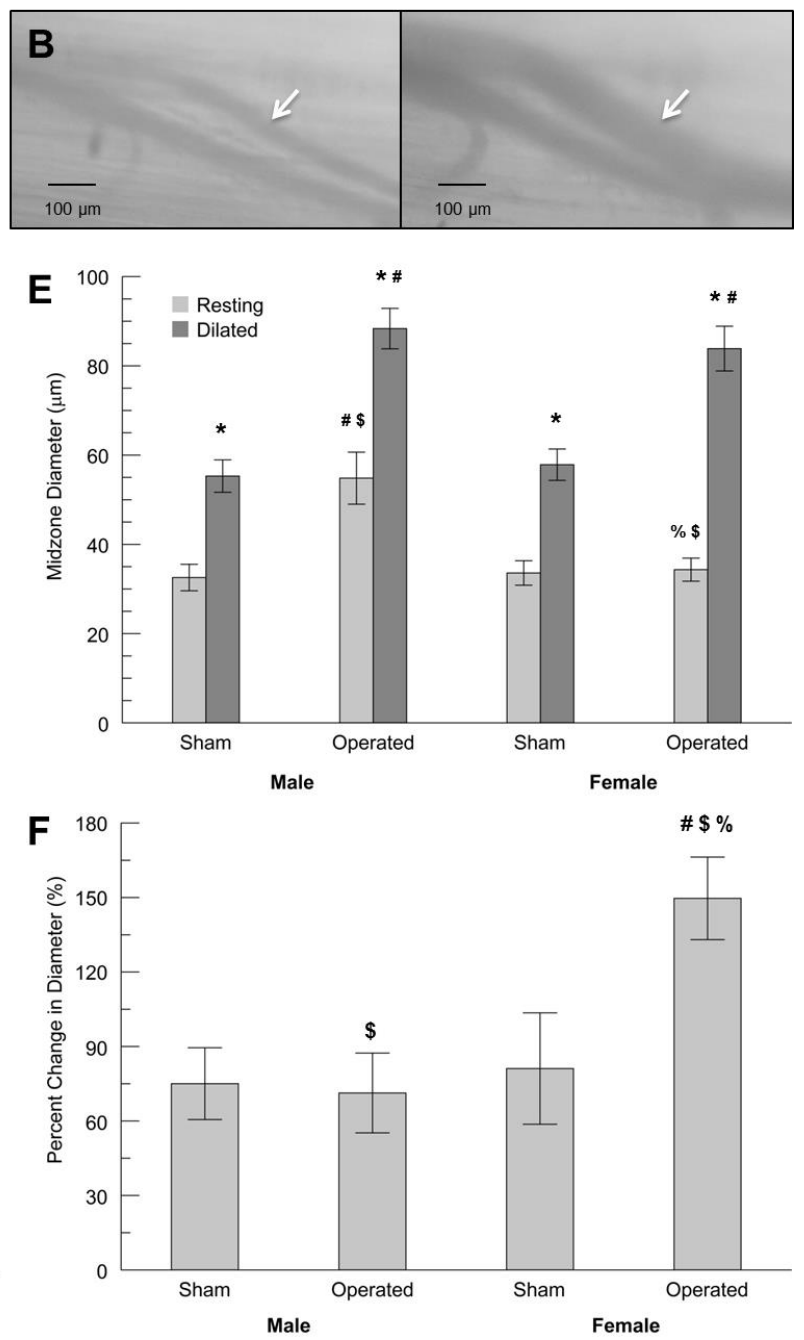

Figure 1. Collateral functional vasodilation is impaired at day $\mathbf{7}$ and restored at day 28 . Changes in vessel diameter were observed at the collateral midzone in sedentary mice at 7 days (A,C,D) or 28 days (B,E,F) postfemoral artery ligation in the left hindlimb. White arrows indicate the collateral arteriole when multiple vessels are present in the field of view. At each time point, the gracilis muscles of male $(n=8)$ and female $(n=8) C 57 \mathrm{~B} 1 / 6$ mice were stimulated with tungsten microelectrodes and an isolated stimulator. Visualization of the gracilis collateral arteriole was improved using trans-illumination, and images were acquired at rest and immediately after stimulation using intravital microscopy. At day 7, both the resting and dilated diameters were increased in the operated limb compared to the sham (C), and the percent change in vessel diameter was decreased (D). At day 28, the dilated diameter remained increased in comparison to the sham, but the resting diameters were smaller than at day 7 (E). Percent change in operated limb vessel diameter at day 28 was greater than at day 7 , and either was comparable or increased compared to the sham (F). Functional vasodilation was similar between sexes at both time points, except for a smaller resting diameter and larger percent change in the female operated limb at day 28 . ( ${ }^{*} \mathrm{p}<0.05$ vs. resting, $\# \mathrm{p}<0.05$ vs. sham, $\$ \mathrm{p}<0.05$ vs. day $7, \% \mathrm{p}<0.05$ vs. male)

To determine if exercise training, which alleviates claudication symptoms in patients and increases

collateral-dependent blood flow in animal models, improves collateral vasodilation, mice were provided with in-cage running wheels immediately following femoral artery ligation. Interestingly, C57B1/6 mice 
in cages of two or three males ran less per day on average $(0.2 \mathrm{~km}$ and $0.8 \mathrm{~km}$, respectively) than mice in cages with four males $(2.6 \mathrm{~km})$ or cages with females $(2.9 \mathrm{~km}$ for two mice; $2.2 \mathrm{~km}$ for four mice) (Figure 2). Male Balb/c mice housed with two animals per cage $(1.3 \mathrm{~km})$ ran more per day on average than $\mathrm{C} 57 \mathrm{~B} 1 / 6$ mice in cages of two or three males, but they still ran less than male Balb/c mice housed with four animals per cage $(1.9 \mathrm{~km})$.

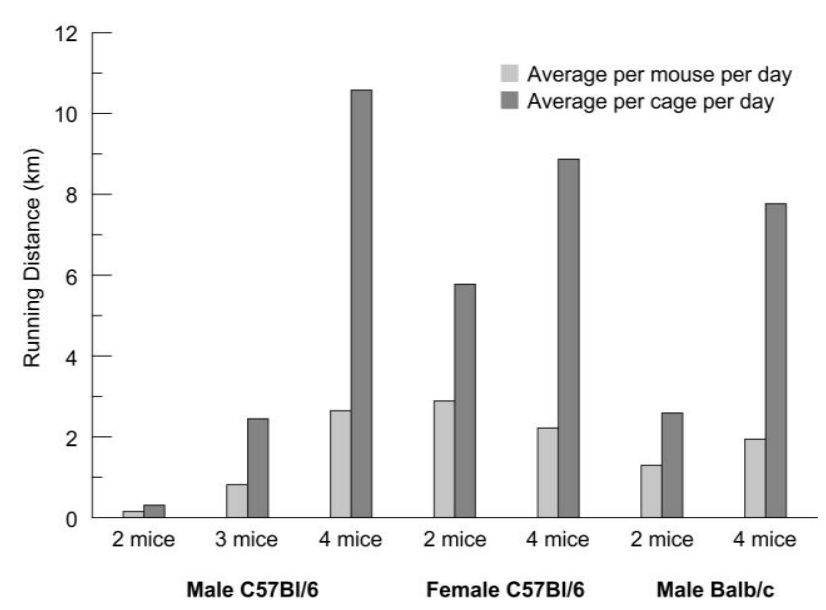

Figure 2. Activity of exercise-trained mice. Animals in the exercise group were provided with in-cage running wheels post-femoral artery ligation. Total running distances were recorded for cages of two to four mice, and were divided by the number of mice in the cage to obtain an average value for running distance per mouse. C57B1/6 mice in cages with two or three males ran less per day on average than mice in cages with four males or two or four females. Balb/c mice in cages of two also ran less per day on average than mice in cages of four.

To test the hypothesis that reactivity is improved with voluntary exercise, functional vasodilation was assessed at the collateral midzone of exercise-trained mice at day 7 or day 28 (Figure 3A, 3B). Exercise training led to restoration of collateral dynamic range, as there were no differences in vessel diameter percent change between the operated and sham limbs at day 7 (44 $\pm 12 \%$ versus $58 \pm 7 \%$ in males; $92 \pm$ $21 \%$ versus $84 \pm 15 \%$ in females) (Figure 3D) or day $28(101 \pm 29 \%$ versus $76 \pm 13 \%$ in males; $95 \pm$ $14 \%$ versus $71 \pm 13 \%$ in females) (Figure 3F). This increase in functional vasodilation was accompanied by a general reduction in operated limb resting diameter, which was smaller than dilated diameter at both day 7 (62 $\pm 7 \mu \mathrm{m}$ in males; $45 \pm 6 \mu \mathrm{m}$ in females) (Figure 3C) and day 28 (45 $\pm 7 \mu \mathrm{m}$ in males; $44 \pm 6$ $\mu \mathrm{m}$ in females) (Figure 3E). At day 7, female operated limb resting diameter was also smaller than in sedentary mice, and was no different from sham values ( $32 \pm 3 \mu \mathrm{m}$ in males; $30 \pm 4 \mu \mathrm{m}$ in females), while 
at day 28 , male operated limb resting diameter was no different from sham values $(29 \pm 2 \mu \mathrm{m}$ in males; $29 \pm 2 \mu \mathrm{m}$ in females). Similar to the observations in sedentary mice, the dilated diameter with voluntary exercise increased in the operated limb in comparison to the sham at day $7(84 \pm 6 \mu \mathrm{m}$ versus $49 \pm 4 \mu \mathrm{m}$ in males; $77 \pm 4 \mu \mathrm{m}$ versus $53 \pm 2 \mu \mathrm{m}$ in females $)$ and day 28 (79 $\pm 6 \mu \mathrm{m}$ versus $50 \pm 2 \mu \mathrm{m}$ in males; $82 \pm$ $5 \mu \mathrm{m}$ versus $48 \pm 2 \mu \mathrm{m}$ in females) due to arteriogenesis.

\section{Day 7}
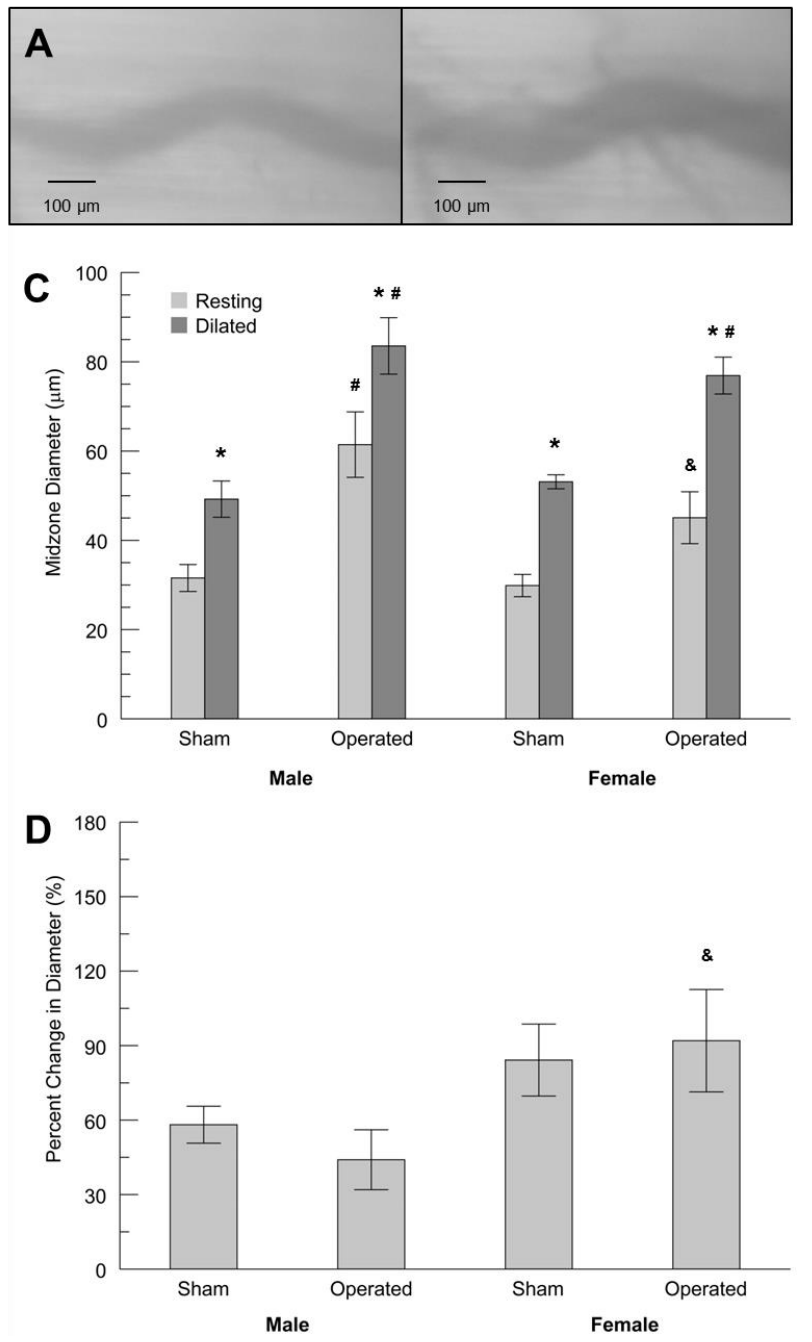

Day 28
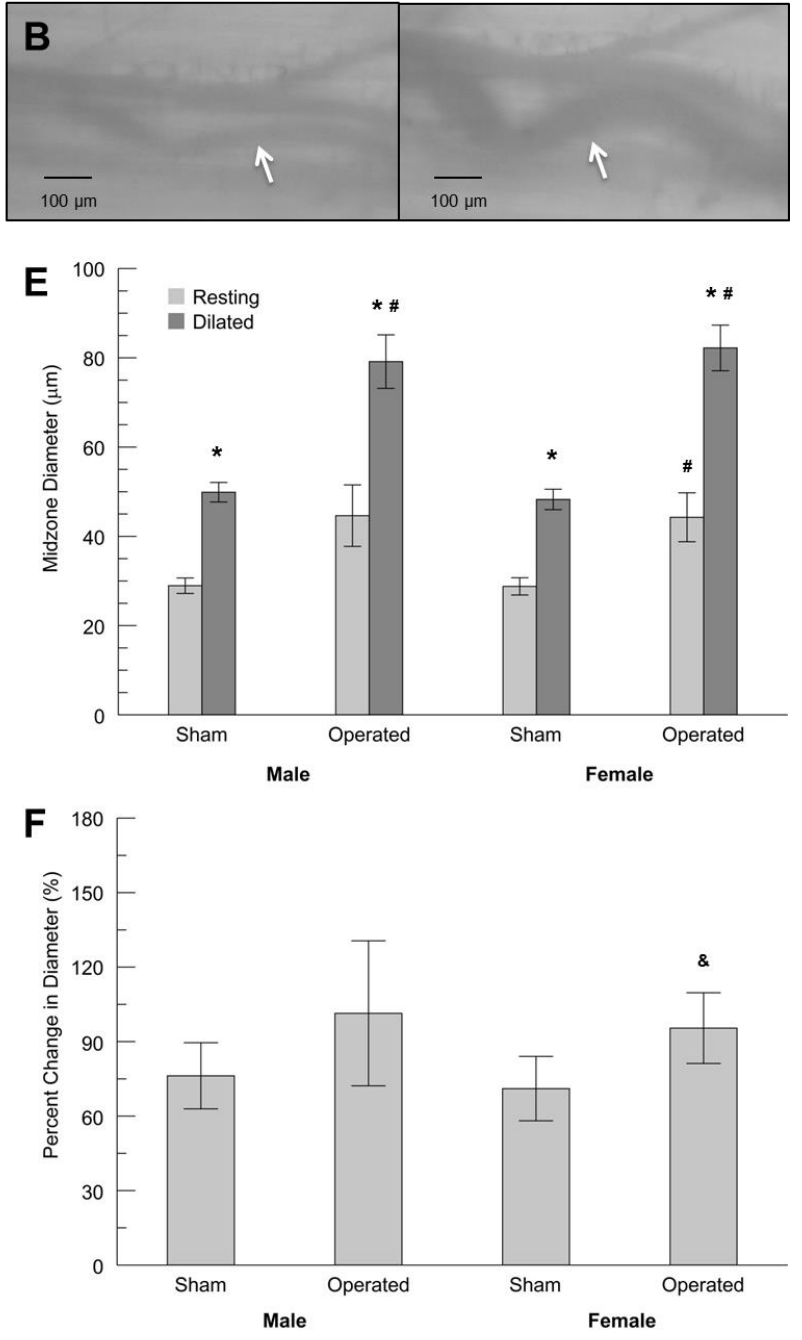

Figure 3. Collateral functional vasodilation is improved with exercise training. Changes in vessel diameter were observed at the collateral midzone in exercise-trained mice at 7 days (A,C,D) or 28 days (B,E,F) post-femoral artery ligation in the left hindlimb. White arrows indicate the collateral arteriole when multiple vessels are present in the field of view. At each time point, the gracilis muscles of male $(n=8)$ and female $(n=8) C 57 \mathrm{Bl} / 6$ mice were stimulated with tungsten microelectrodes and an isolated stimulator. Visualization of the gracilis collateral arteriole was improved using trans-illumination, and images were acquired at rest and immediately after stimulation using intravital microscopy. At day 7, the dilated diameters were increased in the operated limb compared to the sham, but female resting diameter was similar to the sham and decreased compared to sedentary mice, while resting diameter was smaller than dilated diameter for both sexes (C). The percent change in vessel diameter was similar in the 
operated and sham limbs at day 7 (D). At day 28, the dilated diameters in the operated limb remained increased in comparison to the sham, but male resting diameter was similar to the sham, while resting diameter was smaller than dilated diameter for both sexes (E). Percent change in vessel diameter at day 28 was comparable in the both the operated and sham limbs $(\mathrm{F})$. Functional vasodilation was similar between males and females at both time points. (* $\mathrm{p}<0.05$ vs. resting, \# $\mathrm{p}<0.05$ vs. sham, $\$ \mathrm{p}<0.05$ vs. day $7, \% \mathrm{p}<0.05$ vs. male, $\& \mathrm{p}<0.05$ vs. sedentary)

In order to determine whether collateral diameter in the ischemic hindlimb is altered simply based on access to exercise, or if changes are dependent upon the amount of exercise performed, running distances and vessel diameters at rest and after stimulation were compared among the exercise-trained groups.

There was a decreasing trend in resting diameter observed with increased running distance. However, dilated diameter did not appear to vary with running distance and remained fairly consistent in exercisetrained animals.
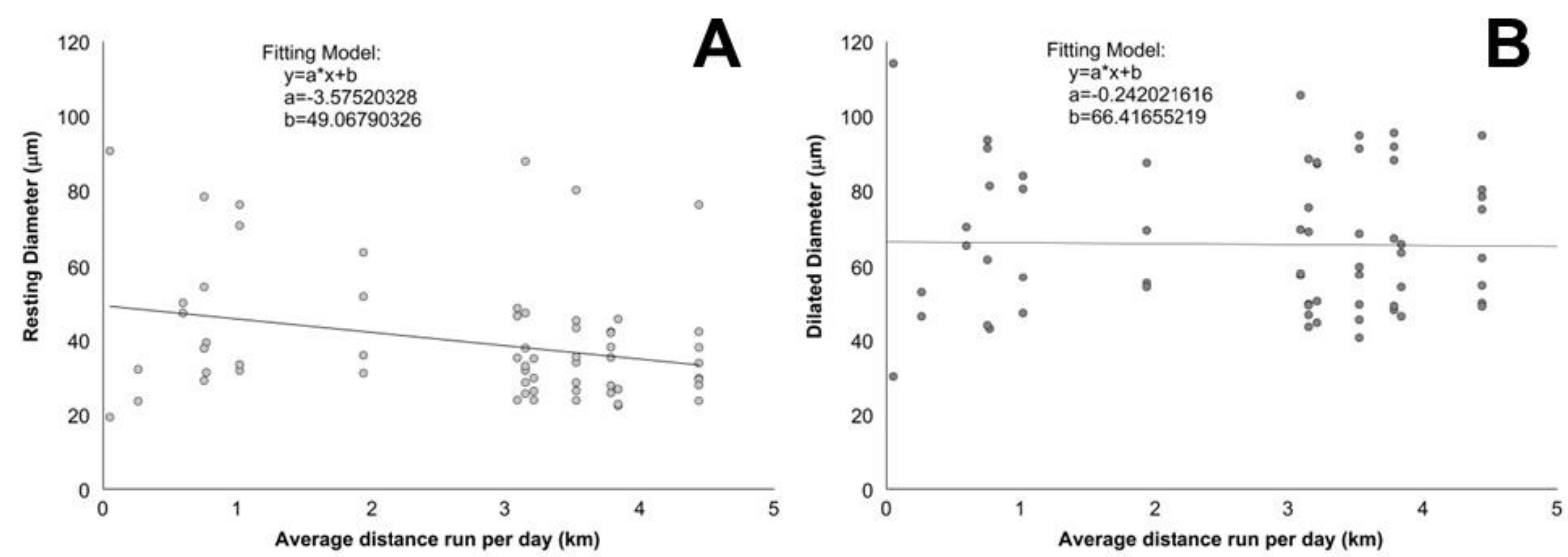

Figure 4. Relationship between access to exercise and collateral resting diameter. Male $(n=8)$ and female $(n=8)$ C57B1/6 mice in the exercise group were provided with in-cage running wheels post-femoral artery ligation. Total running distances were recorded for cages of two to four mice, and were divided by the number of mice in the cage and then by the number of days of observation to obtain an average value for running distance per mouse per day. Gracilis collateral arteriole diameters at rest and after stimulation were observed at 7 days or 28 days post-ligation. A decreasing trend in collateral resting diameter was observed with increased running distance (A), while exercise did not appear to affect dilated diameters (B).

Balb/c mice exhibit greater hypoxia than $\mathrm{C} 57 \mathrm{Bl} / 6$ mice in both the collateral and calf regions of the hindlimb following occlusion [66]. To determine if a greater demand for oxygen and blood flow increases collateral resting diameter, decreasing the dynamic range of the vessel, functional vasodilation was measured at the midzone in sedentary Balb/c mice 7 days post-ligation (Figure 5A). As seen in C57B1/6 mice, both the resting and dilated diameters were increased in the operated limbs $(65 \pm 3 \mu \mathrm{m}$ and $70 \pm 3$ $\mu \mathrm{m}$, respectively) in comparison to the sham limbs (33 $\pm 4 \mu \mathrm{m}$ and $51 \pm 4 \mu \mathrm{m}$, respectively) for the 
sedentary group (Figure 5C). Additionally, the percent change in vessel diameter was smaller in the operated limb $(9 \pm 3 \%)$ than in the sham limb $(60 \pm 11 \%)$ (Figure 5D). Then, to evaluate the ability of therapeutic exercise to rescue vasodilation in a more hypoxic model, Balb/c mice were provided exercise wheels post-ligation and functional vasodilation was assessed at the midzone at day 7 (Figure 5B).

Exercise training had a similar effect in Balb/c mice as it did in $\mathrm{C} 57 \mathrm{~B} 1 / 6$ mice, as the operated limb dilated diameter $(72 \pm 6 \mu \mathrm{m})$ remained elevated compared to the sham $(41 \pm 2 \mu \mathrm{m})$, while the operated resting diameter appeared to decrease $(53 \pm 7 \mu \mathrm{m})$ but was still greater than the sham $(26 \pm 2 \mu \mathrm{m})$ (Figure 5C). However, percent change in exercise-trained Balb/c mice was no different in the operated limb (49 \pm $25 \%)$ and the sham limb $(55 \pm 6 \%)$ (Figure 5D).
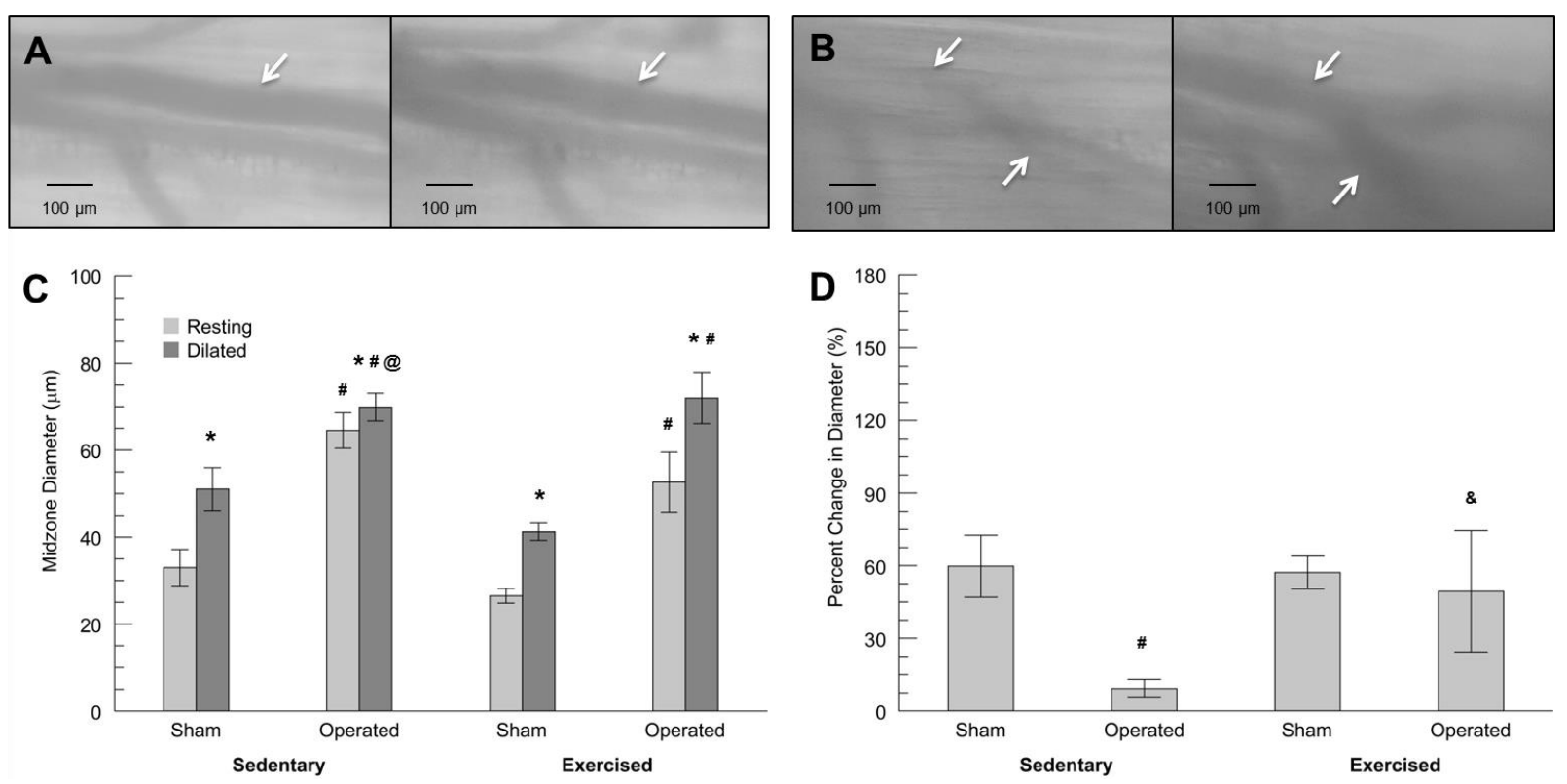

Figure 5. Balb/c collateral functional vasodilation is impaired at day 7 but improved with exercise. Changes in vessel diameter were observed at the collateral midzone in sedentary (A) or exercise-trained (B) Balb/c mice at 7 days post-femoral artery ligation in the left hindlimb. White arrows indicate the collateral arteriole when multiple vessels are present in the field of view. The gracilis muscles of male $(n=6)$ Balb/c mice were stimulated with tungsten microelectrodes and an isolated stimulator. Visualization of the gracilis collateral arteriole was improved using trans-illumination, and images were acquired at rest and immediately after stimulation using intravital microscopy. In both sedentary and exercised mice, the resting and dilated diameters were increased in the operated limb compared to the sham, but resting diameter appeared closer to sham values with exercise (C). The percent change in vessel diameter was decreased in the operated limb of sedentary mice in comparison to the sham, but was greater than in sedentary mice and no different from the sham in exercise-trained mice (D). (* p $<0.05$ vs. resting, \# p $<0.05$ vs. sham, @ p $<0.05$ vs. C57B1/6) 
To determine if exercise training could rescue a more hypoxic mouse model of ischemia, hindlimb

functionality was assessed by exercise activity and ambulation in Balb/c mice. Running distances were similar for cages of $\mathrm{Balb} / \mathrm{c}$ and $\mathrm{C} 57 \mathrm{Bl} / 6$ mice with same number of mice per cage over the seven days following surgery (Figure 6B). However, by day 7 post-ligation, C57Bl/6 mice were more ambulatory than Balb/c mice (Figure 6A). Interestingly, no differences in ambulation were observed between sedentary and exercise-trained groups for either mouse strain.
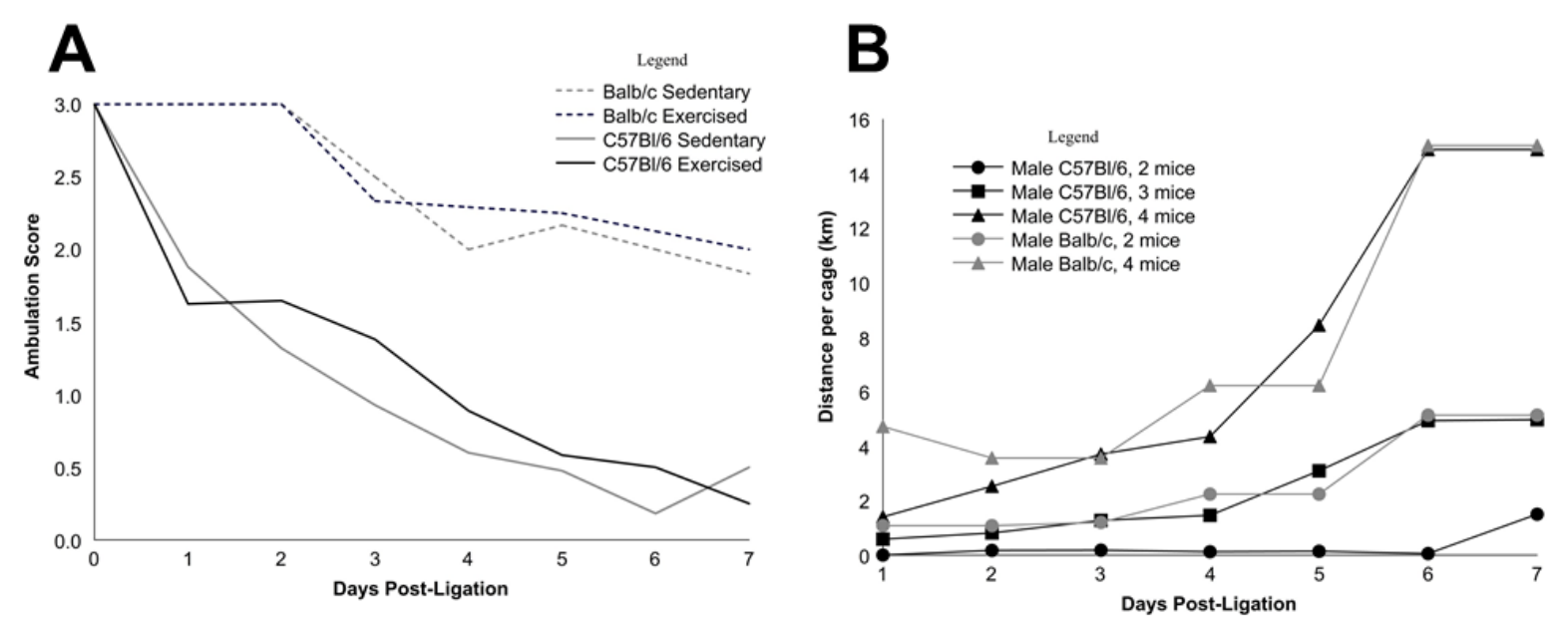

Figure 6. Activity and ambulation of exercise-trained Balb/c mice. Animals in the exercise group were provided with in-cage running wheels post-femoral artery ligation. Over the seven days post-ligation, total running distances were recorded for cages of two to four mice and ambulation was scored on a scale from 0 to 3 ( $3=$ dragging hindpaw, $2=$ dorsiflexion but no plantar flexion, $1=$ some plantar flexion, and $0=$ normal ambulation). Differences in ambulation patterns between strains were observed, as $\mathrm{C} 57 \mathrm{~B} 1 / 6$ mice demonstrated close to normal ambulation by day 7 while Balb/c mice did not (A). Ambulation trends were similar between sedentary and exercise-trained groups for both mouse strains. Exercise activity was similar between Balb/c mice and C57B1/6 mice in cages of four mice and cages of two or three mice (B). 


\section{DISCUSSION}

Patients with PAOD often present with intermittent claudication, which may be caused by impaired vasodilation. Impaired vasodilation in the collateral circulation is most likely to have the greatest impact, as it is the primary site of vascular resistance to the ischemic zone. Collateral vessel functionality following arterial occlusion is not well defined, although immature collaterals demonstrate impairments in both endothelial-dependent $[22,23,24,25,26]$ and smooth muscle-dependent vasodilation $[26,30,31]$. There also appears to be a sexually dimorphic response to PAOD, as females generally exhibit poorer physical function. A common recommended therapy for intermittent claudication is exercise training, but it is unclear if exercise improves blood flow and alleviates claudication primarily by enhancing structural adaptations or vascular reactivity. Furthermore, females with PAOD may not respond to therapeutic exercise training as efficaciously as males, warranting a comparison of the impact of exercise on collateral vasodilation between the sexes. Therefore, we assessed functional vasodilation in immature and mature collaterals, in females and males, and with or without exercise training

As expected, functional vasodilation was 'impaired' at day 7, 'restored' by day 28 , and 'improved' with exercise, as measured by percent change in collateral diameter, a common presentation of vascular reactivity $[67,68,69]$. However, a closer examination of the data reveals that this percent change was largely influenced by decreases in resting vessel diameter, and not the expected increase in dilated vessel diameter. Surprisingly, collateral diameter following muscle contraction (i.e. functional vasodilation) was similar between males and females at both time points in sedentary and exercised mice.

Immature collateral arterioles exhibited large resting diameters and consequently, minimal reactivity at day 7. This could be due to a number of factors. First, the sustained diameter increase observed could be due to a loss of sympathetic tone, resulting in decreased vasoconstriction via decreased activation of $\alpha$ adrenergic receptors. In canine models, $\alpha$-adrenergic stimulation failed to produce a vasoconstriction response in coronary collateral vessels at both immature and mature stages of development, indicating that these collaterals do not contain functioning $\alpha$-adrenergic receptors $[70,71]$. The studies in mature 
collaterals were performed six months after arterial occlusion, which is roughly the time period required for development of the collateral vessel wall in canine models [72]. Additionally, there is a lack of data regarding collateral response to adrenergic agents in small animal models. Therefore, although increased resting diameters were only observed in immature collaterals in our study, this decrease in $\alpha$-adrenergic modulation may still be relevant, as collateral maturation occurs more quickly in mice $[65,73]$ and may be varied between coronary and hindlimb collateral circuits [74].To determine this relevance, collateral sympathetic tone and adrenergic responsiveness could be assessed in the murine hindlimb by applying an $\alpha$-blocker and an $\alpha$-agonist, respectively. If elevated resting diameters are caused by reduced sympathetic tone or adrenergic responsiveness, then a blunted response to either or both agents would be expected.

If a loss of adrenergic tone is responsible for the large resting diameters of immature collaterals, the decrease in resting diameter seen in exercise-trained mice at day 7 indicates some restoration of sympathetic influence. In exercise-trained animals, non-specific inhibition of $\alpha$-adrenergic receptors increased collateral conductance post-acute femoral artery occlusion [61], suggesting that sympathetic tone may be increased with exercise training. However, conductance was measured during treadmill running [61], and throughout periods of exercise, sympathetic tone is increased to elevate heart rate and constrict non-active vascular beds to enhance blood flow to active skeletal muscle, tempering the rapid elevation in blood flow that occurs at the onset of exercise [75]. Based on this, it is unclear if the improvement in sympathetic tone due to training is lasting or merely transient, presenting only during exercise. Other studies provide evidence for a more permanent sympathetic tone increase- adrenergic vasoconstriction is enhanced in the skeletal muscle arterioles of trained rats at rest [76]. The ability of exercise to restore adrenergic tone could explain the decrease in the immature collateral resting diameter of exercise-trained mice in comparison to sedentary mice.

Another explanation for the observed increase in immature collateral resting diameter at day 7 is that the hypoxic downstream environment created after ligation increases the demand for oxygen and blood flow, essentially promoting a prolonged state of vasodilation. Long periods of exposure to vasoconstrictor 
agents inhibit the ability of resistance arterioles to return to the initial diameter after the vasoconstrictor stimulus is removed, as the vessels begin to remodel inwardly $[77,78]$. The opposite phenomenon can also occur due to elevated downstream flow demand, and long-term vasodilation of the collateral vessels may lead to outward remodeling. For instance, mechanoadaptation leads to reorientation, but not proliferation, of smooth muscle cells in the profunda femoris feed artery to increase vessel diameter following arterial occlusion [79]. In contrast to the slight hypoxia in C57B1/6 mice present only immediately after ligation, Balb/c mice exhibit severe hypoxia in the thigh region immediately and in the calf after 7 days [66]. A greater increase in resting diameter and decrease in reactivity in Balb/c mice, a more hypoxic model, would indicate that the state of the ischemic zone is a large determinant of resting diameter. However, the vessel diameters and functional vasodilation were similar at day 7 in $\mathrm{C} 57 \mathrm{Bl} / 6$ mice and Balb/c mice. That being said, because the resting and dilated diameters were so close and the change in diameter was almost negligible in C57B1/6 mice at day 7, it would be difficult to observe a more significant resting diameter increase or vasodilatory impairment, so this interpretation remains somewhat inconclusive.

A third cause for the increase in resting diameter at day 7 could be the lack of a contractile phenotype in vascular smooth muscle cells. During arteriogenesis, smooth muscle cells differentiate from a contractile to a synthetic phenotype for proliferation and migration [80]. This synthetic state is non-contractile yet reversible; the smooth muscle cells regain contractility as vessel development progresses $[80,81]$. Smooth muscle cell differentiation back to a contractile phenotype could also explain the observation that, in contrast to the increased resting diameters of immature collaterals at day 7 , the diameters of mature collaterals at day 28 were smaller at rest. At day 28, resting diameters in the operated limb resembled those in the sham limbs more closely than they did those in the operated limbs at day 7, indicating an improved vascular tone. This is similar to the response observed in feed arteries previously by our group; the resting diameter of the profunda femoris artery was elevated at day 7 but returned to sham values by day 28 after the completion of feed artery outward remodeling [29]. In the profunda, there is no smooth 
muscle cell proliferation [35], so this response is likely due to smooth muscle cell mechanoadaptation [29]. However, because smooth muscle cell proliferation does occur during arteriogenesis in the collaterals, the transition from a synthetic phenotype back to a contractile one may be responsible for the decrease in resting diameter we observed in the current study between day 7 and day 28 . Furthermore, exercise training maintains a contractile smooth muscle phenotype in coronary vascular smooth muscle [82], which could explain why exercise training decreased collateral resting diameters and increased reactivity. Alterations in vascular smooth muscle contractile state are able to describe the diameter and reactivity trends observed throughout collateral maturation, including the increased resting diameter at day 7 and the decrease in resting diameter with exercise and in mature collaterals at day 28.

An alternative interpretation of the decrease in resting diameter over time is that the gracilis collateral is not the primary collateral at day 28 following ligation. Although the gracilis collateral is the primary collateral at day 14 following ligation in this model [83], not all collateral vessels are of equal importance in the hindlimb circulation, and the relative contribution of each collateral can vary over time [3]. With a decrease in flow and shear stress, decompensation and inward remodeling can occur [84]; many vessels begin to increase diameter upon occlusion, but only a few remain enlarged after chronic vascular adaptation is complete [85]. For instance, in rats, the perforating artery is enlarged at 7 days [86] but not at 14 days post-femoral artery ligation in comparison to the non-ligated control [73], while the superficial circumflex iliac artery remains enlarged after 14 days [3]. This suggests that while both vessels are important as collaterals initially, the superficial circumflex iliac artery is the primary collateral while the perforating artery is not. Because the gracilis arteriole in the mouse followed the same diameter pattern as the rat perforating artery, it may not be as important later in the collateral development process. Furthermore, a similar remodeling trend was observed previously in this specific vessel, although in response to a different alteration in blood supply; the average diameter of the gracilis arteriole increased, peaked at 21 days, and then decreased following removal of one of its feed arteries $[87,88]$. Although these studies were performed using maximally dilated preparations while our results showed decreased 
resting diameter but no variation in maximum diameter, they still support the idea that collateral enlargement is not permanent or static. Determining if the gracilis collateral remains the primary hindlimb collateral at day 28 could be accomplished by perfusing with a silicone injection casting compound and observing the quickest collateral path to the saphenous artery [83]. The importance of the gracilis collateral could further be evaluated by occluding the gracilis collateral at day 28 and measuring the resting blood flow and hyperemia in the distal leg.

The decrease in collateral reactivity observed at day 7 was not surprising, based on previous reports of impaired endothelium-dependent and smooth muscle-dependent vasodilation in maturing collaterals $[22,23,24,25,26,30,31]$. While decreased endothelial functionality could be the cause of the observed lack of vascular reactivity, smooth muscle dysfunction is a more likely cause, given the attenuation of endothelium-dependent and endothelium-independent reactivity, which both are contingent upon smooth muscle cell function. At day 28, reactivity in the collaterals matched, and even surpassed, that of control collaterals. This was expected, based on previous work by our group, demonstrating that endotheliumdependent, smooth muscle-dependent, and functional vasodilation were all impaired in immature feed arteries but restored after maturation [29]. In the present study, collateral functional vasodilation followed the same pattern, potentially due to alterations of smooth muscle cell phenotype during arteriogenesis, as discussed earlier. Additionally, exercise training improved functional vasodilation in both immature and mature collaterals. This was also expected, based on the knowledge that exercise training augments endothelial-dependent dilation of collateral vessels and exercise performance $[30,89]$ and also maintains a contractile smooth muscle phenotype in coronary vascular smooth muscle [82].

Compared to sedentary mice at day 7 post-ligation, exercise training increased vascular reactivity as measured by percent change in vessel diameter at both day 7 and day 28, and also decreased resting diameter. These effects are similar to those observed in sedentary mice at day 28; it appears that resting diameter decreases throughout gracilis collateral maturation, and exercise training expedites the process. Generally, mice with greater exercise activity had smaller resting diameters, although this trend is based 
on estimating the distance run by each individual mouse in multi-mouse cages. However, the data indicate that access to a running wheel reduces resting diameter and, consequently, improves collateral vasodilation, as hypothesized. The observation that exercise enhances vascular reactivity also warranted investigation into the extent of its therapeutic potential. To see if exercise training could rescue a more hypoxic mouse model of hindlimb ischemia, functional vasodilation was assessed in Balb/c mice. Similar to the $\mathrm{C} 57 \mathrm{Bl} / 6$ mice, there was a decreasing trend in resting diameter and an increasing trend in percent change in diameter at day 7 post-ligation for exercise-trained Balb/c mice in comparison to sedentary Balb/c mice. Based on these results, exercise enhances vasodilation despite a more severe hypoxic environment downstream and transient severe hypoxia in the region of collateral growth [66]. Although exercise activity was similar in Balb/c and C57B1/6 mice, ambulation was still noticeably more impaired in Balb/c mice over the seven days post-ligation, indicating that the more hypoxic environment in Balb/c mice has a physical impact despite improvements in vasodilation. To further address the question of whether or not improved collateral vasodilation helps physical functionality, downstream force production could be measured in the ischemic hindlimbs of exercise-trained mice.

Although arteriogenic processes involving endothelial or smooth muscle cells are potentially responsible for reduced collateral vasodilation in general, percent change in vessel diameter was largely dependent on collateral resting diameter and not the diameter after stimulation. The fact that our dilated diameters were consistent among the different groups while resting diameters were not suggests that the vessels remodeled as much as was necessary to normalize maximal shear stress, which may be similar during exercise and daily locomotion, and not in response to average shear stress, which is likely increased with exercise. Additionally, maximum collateral diameter may be a more accurate reflection of arteriogenesis than resting diameter. In large animal models, administration of vasodilator agents significantly increases flow and decreases resistance in coronary vessels during maximal exercise, indicating a substantial coronary vasodilator reserve [90]. A similar preserved vasodilator capacity is also seen in collaterals, since during exercise, resistance vessels in the coronary collateral region vasodilate to increase blood flow 
without a decrease in transcollateral resistance [90]. Taken together, these observations suggest that in collaterals and even at maximal exercise intensity, a vasodilator reserve is present; it stands to reason that the same could be true in the hindlimb collateral circulation, meaning that electrode stimulation may not produce a true maximal vessel diameter. Furthermore, vascular remodeling is most commonly classified according to a scheme that bases its occurrence on the passive, or fully relaxed, luminal diameter [78]. Therefore, in the future, maximally dilating with sodium nitroprusside and adenosine at the end of each experiment may provide a better indication of any diameter change caused by arteriogenesis. As for resting diameter, there is a lack of reported values for this parameter, as it is a common practice to assess reactivity in collateral vessels by measuring vascular resistance and conductance $[30,52,57,59,61]$ or to dilate the vessels before measuring diameter $[34,65,72,78]$. The physiological significance of collateral diameter at rest remains unclear, but our results may provide insight as to the elements influencing its variation.

However, it is also necessary to note that the observed decrease in collateral resting diameter and improvement in vasodilation with exercise could be due to other physiological adaptations not directly related to the vasculature. For instance, mitochondrial biogenesis is induced in skeletal muscle as a result of exercise training [91], along with increases in citrate synthase activity and protein content and activity of electron transport chain components [92]. Another adaptation that occurs with exercise is skeletal muscle fast-twitch fiber type switching from type IIb to type IIx and type IIa, which is an oxidative fiber type $[91,93]$. Furthermore, exercise training increases myoglobin concentration in fast-twitch oxidative muscles [94], which may improve oxygen storage and delivery to the mitochondria. Increased number of mitochondria, improved mitochondrial efficiency, and increased myoglobin likely promote better oxygen utilization, which might decrease the demand for blood flow. Alterations in metabolite transport might have a similar effect, as both glucose and fatty acid transport proteins are increased with exercise training $[95,96]$. Any combination of these non-vascular adaptations may contribute to the decrease in collateral resting diameter perceived with exercise. 
As mentioned earlier, a limitation of this study was that the activity of the exercise-trained mice was obtained by cage instead of by individual mouse. Because of this, we were only able to estimate the distance run by each animal as the total distance run for the entire cage divided by the number of mice in the cage. Interestingly, estimated activity per animal in cages with two or three males was less than those in cages with four males or in cages with females. This is possibly because of aggression brought on by the addition of an exercise wheel to the cage; possessive behavior was observed in cages with two or three males that also had low exercise activity, but was not seen among females or in cages with four males. Furthermore, access to exercise appeared to decrease collateral resting diameter at day 7 in females, but exercised males were not different from sedentary animals at this time point. Because the cages with aggression and low exercise contained males in this group, these animals likely did not fully experience the vascular adaptations demonstrated in the other exercise-trained groups. If individual exercise wheel activity had been monitored, it would have been possible to determine how much each animal was running in situations like this, and for all of the other cages. In the future, this could be accomplished by tracking each mouse with a unique radio-frequency identification tag that would register which mouse was on the exercise wheel. However, this first study exploring exercise indicates that access to exercise decreases collateral resting diameter and increases vasodilation.

Even without exercise as a factor, aggression-induced stress may still have influenced collateral maturation during the recovery from chronic ischemia. In sedentary mice at day 28 , females had a large increase in reactivity in comparison to day 7 , while males did not. Some of the males in this group exhibited aggression post-surgery, requiring separation and isolation housing for multiple weeks of recovery. Mice respond poorly to isolation housing as assessed by both behavioral and physiological changes [97]. In addition to altered food intake, organ weights, anxiety-like reactions, and body temperature in isolated mice $[98,99,100,101]$, differences in cardiovascular parameters were also observed, including increased heart rate [101]. Therefore, it is possible that the stress of isolation 
diminished the restoration of collateral dynamic range, leading to this inconsistency between males and females.

Aside from the discrepancies between sexes mentioned above that may have been the result of aggression-induced stress and lack of activity, there were no major differences observed between males and females. While clinical data suggests that female patients with PAOD experience more impairment physically and respond less efficaciously to therapeutic exercise, female mice in this study recovered their vasodilatory capabilities both with collateral maturation and with access to exercise just as well as males did, and in some cases even more effectively. It is not surprising that these observations are varied in human patients when compared to our animal model, as the female mice used in this study were young and healthy. The sexually dimorphic response seen clinically may emerge with additional co-morbidities or risk factors for PAOD present, or as a result of estrogen deficiency. For instance, hypercholesterolemia and ovariectomy in female mice each lead to impaired endothelial-dependent vasodilation in the resistance vessels [102]. This finding is accompanied by controversial reports regarding the influence of sex on atherosclerosis [103]; recent studies show that atherosclerotic lesions in apolipoprotein E-deficient mice are more prevalent in females $[104,105,106]$. Whether impaired female vascular function is a result of worse disease progression or poorer adaptation, diseased animal models have greater potential to more accurately represent the sexually dimorphic response observed in human patients with PAOD.

Finally, although the retest correlation of vessel diameter measurements made using our methods was high and the standard deviation and range of these measurements were relatively small, certain methods could be implemented in future experiments to further minimize this error resulting from measurement variation. Blinded measurements would help to eliminate bias based on the identity of each experimental group, while obtaining and averaging multiple measurements for each diameter value would improve accuracy. Additionally, measurement accuracy could be improved by minimizing the error present due to poorer-quality images. Image processing techniques such as threshold image analysis might improve the contrast between the blood vessels and the surrounding tissue in each image, more clearly defining the 
vessel walls and allowing for more accurate diameter measurements. To improve collateral visualization further before image capture, a contrast agent such as Evans blue could be injected into the bloodstream and viewed with white light. Alternatively, a fluorescent contrast agent such as fluorescein isothiocyanate-dextran (FITC-dextran) might achieve better visualization for improved image quality. If a blue light of the proper wavelength was used with the current trans-illumination method, it could excite the FITC-dextran in the collateral circulation, which might allow for better images acquired with a fluorescent microscope. Utilizing these methods in the future would likely improve the accuracy of blood vessel diameter measurements.

Functional vasodilation as assessed by vascular dynamic range is impaired in immature collateral vessels and restored with maturation. This reinforces the hypothesis that intermittent claudication may be the result of impaired vasodilation. Because the collateral circulation is the primary site of resistance to the ischemic zone, impaired collateral vasodilation would likely have the greatest impact. Additionally, exercise training appears to enhance collateral reactivity, suggesting that its therapeutic benefits are linked not only to structural adaptation but also to vessel functionality. However, we found that vascular reactivity is largely dependent on resting diameter, while diameter after stimulation remained consistent among groups. Therefore, further research is required to determine the functional relevance of collateral resting diameter in the ischemic limb circulation. 


\section{REFERENCES}

[1] Schainfeld RM. Management of peripheral arterial disease and intermittent claudication. J Am Board Fam Pract 14: 443-450, 2001.

[2] Aronow WS. Peripheral arterial disease of the lower extremities. Archives of Medical Science: AMS 8: 375-388, 2012.

[3] Ziegler MA, Distasi MR, Bills RG, Miller SJ, Alloosh M, Murphy MP, Akingba AG, Sturek M, Dalsing MC, Unthank JL. Marvels, mysteries, and misconceptions of vascular compensation to peripheral artery occlusion. Microcirculation 17: 3-20, 2010.

[4] Smith RB III. Claudication. In: Clinical Methods: The History, Physical, and Laboratory Examinations, edited by Walker HK, Hall WD, Hurst JW. 3rd edition. Boston: Butterworths, 1990.

[5] Yang HT, Prior BM, Lloyd PG, Taylor JC, Li Z, Laughlin MH, Terjung RL. Training-induced vascular adaptations to ischemic muscle. J Physiol Pharmacol 59: 57-70, 2008.

[6] Scholz D, Cai W, Schaper W. Arteriogenesis, a new concept of vascular adaptation in occlusive disease. Angiogenesis 4: 247-257, 2001.

[7] Collinson DJ, Donnelly R. Therapeutic angiogenesis in peripheral arterial disease: can biotechnology produce an effective collateral circulation? Eur J Vasc Endovasc Surg 28: 9-23, 2004.

[8] Raval Z, Losordo D. Cell therapy of peripheral arterial disease. Circ Res 112: 1288-1302, 2013.

[9] Botham CM, Bennett WL, Cooke JP. Clinical trials of adult stem cell therapy for peripheral artery disease. Methodist Debakey Cardiovasc J. 10: 134, 2014.

[10] Gardner AW, Montgomery PS, Afaq A. Exercise performance in patients with peripheral arterial disease who have different types of exertional leg pain. J Vasc Surg 46: 79-86, 2007.

[11] Versluis B, Leiner T, Nelemans PJ, Wildberger JE, Schurink G, Backes WH. Magnetic resonance imaging-based monitoring of collateral artery development in patients with intermittent claudication during supervised exercise therapy. J Vasc Surg 58: 1236-1243, 2013.

[12] Liao JK, Bettmann MA, Sandor T, Tucker JI, Coleman SM, Creager MA. Differential impairment of vasodilator responsiveness of peripheral resistance and conduit vessels in humans with atherosclerosis. Circ Res 68: 1027-1034, 1991.

[13] Poredos P, Golob M, Jensterle M. Interrelationship between peripheral arterial occlusive disease, carotid atherosclerosis and flow mediated dilation of the brachial artery. International Angiology 22: 83, 2003.

[14] Weiss T, Fischer D, Hausmann D, Weiss C. Endothelial function in patients with peripheral vascular disease: influence of prostaglandin E1. Prostaglandins, Leukotrienes and Essential Fatty Acids 67: 277-281, 2002. 
[15] Lindner JR, Womack L, Barrett EJ, Weltman J, Price W, Harthun NL, Patrie JT. Limb Stress-Rest Perfusion Imaging With Contrast Ultrasound for the Assessment of Peripheral Arterial Disease Severity. J Am Coll Cardiol Img 1: 343-350, 2008.

[16] Cooke JP, Losordo DW. Modulating the vascular response to limb ischemia. Circ Res 116: 1561$1578,2015$.

[17] Stoyioglou A, Jaff MR. Medical treatment of peripheral arterial disease: a comprehensive review. J Vasc Interv Radiol 15: 1197-1207, 2004.

[18] Sanne H, Sivertsson R. The effect of exercise on the development of collateral circulation after experimental occlusion of the femoral artery in the cat. Acta Physiologica 73: 257-263, 1968.

[19] Lash JM, Nixon JC, Unthank JL. Exercise training effects on collateral and microvascular resistances in rat model of arterial insufficiency. Am J Physiol 268: H125-H137, 1995.

[20] Unthank JL, Nixon JC, Lash JM. Early adaptations in collateral and microvascular resistances after ligation of the rat femoral artery. J Appl Physiol (1985) 79: 73-82, 1995.

[21] McFalls EO, Araujo LI, Lammertsma A, Rhodes CG, Bloomfield P, Pupita G, Jones T, Maseri A. Vasodilator reserve in collateral-dependent myocardium as measured by positron emission tomography. Eur Heart J 14: 336-343, 1993.

[22] Takeshita S, Isshiki T, Ochiai M, Eto K, Mori H, Tanaka E, Umetani K, Sato T. Endotheliumdependent relaxation of collateral microvessels after intramuscular gene transfer of vascular endothelial growth factor in a rat model of hindlimb ischemia. Circulation 98: 1261-1263, 1998.

[23] Bauters C, Asahara T, Zheng LP, Takeshita S, Bunting S, Ferrara N, Symes JF, Isner JM. Recovery of disturbed endothelium-dependent flow in the collateral-perfused rabbit ischemic hindlimb after administration of vascular endothelial growth factor. Circulation 91: 2802-2809, 1995.

[24] Orlandi C, Blackshear JL, Hollenberg NK. Specific increase in sensitivity to serotonin of the canine hindlimb collateral arterial tree via the 5-hydroxytryptamine-2 receptor. Microvasc Res 32: 121-130, 1986.

[25] Rapps JA, Myers PR, Zhong Q, Parker JL. Development of endothelium-dependent relaxation in canine coronary collateral arteries. Circulation 98: 1675-1683, 1998.

[26] Kelsall CJ, Brown MD, Hudlicka O. Alterations in reactivity of small arterioles in rat skeletal muscle as a result of chronic ischaemia. $J$ Vasc Res 38: 212-218, 2001.

[27] Sellke FW, Quillen JE, Brooks LA, Harrison DG. Endothelial modulation of the coronary vasculature in vessels perfused via mature collaterals. Circulation 81: 1938-1947, 1990.

[28] Granger DN, Senchenkova E. Impaired Vasomotor Responses. In: Inflammation and the Microcirculation. San Rafael, CA: Morgan \& Claypool Life Sciences, 2010. 
[29] Gallagher R. Dec 2012. The Impact of Outward Remodeling on Vasodilation in Skeletal Muscle Resistance Arteries [Online]. California Polytechnic State University. http://digitalcommons.calpoly.edu/theses/914 [May 2016].

[30] Colleran PN, Li Z, Yang HT, Laughlin MH, Terjung RL. Vasoresponsiveness of collateral vessels in the rat hindlimb: influence of training. J Physiol 588: 1293-1307, 2010.

[31] Takeshita S, Isshiki T, Mori H, Tanaka E, Tanaka A, Umetani K, Eto K, Miyazawa Y, Ochiai M, Sato T. Microangiographic assessment of collateral vessel formation following direct gene transfer of vascular endothelial growth factor in rats. Cardiovasc Res 35: 547-552, 1997.

[32] Owens GK, Kumar MS, Wamhoff BR. Molecular Regulation of Vascular Smooth Muscle Cell Differentiation in Development and Disease. Physiol Rev 84: 767-801, 2004.

[33] Rensen SSM, Doevendans PAFM, van Eys GJJM. Regulation and characteristics of vascular smooth muscle cell phenotypic diversity. Neth Heart J 15: 100-108, 2007.

[34] Heuslein JL, Meisner JK, Li X, Song J, Vincentelli H, Leiphart RJ, Ames EG, Blackman BR, Price RJ. Mechanisms of Amplified Arteriogenesis in Collateral Artery Segments Exposed to Reversed Flow Direction. Arterioscler Thromb Vasc Biol 35: 2354-2365, 2015.

[35] Bynum AJ. Dec 2011. Impact of Collateral Enlargement on Smooth Muscle Phenotype. California Polytechnic State University. http://digitalcommons.calpoly.edu/theses/658 [Aug 2016].

[36] Gardner AW, Parker DE, Montgomery PS, Khurana A, Ritti-Dias RM, Blevins SM. Gender differences in daily ambulatory activity patterns in patients with intermittent claudication. $J$ Vasc Surg 52: 1204-1210, 2010.

[37] Gardner AW. Sex differences in claudication pain in subjects with peripheral arterial disease. Med Sci Sports Exerc 34: 1695-1698, 2002.

[38] Sampson UK, Fowkes FG, McDermott MM, Criqui MH, Aboyans V, Norman PE, Forouzanfar MH, Naghavi M, Song Y, Harrell FE Jr, Denenberg JO, Mensah GA, Ezzati M, Murray C. Global and regional burden of death and disability from peripheral artery disease: 21 world regions, 1990 to 2010. Glob Heart 9: 145-148, 2014.

[39] Hussain MA, Lindsay TF, Mamdani M, Wang X, Verma S, Al-Omran M. Sex differences in the outcomes of peripheral arterial disease: a population-based cohort study. CMAJ Open 4: E124-E131, 2016.

[40] Barochiner J, Aparicio LS, Waisman GD. Challenges associated with peripheral arterial disease in women. Vascular Health and Risk Management 10: 115-128, 2014.

[41] Higgins JP, Higgins JA. Epidemiology of peripheral arterial disease in women. J Epidemiol 13: 1-14, 2003.

[42] Huynh TTT, Choi L. Limb salvage in women. Methodist DeBakey Cardiovascular Journal 9: 84-89, 2013. 
[43] Teodorescu VJ, Vavra AK, Kibbe MR. Peripheral arterial disease in women. J Vasc Surg 57: 18S26S, 2013.

[44] Collins TC, Suarez-Almazor M, Bush RL, Petersen NJ. Gender and peripheral arterial disease. J Am Board Fam Med 19: 132-40, 2006.

[45] McDermott MM, Greenland P, Liu K, Criqui MH, Guralnik JM, Celic L, Chan C. Sex differences in peripheral arterial disease: leg symptoms and physical functioning. J Am Geriatr Soc 51: 222-228, 2003.

[46] Brevetti G, Bucur R, Balbarini A, Melillo E, Novo S, Muratori I, Chiariello M. Women and peripheral arterial disease: same disease, different issues. J Cardiovasc Med (Hagerstown) 9: 382388, 2008.

[47] Sigvant B, Wiberg-Hedman K, Bergqvist D, Rolandsson O, Andersson B, Persson E, Wahlberg E. A population-based study of peripheral arterial disease prevalence with special focus on critical limb ischemia and sex differences. J Vasc Surg 45: 1185-1191, 2007.

[48] Gardner AW, Montgomery PS, Scott KJ, Afaq A, Blevins SM. Patterns of ambulatory activity in subjects with and without intermittent claudication. J Vasc Surg 46: 1208-1214, 2007.

[49] Gardner AW, Montgomery PS, Scott KJ, Blevins SM, Afaq A, Nael R. Association between daily ambulatory activity patterns and exercise performance in patients with intermittent claudication. Journal of vascular surgery 48: 1238-1244, 2008.

[50] Gardner AW, Ritti-Dias RM, Khurana A, Parker DE. Daily ambulatory activity monitoring in patients with peripheral artery disease. Physical Therapy Reviews 15: 212-223, 2010.

[51] Gardner AW, Parker DE, Montgomery PS, Blevins SM. Diabetic women are poor responders to exercise rehabilitation in the treatment of claudication. J Vasc Surg 59: 1036-1043; 2014.

[52] Peng X, Wang J, Lassance-Soares RM, et al. Gender differences affect blood flow recovery in a mouse model of hindlimb ischemia. Amer J Physiol Heart Circ Physiol 300: H2027-H2034, 2011.

[53] Fakhry F, Rouwet EV, den Hoed PT, Hunink MGM, Spronk S. Long-term Clinical Effectiveness of Supervised Exercise Therapy versus Endovascular Revascularization for Intermittent Claudication from a Randomized Clinical Trial. Br J Surg 100: 1164-1171, 2013.

[54] Murphy TP, Cutlip DE, Regensteiner JG, Mohler ER, Cohen DJ, Reynolds MR, Massaro JM, Lewis BA, Cerezo J, Oldenburg NC, Thum CC, Goldberg S, Jaff MR, Steffes MW, Comerota AJ, Ehrman J, Treat-Jacobson D, Walsh ME, Collins T, Badenhop DT, Bronas U, Hirsch AT. Supervised Exercise Versus Primary Stenting for Claudication Resulting From Aortoiliac Peripheral Artery Disease. Circulation 125: 130-139, 2012.

[55] Hirsch AT. Treatment of peripheral arterial disease--extending "intervention" to "therapeutic choice". N Engl J Med 354: 1944-1947, 2006. 
[56] Prior BM, Yang HT, Terjung RL. What makes vessels grow with exercise training? J Appl Physiol 97: 1119-1128, 2004.

[57] Yang HT, Laughlin MH, Terjung RL. Prior exercise training increases collateral-dependent blood flow in rats after acute femoral artery occlusion. Am J Physiol Heart Circ Physiol 279: H1890H1897, 2000.

[58] Lash JM, Bohlen HG. Functional adaptations of rat skeletal muscle arterioles to aerobic exercise training. J Appl Physiol (1985) 72: 2052-2062, 1992.

[59] Yang HT, Ren J, Laughlin MH, Terjung RL. Prior exercise training produces NO-dependent increases in collateral blood flow after acute arterial occlusion. Am J Physiol Heart Circ Physiol 282: H301-H310, 2002.

[60] Sunakawa M, Kohmoto T, Komoto Y. Evaluation of tissue perfusion in ischemic legs of dogs by CO2 clearance rate. Acta Med Okayama 43: 47-54, 1989.

[61] Taylor JC, Li Z, Yang HT, Laughlin MH, Terjung RL. $\alpha$-Adrenergic inhibition increases collateral circuit conductance in rats following acute occlusion of the femoral artery. J Physiol 586: 1649-1667, 2008.

[62] Hirsch AT, Allison MA, Gomes AS, Corriere MA, Duval S, Ershow AG, Hiatt WR, Karas RH, Lovell MB, McDermott MM, Mendes DM, Nussmeier NA, Treat-Jacobson D. A call to action: women and peripheral artery disease: a scientific statement from the American Heart Association. Circulation 125: 1449-1472, 2012.

[63] Gommans LN, Scheltinga MR, van Sambeek MR, Maas AH, Bendermacher BL, Teijink JA. Gender differences following supervised exercise therapy in patients with intermittent claudication. $J$ Vasc Surg 62: 681-688, 2015.

[64] Gardner AW, Parker DE, Montgomery PS, Blevins SM, Nael R, Afaq A. Sex differences in calf muscle hemoglobin oxygen saturation in patients with intermittent claudication. J Vasc Surg 50: 7782, 2009.

[65] Scholz D, Ziegelhoeffer T, Helisch A, Wagner S, Friedrich C, Podzuweit T, Schaper W. Contribution of arteriogenesis and angiogenesis to postocclusive hindlimb perfusion in mice. $J \mathrm{Mol}$ Cell Cardiol 34: 775-787, 2002.

[66] Helisch A, Wagner S, Khan N, Drinane M, Wolfram S, Heil M, Ziegelhoeffer T, Brandt U, Pearlman JD, Swartz HM, Schaper W. Impact of mouse strain differences in innate hindlimb collateral vasculature. Arterioscler Thromb Vasc Biol 26: 520-526, 2006.

[67] Hudlicka O, Brown SE, Dawson JM. Effect of long-term electrical stimulation on vascular supply and fatigue in chronically ischemic muscles. J Appl Physiol 77: 1317-1324, 1994.

[68] Lamping KG, Nuno DW, Brooks LA, Fujii M. Response of coronary microvascular collaterals to activation of ATP-sensitive $\mathrm{K}^{+}$channels. Cardiovasc Res 35: 377-383, 1997. 
[69] Frisbee JC, Hollander JM, Brock RW, Yu H, Boegehold MA. Integration of skeletal muscle resistance arteriolar reactivity for perfusion responses in the metabolic syndrome. Am J Physiol Regul Itegr Comp Physiol 296: R1771-R1782, 2009.

[70] Harrison DG, Chilian WM, Marcus ML. Absence of functioning $\alpha$-adrenergic receptors in mature canine coronary collaterals. Circ Res 59: 133-142, 1986.

[71] Hautamaa PV, Dai XZ, Homans DC, Robb JF, Bache RJ. Vasomotor properties of immature canine coronary collateral circulation. Amer J Physiol 252: H1105-H1111, 1987.

[72] Schaper W. The Collateral Circulation of the Heart. Amsterdam: North Holland Publishing Co, 1971, p. 276.

[73] Prior BM, Lloyd PG, Ren J, Li H, Yang HT, Laughlin MH, Terjung RL. Time course of changes in collateral blood flow and isolated vessel size and gene expression after femoral artery occlusion in rats. Am J Physiol Heart Circ Physiol 287:H2434-H2447, 2004.

[74] Heil M, Schaper W. Influence of Mechanical, Cellular, and Molecular Factors on Collateral Artery Growth (Arteriogenesis). Circ Res 95: 449-458, 2004.

[75] Hamann JJ, Buckwalter JB, Valic Z, Clifford PS. Sympathetic restraint of muscle blood flow at the onset of dynamic exercise. J Appl Physiol (1985) 92: 2452-2456, 2002.

[76] Lash JM. Exercise training enhances adrenergic constriction and dilation in the rat spinotrapezius muscle. J Appl Physiol 85: 168-174, 1998.

[77] Martinez-Lemus LA, Hill MA, Bolz SS, Pohl U, Meininger GA. Acute mechanoadaptation of vascular smooth muscle cells in response to continuous arteriolar vasoconstriction: implications for functional remodeling. FASEB J 18: 708-710, 2004.

[78] Martinez-Lemus LA, Hill MA, Meininger GA. The plastic nature of the vascular wall: a continuum of remodeling events contributing to control of arteriolar diameter and structure. Physiology 24: 4557, 2009.

[79] Krall A. Jun 2014. Smooth Muscle Cell Organization in the Stem Region of the Gracilis Collateral Circulation [Online]. California Polytechnic State University. http://digitalcommons.calpoly.edu/bmedsp/63 [Sept 2016].

[80] Rzucidlo EM, Martin KA, Powell RJ. Regulation of smooth muscle cell differentiation. J Vasc Surg 45: 25A-32A, 2007.

[81] Heilmann C, Beyersdorf F, Lutter G. Collateral growth: cells arrive at the construction site. Cardiovasc Surg 10: 570-578, 2002.

[82] Bowles DK, Wamhoff BR. Coronary smooth muscle adaptation to exercise: does it play a role in cardioprotection? Acta Physiol Scand 178: 117-121, 2003. 
[83] Distasi MR, Case J, Ziegler MA, Dinauer MC, Yoder MC, Haneline LS, Dalsing MC, Miller SJ, Labarrere CA, Murphy MP, Ingram DA, Unthank JL. Suppressed hindlimb perfusion in $R a c 2^{-/-}$and $N o x 2^{-1-}$ mice does not result from impaired collateral growth. Am J Physiol Heart Circ Physiol 296: H877-H886, 2009.

[84] Tuttle JL, Nachreiner RD, Bhuller AS, Condict KW, Connors BA, Herring BP, Dalsing MC, Unthank JL. Shear level influences resistance artery remodeling: wall dimensions, cell density, and eNOS expression. Am J Physiol Heart Circ Physiol 281: H1380-H1389, 2001.

[85] Longland CJ. The Collateral Circulation of the Limb: Arris and Gale Lecture delivered at the Royal College of Surgeons of England on 4th February, 1953. Annals of The Royal College of Surgeons of England. 1953;13(3):161-176

[86] Herzog S, Sager H, Khmelevski E, Deylig A, Wulf D. Collateral arteries grow from preexisting anastomoses in the rat hindlimb. Am J Physiol Heart Circ Physiol 283: H2012-H2020, 2002.

[87] Gruionu G, Hoying JB, Pries AR, Secomb TW. Structural remodeling of mouse gracilis artery after chronic alteration in blood supply. Am J Physiol Heart Circ Physiol 288: H2047-H2054, 2005.

[88] Gruionu G, Hoying JB, Pries AR, Secomb TW. Structural Remodeling of the Mouse Gracilis Artery: Coordinated Changes in Diameter and Medial Area Maintain Circumferential Stress. Microcirculation (New York, NY: 1994 19: 610-618, 2012.

[89] McAllister RM, Jasperse JL, Laughlin MH. Nonuniform effects of endurance exercise training on vasodilation in rat skeletal muscle. J Appl Physiol (1985) 98: 753-761, 2005.

[90] Duncker DJ, Bache RJ. Regulation of Coronary Blood Flow During Exercise. Physiol Rev 88: 10091086, 2008.

[91] Yan Z, Okutsu M, Akhtar YN, Lira VA. Regulation of exercise-induced fiber type transformation, mitochondrial biogenesis, and angiogenesis in skeletal muscle. J Appl Physiol (1985) 110: 264-274, 2011.

[92] Tanner CB, Madsen SR, Hallowell DM, Goring DM, Moore TM, Hardman SE, Heninger MR, Atwood DR, Thomson DM. Mitochondrial and performance adaptations to exercise training in mice lacking skeletal muscle LKB1. Am J Phyiol Endocrinol Metab 305: E1018-E1029, 2013.

[93] Röckl KSC, Hirshman MF, Brandauer J, Fujii N, Witters LA, Goodyear LJ. Skeletal Muscle Adaptation to Exercise Training. Diabetes 56: 2062-2069, 2007.

[94] Harms SJ, Hickson RC. Skeletal muscle mitochondria and myoglobin, endurance, and intensity of training. J Appl Phyisol 54: 798-802, 1983.

[95] Richter EA, Hargreaves M. Exercise, GLUT4, and Skeletal Muscle Glucose Uptake. Physiol Rev 93: 993-1017, 2013. 
[96] Talanian JL, Holloway GP, Snook LA, Heigenhauser GJ, Bonen A, Spriet LL. Exercise training increases sarcolemmal and mitochondrial fatty acid transport proteins in human skeletal muscle. Am J Physiol Endocrinol Metab 299: E180-E188, 2010.

[97] Claassen V. Neglected Factors in Pharmacology and Neuroscience Research, edited by Huston JP. Amsterdam: Elsevier, 1994.

[98] Cairns RB, Hood KE, Midlam J. On fighting in mice: is there a sensitive period for isolation effects? Animal Behaviour 33: 166-180, 1985.

[99] Benton D, Brain PF. Behavioural comparisons of isolated, dominant and subordinate mice. Behav Processes 4: 211-219, 1979.

[100] Võikar V, Polus A, Vasar E, Rauvala H. Long-term individual housing in C57BL/6J and DBA/2 mice: assessment of behavioral consequences. Genes Brain Behav 4: 240-252, 2005.

[101] Späni D, Arras M, König B, Rülicke T. Higher heart rate of laboratory mice housed individually vs in pairs. Lab Anim 37: 54-62, 2003.

[102] Cola MS, Gava AL, Meyrelles SS, Vasquez EC. Endothelial dysfunction of resistance vessels in female apolipoprotein E-deficient mice. Lipids in Health and Disease 9: 51, 2010.

[103] Meyrelles SS, Peotta VA, Pereira TMC, Vasquez EC. Endothelial dysfunction in the apolipoprotein E-deficient mouse: insights into the influence of diet, gender and aging. Lipids in Health and Disease 10: 211, 2011.

[104] Smith DD, Tan X, Tawfik O, Milne G, Stechschulte DJ, Dileepan KN. Increased aortic atherosclerotic plaque development in female apolipoprotein E-null mice is associated with elevated thromboxane A2 and decreased prostacyclin production. J Physiol Pharmacol 61: 309-316, 2010.

[105] Maeda N, Johnson L, Kim S, Hagaman J, Friedman M, Reddick R. Anatomical differences and atherosclerosis in apolipoprotein E-deficient mice with 129/SvEv and C57BL/6 genetic backgrounds. Atherosclerosis 195: 75-82, 2007.

[106] Surra JC, Guillén N, Arbonés-Mainar JM, Barranquero C, Navarro MA, Arnal C, Orman I, Segovia JC, Osada J. Sex as a profound modifier of atherosclerotic lesion development in apolipoprotein Edeficient mice with different genetic backgrounds. J Atheroscler Thromb 17: 712-721, 2010. 


\section{APPENDICES}

\section{Appendix A: Surgery and Experimental Protocols}

Femoral Artery Ligation Protocol

$$
\text { Date__ Hindlimb Ischemia Surgery - Femoral Artery Ligation Initials }
$$

Mouse Information
Age:
Sex:
Tag:
Genotype/strain:
Cage:

Purpose:

\section{Materials}

Pre-sterilize in autoclave

$\begin{array}{ll}\text { 1. } & \text { Standard pattern forceps (1) } \\ \text { 2. } & \text { Fine forceps-S\& T (2) } \\ \text { 3. } & \text { Ultrafine forceps }-545 \text { (1) } \\ \text { 4. } & \text { Curved iris scis s ors (1) } \\ \text { 5. } & \text { Microdis section } 5 \text { cissors (1) } \\ \text { 6. } & \text { Gauze sponges - } 2 \times 2 \text { and } 4 \times 4 \\ \text { 7. } & \text { Cotton swabs } \\ \text { 8. } & 6.0 \text { silk suture }(2 \times 1 \text {-inch pieces) } \\ \text { 9. } & 7.0 \text { prolene suture } \\ \text { 10. } & \text { Needle holder (1) }\end{array}$

Obtain in surgery suite

\begin{tabular}{|c|c|}
\hline 11. & $\begin{array}{l}\text { Depilatory cream-Veet } \\
\text { Non-sterile cotton } 5 \text { wabs }\end{array}$ \\
\hline 13. & Non-sterile gauze sponges ( $2 \times 2$ and $4 \times 4)$ \\
\hline 14. & Chlorhexidene diacetate (Nolvasan) \\
\hline 15. & $1-m L$ insulin syringes (2) \\
\hline 16. & Buprenorphine analges ic $\left(0.03 \mathrm{mg} \cdot \mathrm{ml}^{-1}\right)$ \\
\hline 17. & Ear punch \\
\hline 18. & Veterinary ointment \\
\hline 19. & Surgical tape \\
\hline 20. & FST heat pad w/ rectal probe \\
\hline 21 . & Surgical scrubs \\
\hline 22. & Sterile petri dish (1) \\
\hline 23 . & Sterile $5-\mathrm{mL}$ syringe (1) \\
\hline 24. & Sterile saline \\
\hline 25. & Is olation mask and cap \\
\hline 26. & Sterile gloves \\
\hline 27. & Recovery bin and heat pad \\
\hline 28. & $70 \%$ is opropyl alcohol(IPA) \\
\hline
\end{tabular}

\section{Animal preparation}

29. Spray surgery area with Nolvasan.

30. Place animal in induction chamber.

31. Open oxygen cylinder. Set flow high and is ofluorane to $5 \%$.

32. Once anesthetized, weigh animal and move to preparatory bench in a supine position.

33. Reduce is oflurane to $1-3 \%$ and flow to 0.5 $1.51 \cdot \min ^{-1}$.
34. Gently apply veterinary ointment to eyes using a cotton swab.

35. Apply depilatory cream to hindlimb with a cotton $5 w a b$ and let sit for 1-3 minutes.

36. Spray a $2 \times 2$ gauze sponge with Nolvas an and wipe hindlimb clean of cream and hair.

37. Flip animal over and apply ear punch.

38. Administer pre-op buprenorphine dose $\left(0.075 \mathrm{mg} \cdot \mathrm{kg}^{-1}\right)$ by subcutaneous injection.

39. Cover heat pad with a $4 \times 4$ gauze sponge and transfer animal to surgery stage.

40. Apply lubricant to rectal probe and insert. Set thermo-controller to $35^{\circ} \mathrm{C}$.

41. Change into surgical scrubs and wash hands/forearms.

42. Open sterile instrument tray and sterile pack:

43. Obtain sterile petri dish in sterile field and fill with sterile saline, using a $5-\mathrm{mL}$ syringe.

44. Put on mask, cap, and sterile gloves.

Surgery

45. Make a small incision on the middle, medial aspect of the left hindlimb, directly over the neurovascular bundle.

46. Extend incision to the abdominal wall

47. Blunt dis sect subcutaneous connective tissue to maximize surgical exposure.

48. Blunt dis sect and retract epigastric fat pad to expose ligation site, proximal to the popliteal artery and distal to the epigastric.

49. Blunt dis sect connective tis sue over bundle and separate nerve from the artery-vein pair.

50. Use ultrafine forceps to separate the artery from the vein.

51. Tie off the femoral artery with silk suture.

52. Use 7-0 prolene suture to close the incision with spiral sutures.

53. Make a small incision in the middle medial aspect of the left hindlimb.

54. Extend incision to the abdominal wall

55. Blunt dis sect subcutaneous connective tissue to maximize surgical exposure.

56. Use 7-0 prolene suture to close the incision with spiral sutures.

\section{Post-Surgical}

57. Administer post-op buprenorphine dose $\left(0.075 \mathrm{mg} \cdot \mathrm{kg}^{-1}\right)$ by subcutaneous injection.

58. Microwave recovery heat pad for $\sim 1-2 \mathrm{~min}$.

59. Transfer animal to recovery bin.

60. Turn off is oflurane, flow, and clo se oxygen.

61. Wipe down surgical area with IPA and wash all instruments. 
Functional Vasodilation Protocol

Date_- Fun
Mouse Information
Age:
Sex:
Tag:
Genotype/strain:
Cage:

Purpose:

\section{Materials}

\begin{tabular}{|c|c|}
\hline 1. & Standard pattern forceps (1) \\
\hline 2. & Fine forceps- S\&T (2) \\
\hline 3. & Curved iris scissors (1) \\
\hline 4. & Depilatory cream-Veet \\
\hline 5. & Cotton swabs \\
\hline 6. & Gauze sponges ( $2 \times 2$ and $4 \times 4)$ \\
\hline 7. & Chlorhexidene diacetate (Nolvasan) \\
\hline 8. & Veterinary ointment \\
\hline 9. & Surgical tape \\
\hline 10. & FST heat pad w/ rectal probe \\
\hline 11. & Petri dish w/saline \\
\hline 12. & Tungstenmicroelectrodes \\
\hline 13. & Clay \\
\hline 14. & Plastic wrap \\
\hline 15 . & Trans-illuminator device \\
\hline 16. & Data acquisition unit- PowerLab \\
\hline 17. & Digital chart recording so ftware- LabChart \\
\hline 18. & Intravitalmicro scope-Olympus BXFM \\
\hline 19. & Digital imaging s oftware-QCapturePro \\
\hline 20. & Sodium nitroprusside (SNP) \\
\hline 21. & $70 \%$ is opr opyl alcohol (IPA) \\
\hline
\end{tabular}

\section{Animal preparation}

22. Place animal in induction chamber.

23. Open oxygen cylinder. Set flow high and is ofluorane to $5 \%$.

24. Once anesthetized, weigh animal and move to preparatory bench in a supine position.

25. Reduce is oflurane to $1-3 \%$ and flow to 0.5 $1.51 \cdot \mathrm{min}^{-2}$.

26. Apply depilatory cream to hindlimb with a cotton swab and let sit for 1-3 minutes.

27. Spray a $2 \times 2$ gauze sponge with Nolvasan and wipe hindlimb clean of cream and hair.

28. Flip animal over and use clippers to shave the hair from the posterior sides of the hindlimbs.

29. Complete hair removal with depilatory cream.

30. Cover heat pad with a $4 \times 4$ gauze sponge and trans fer animal to surgery stage.

31. Apply veterinary ointment to rectal probe and insert. Set thermo-controller to $35^{\circ} \mathrm{C}$.
Initials

\section{Surgical exposure}

32. Make a small incision on the middle, medial aspect of the left hindlimb.

33. Insert the clo sed scissors underneath the skin and open themrepeatedly to separate the skin from connective tissue.

34. Cut away the skin above the gracilis muscles and the collateral circuit.

35. Blunt dis sect and remove the connective tissue overlying the gracilis muscle.

36. Position the trans-illuminator $L E D$ probe underneath the limb, below the gracilis.

37. Turn on the PowerL ab and open LabChart.

38. Open the Isolated Stimulator Panel and set the frequency to $1 \mathrm{~Hz}$, the duration to $200 \mu \mathrm{s}$, and the current to $1 \mathrm{~mA}$

39. Hook the microelectrodes up to the isolated stimulator attached to the PowerLab.

40. Use clay to hold the wires at the base of the electrodes inplace.

41. Position the electrodes with the tips resting on the surface of the gracilis anterior $(\sim 1 \mathrm{~cm}$ apart, between the saphenous and profunda).

42. Turn on the stimulator and start stimulation.

43. Adjust electrode placement and current for a maximal localized contraction, and then stop stimulation.

44. Apply saline to tis sue, cover preparation with plas tic wrap, and equilibrate for 30 minutes.

\section{FunctionalVasodilation}

45. In LabChart, change the frequency to $8 \mathrm{~Hz}$.

46. Switch on the trans-illuminator and adjust the brightness using the dimmer switch.

47. Open QCapturePro and position the intravital micros cope above the collateral arteriole.

48. Acquire resting images of both the arteriole and the profunda femoris artery.

49. Stimulate the muscle for 90 seconds.

50. Capture images of the collateral and the pro funda immediately after stimulation (series of 10 ) and save all images acquired.

51. Maximally dilate with SNP and capture images of the collateral and the profunda.

52. Repeat the surgical expo sure and functional vas odilation procedures on the control limb.

\section{Post-Surgical}

53. Perform cervical dislocation to euthanize the animal and dispo se of in biohazard.

54. Turn off is ofluorane, flow, and close oxygen.

55. Wash all instruments used during procedure.

56. Wipe down the surgical area with IPA. 
Sample Images of Experimental Set-Up
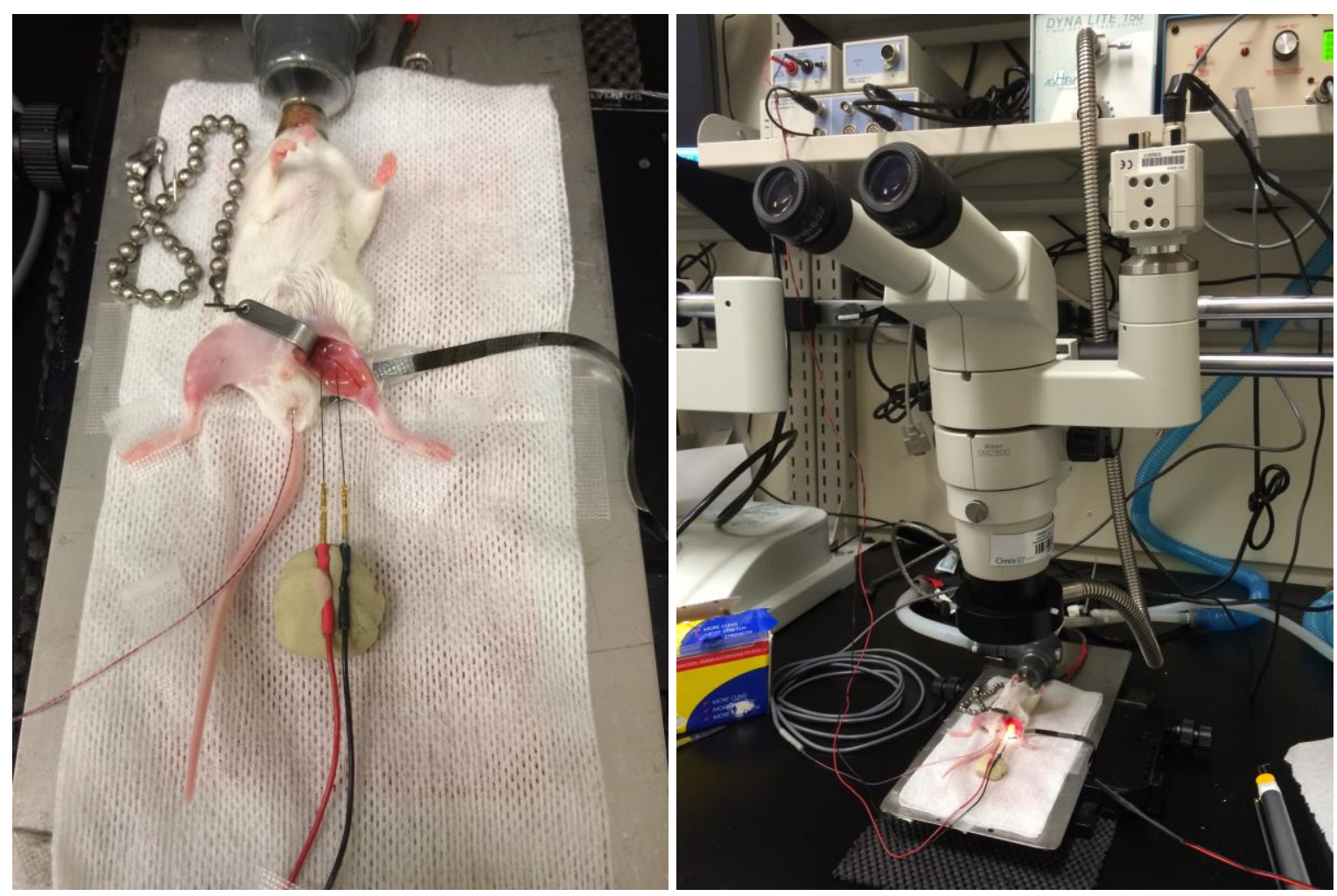
Appendix B: Sample Raw Images

C57B1/6 Male Sedentary Day 7 Operated
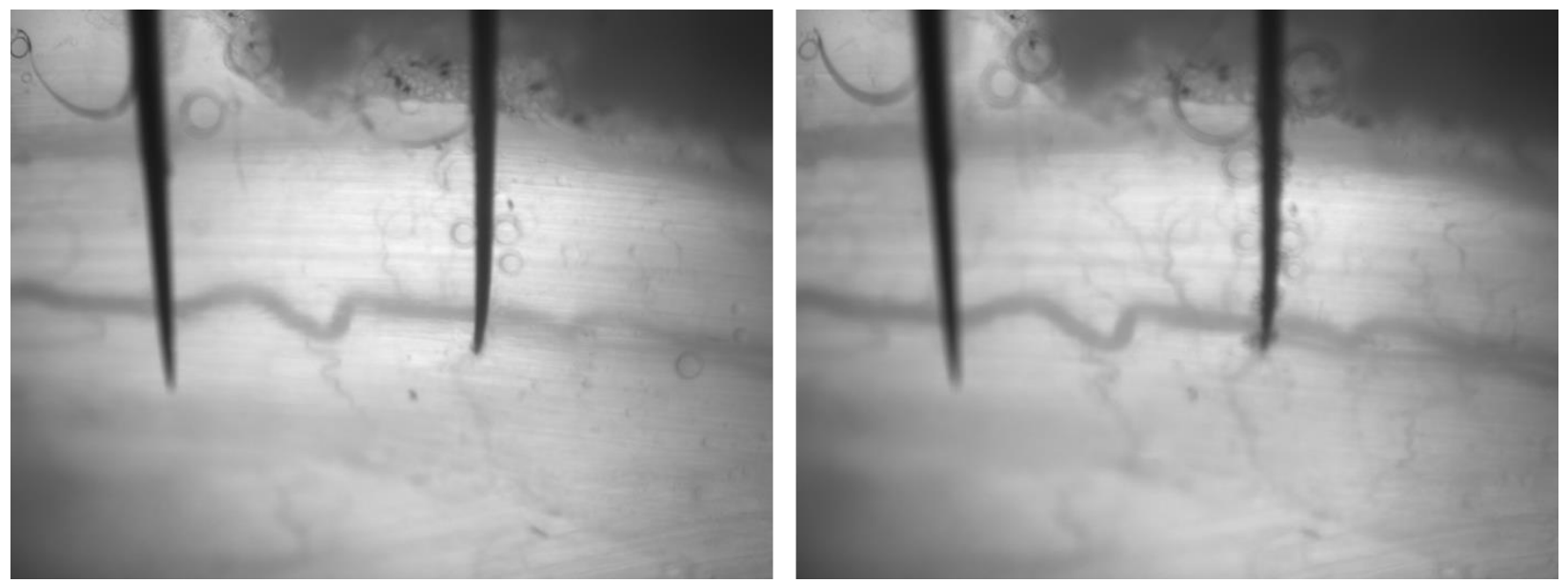

C57B1/6 Male Sedentary Day 7 Sham
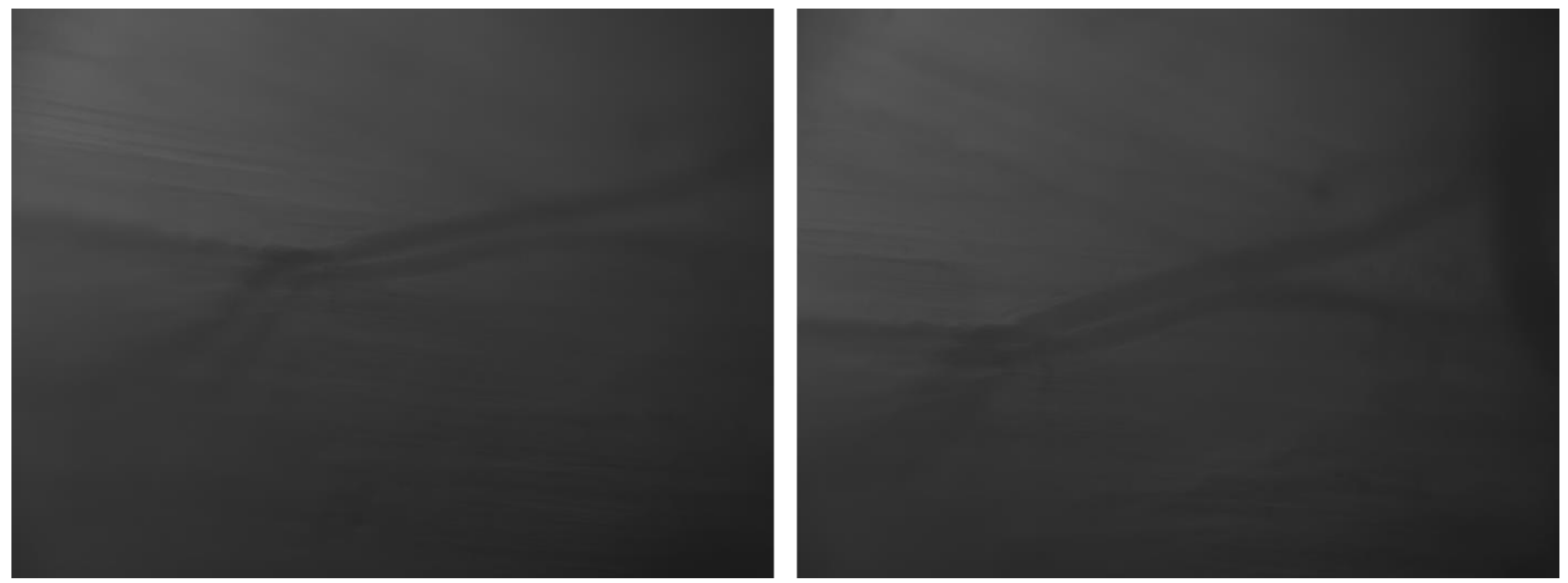

C57B1/6 Male Sedentary Day 28 Operated
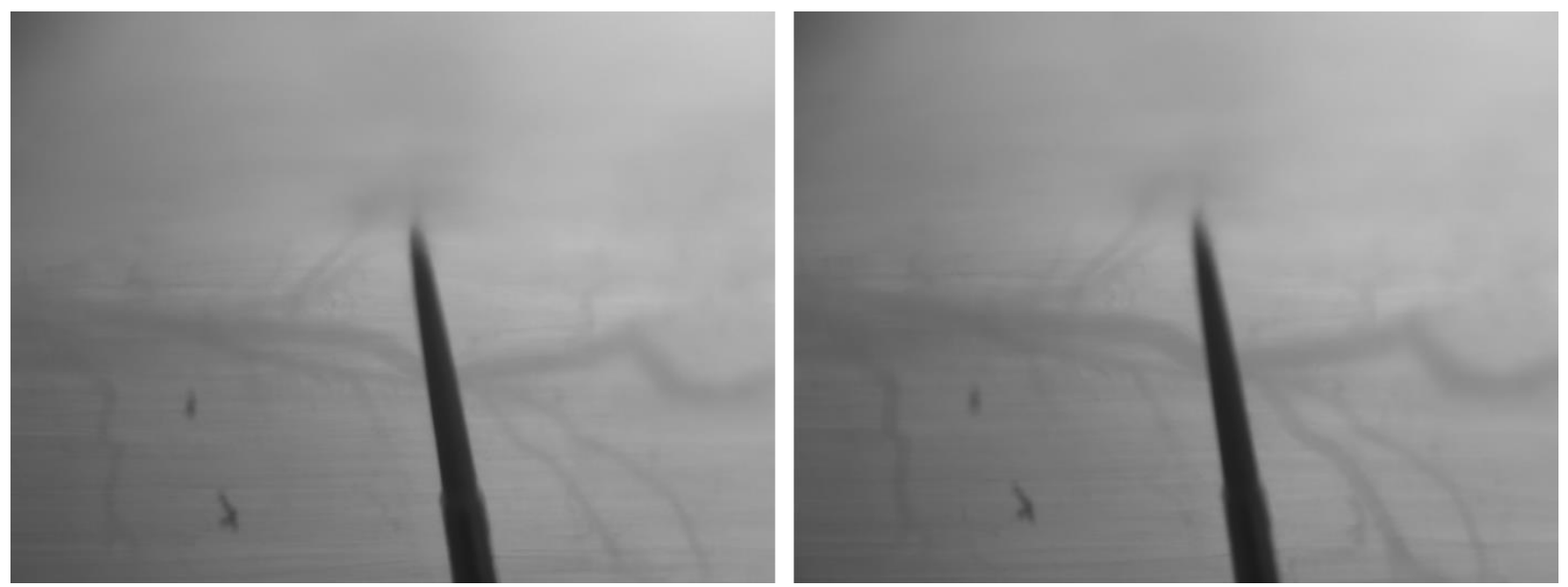

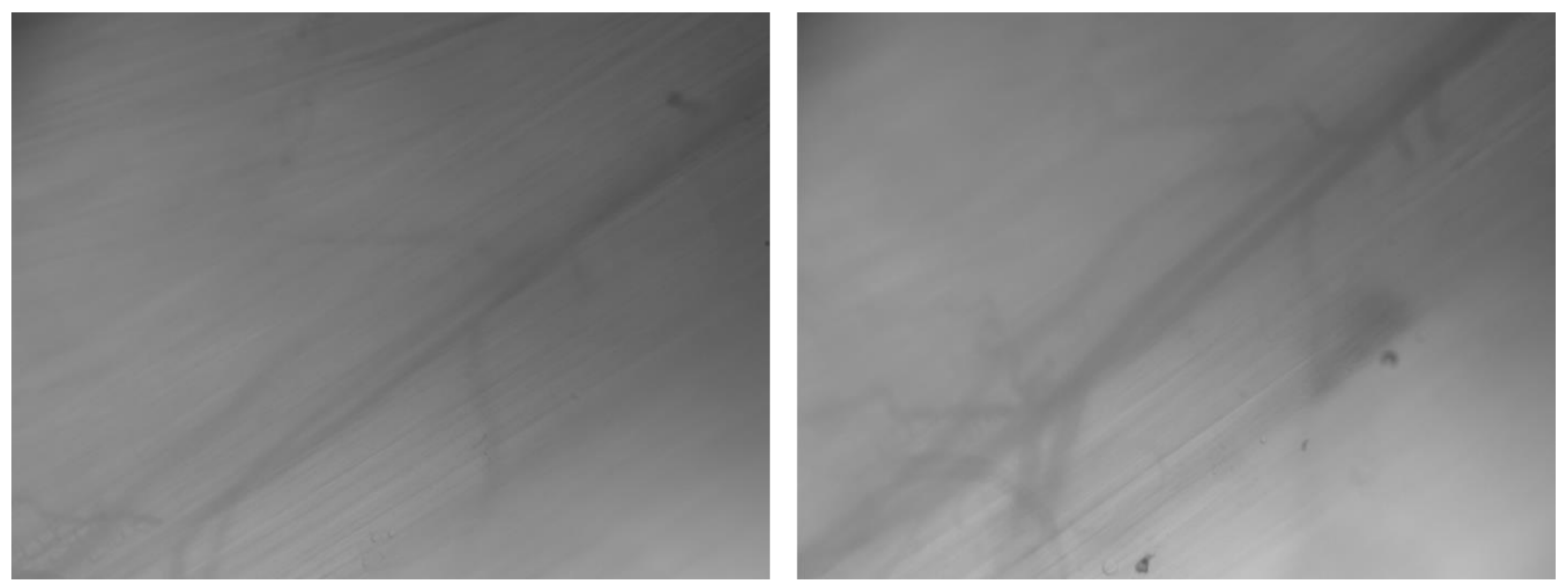

C57B1/6 Male Exercise-Trained Day 7 Operated
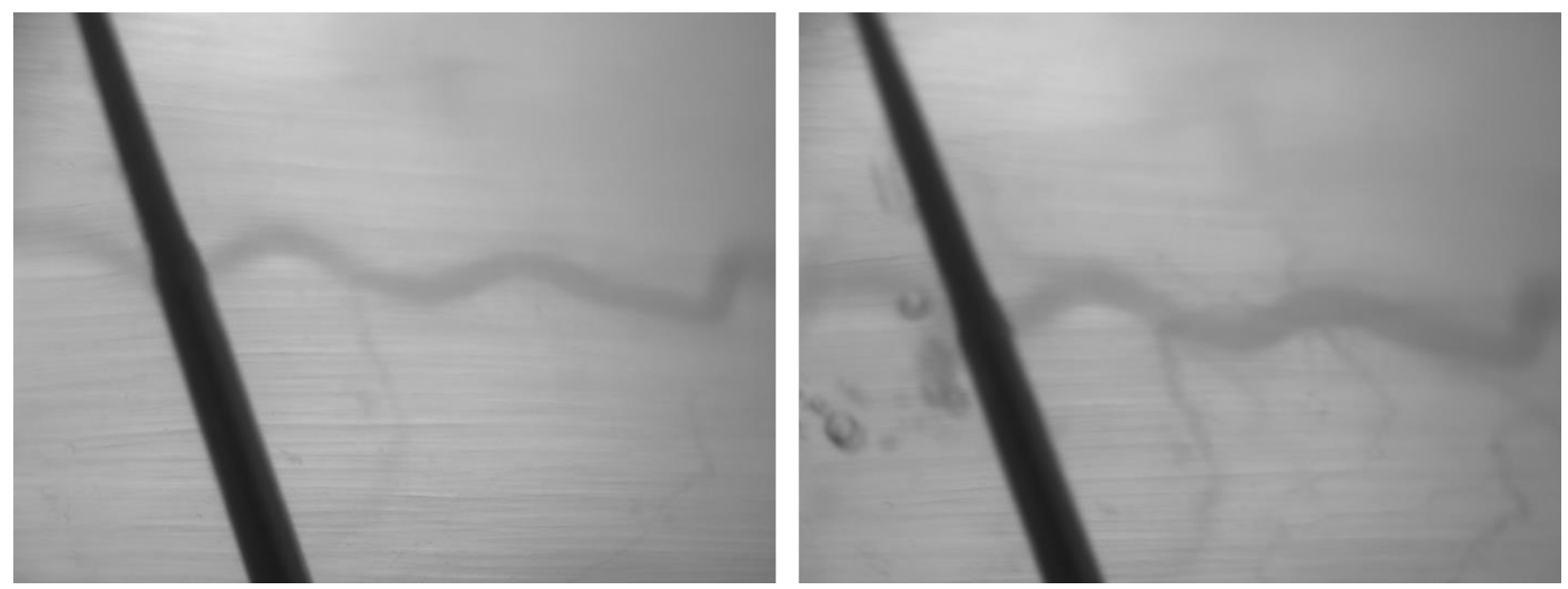

C57Bl/6 Male Exercise-Trained Day 7 Sham
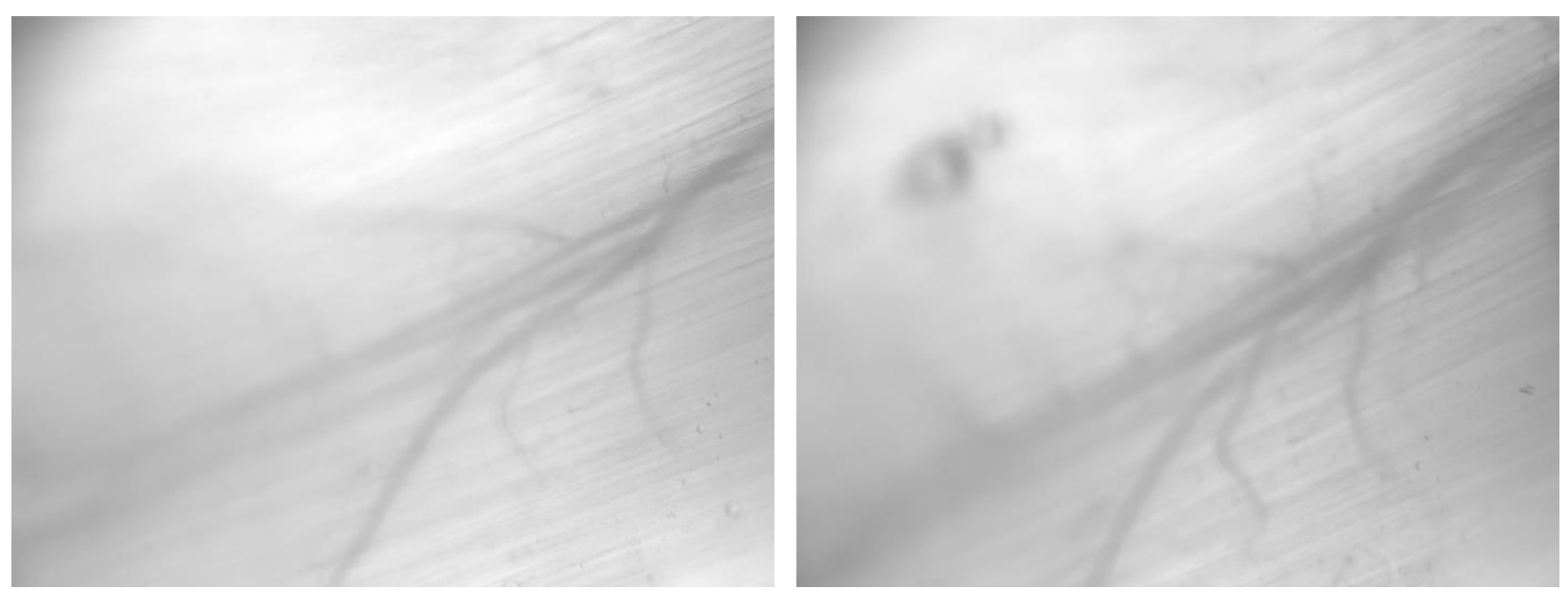

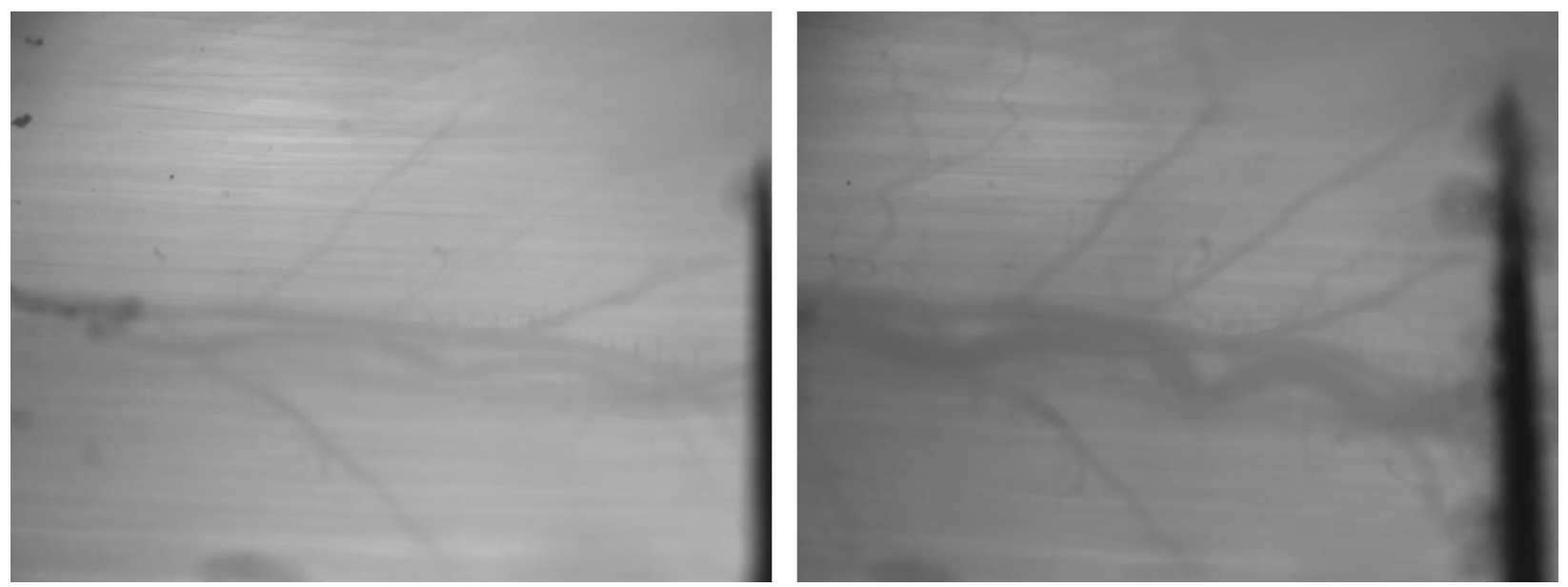

C57B1/6 Male Exercise-Trained Day 28 Sham
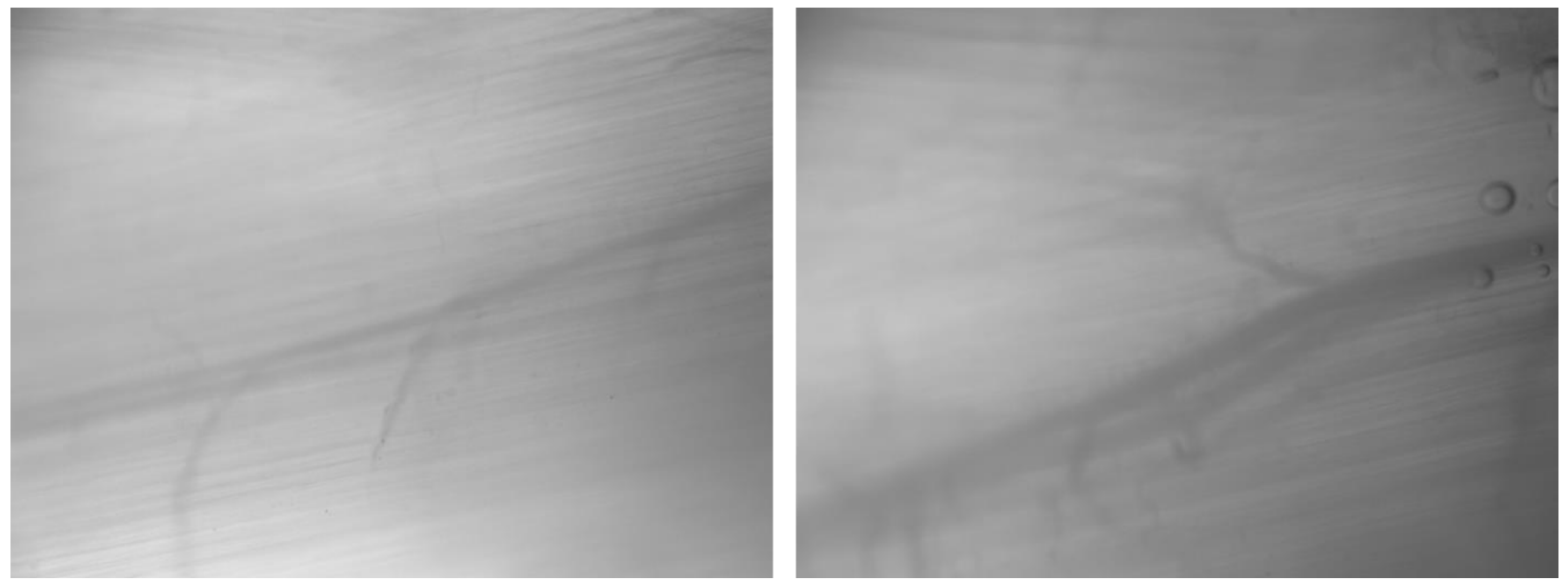

C57B1/6 Female Sedentary Day 7 Operated
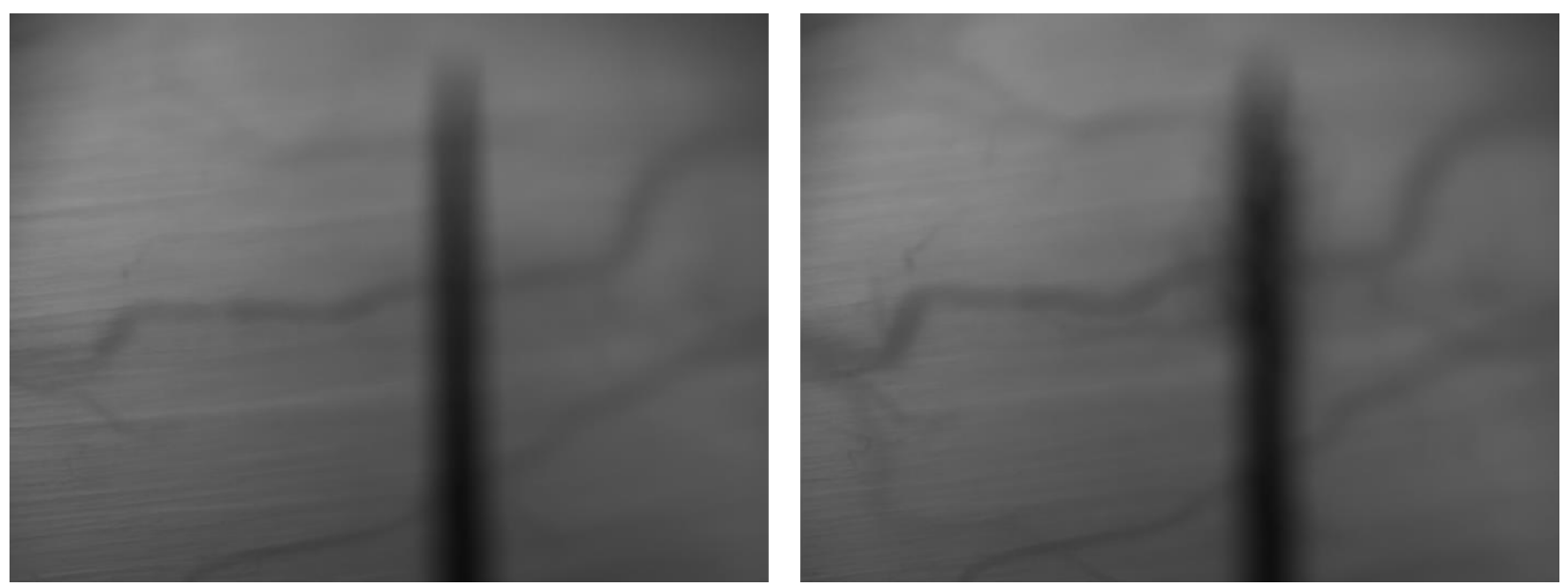
C57B1/6 Female Sedentary Day 7 Sham
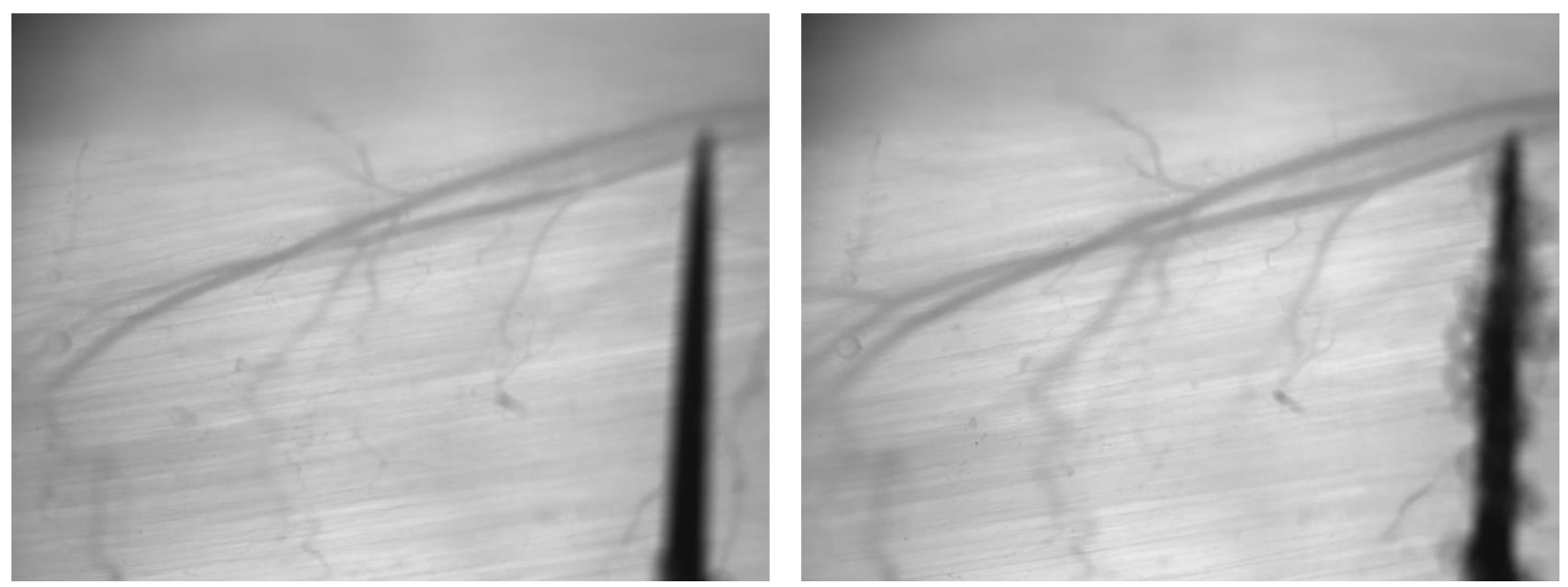

C57B1/6 Female Sedentary Day 28 Operated
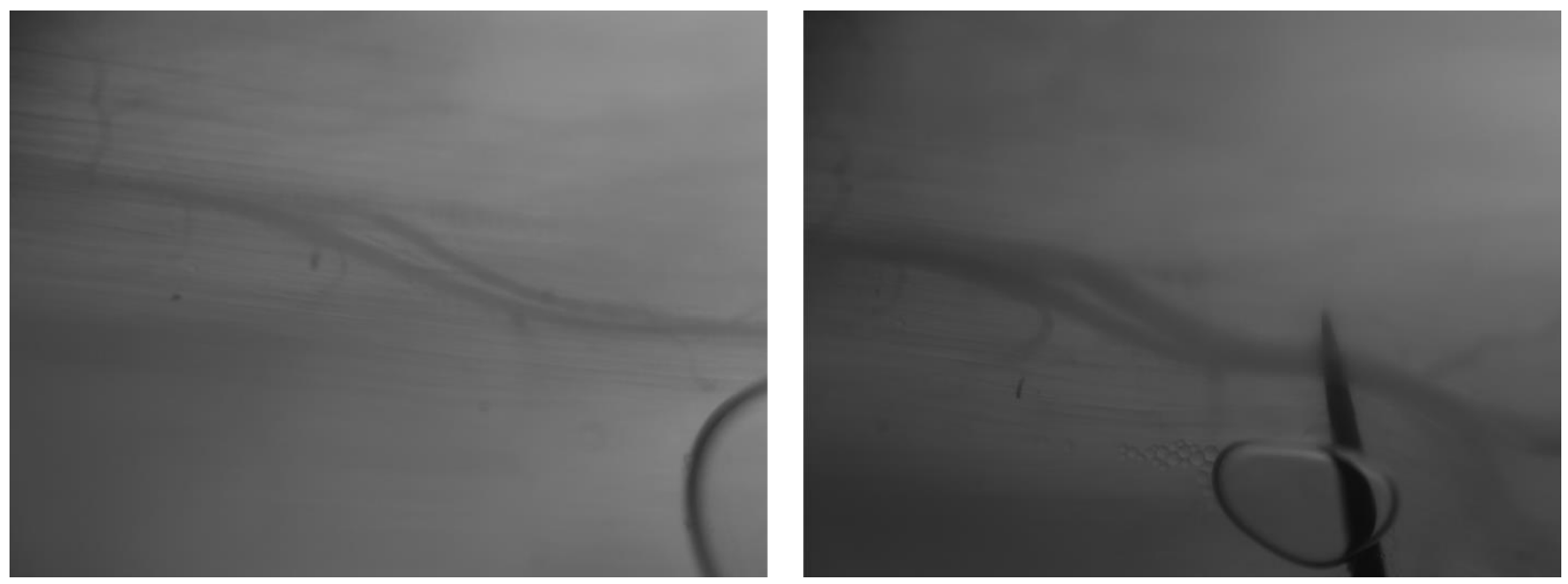

C57B1/6 Female Sedentary Day 28 Sham
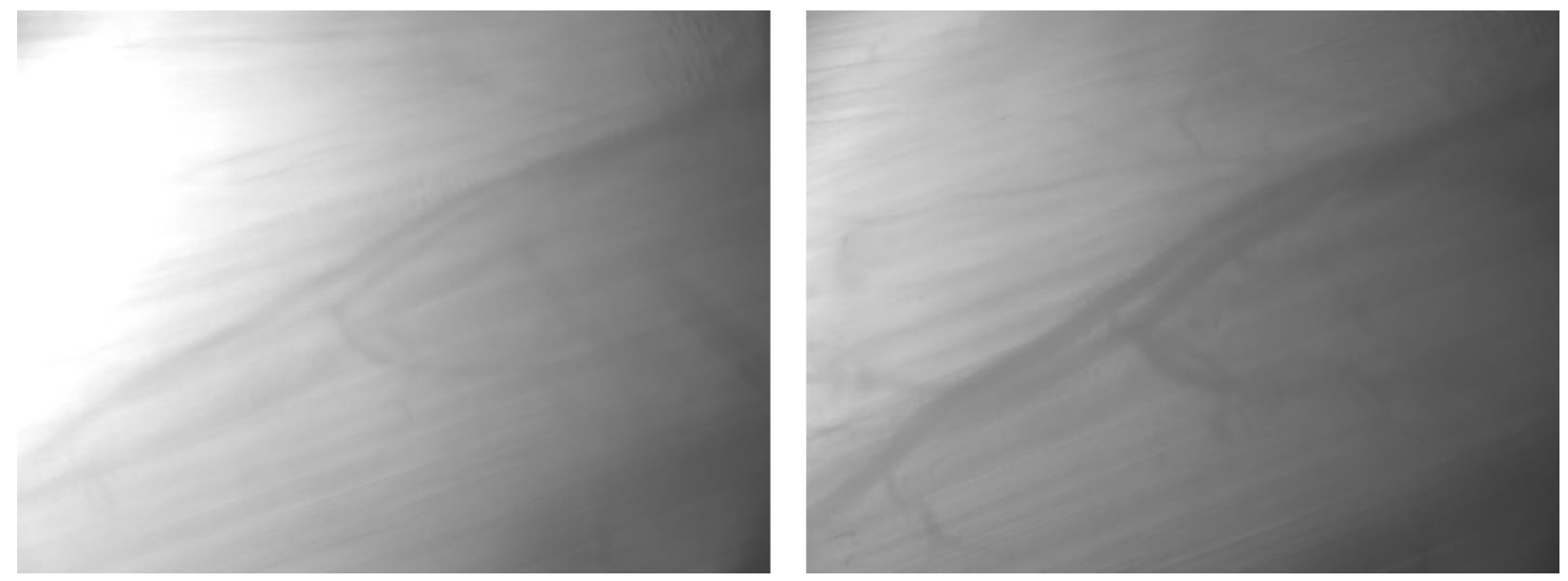
C57B1/6 Female Exercise-Trained Day 7 Operated
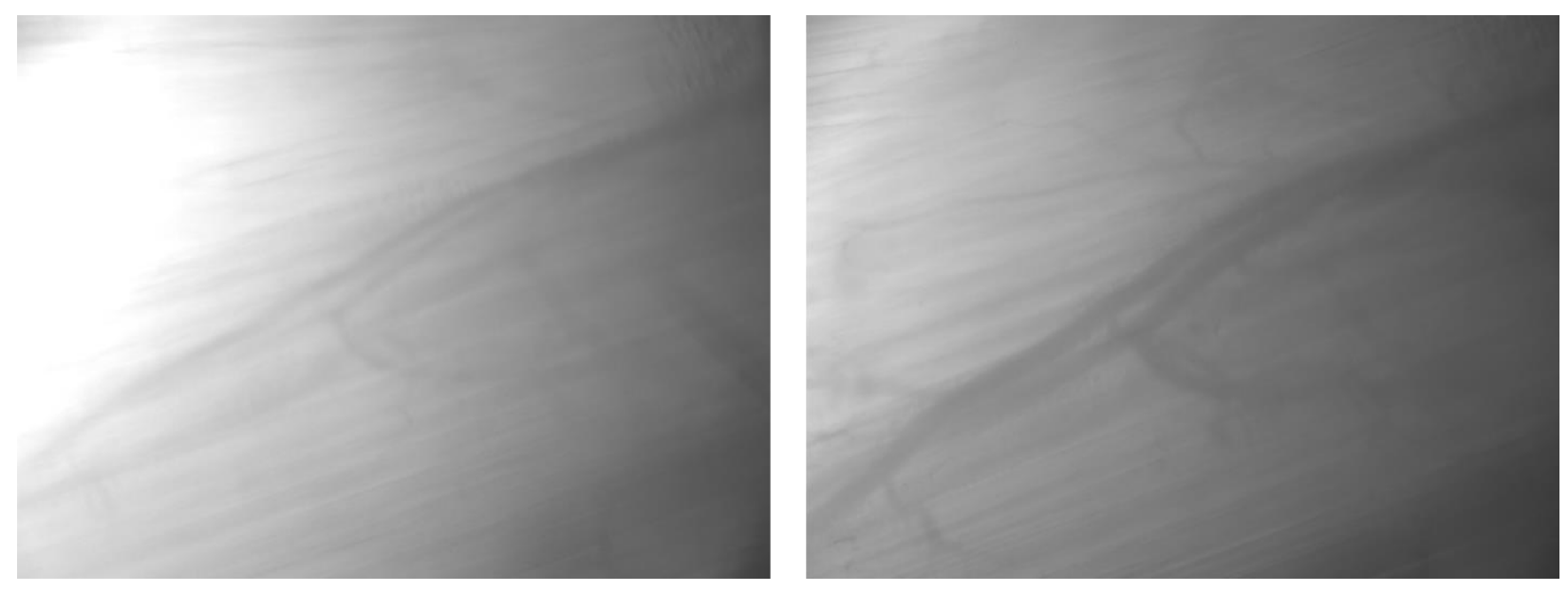

C57B1/6 Female Exercise-Trained Day 7 Sham
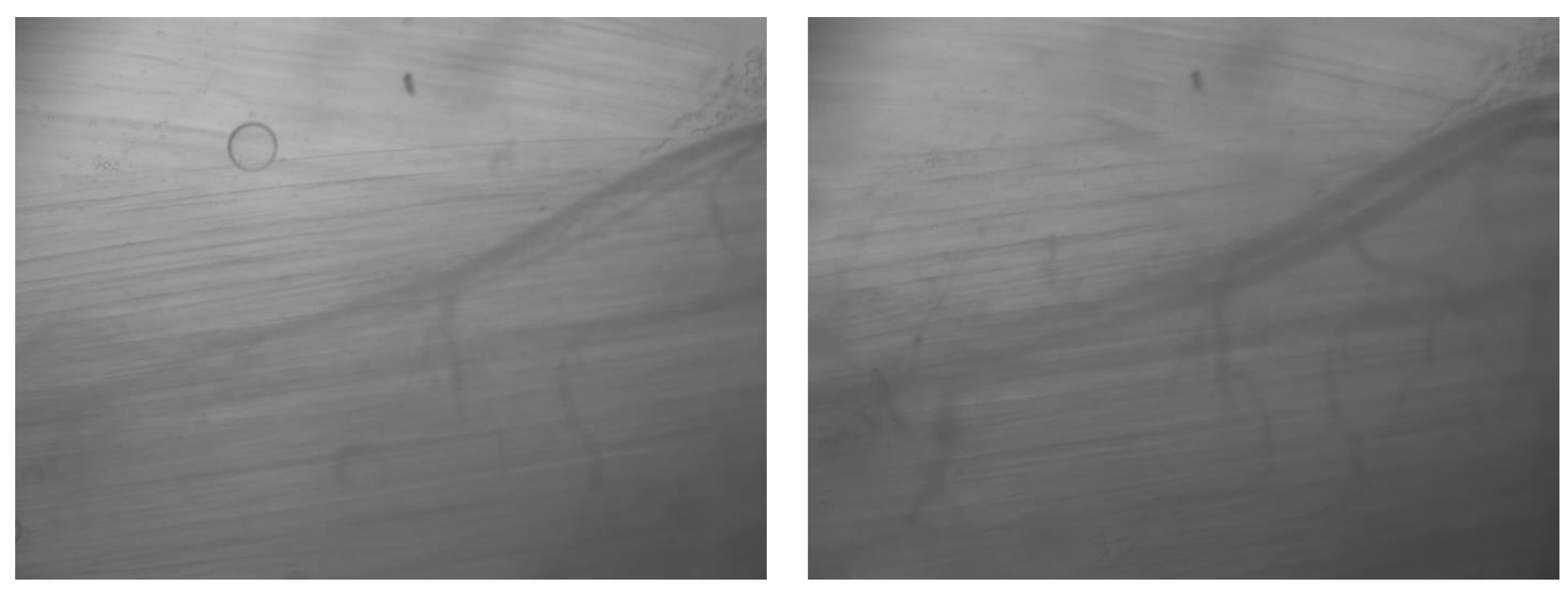

C57B1/6 Female Exercise-Trained Day 28 Operated
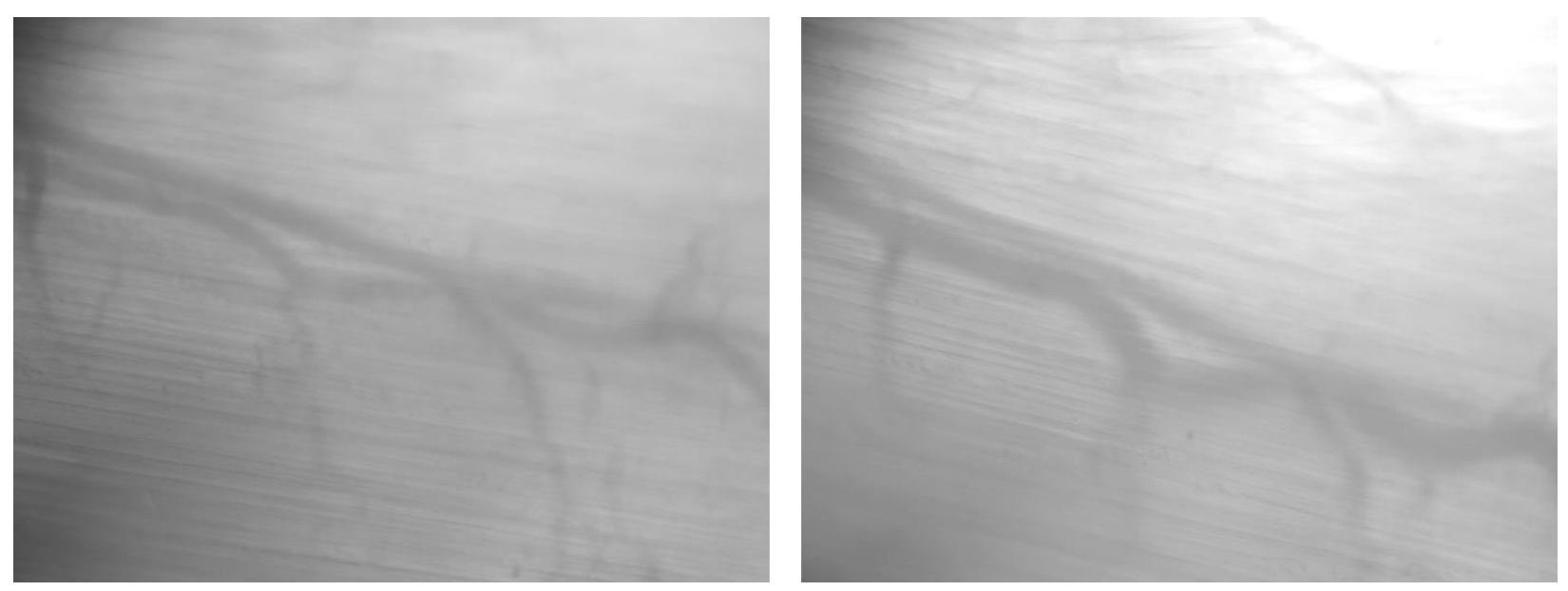

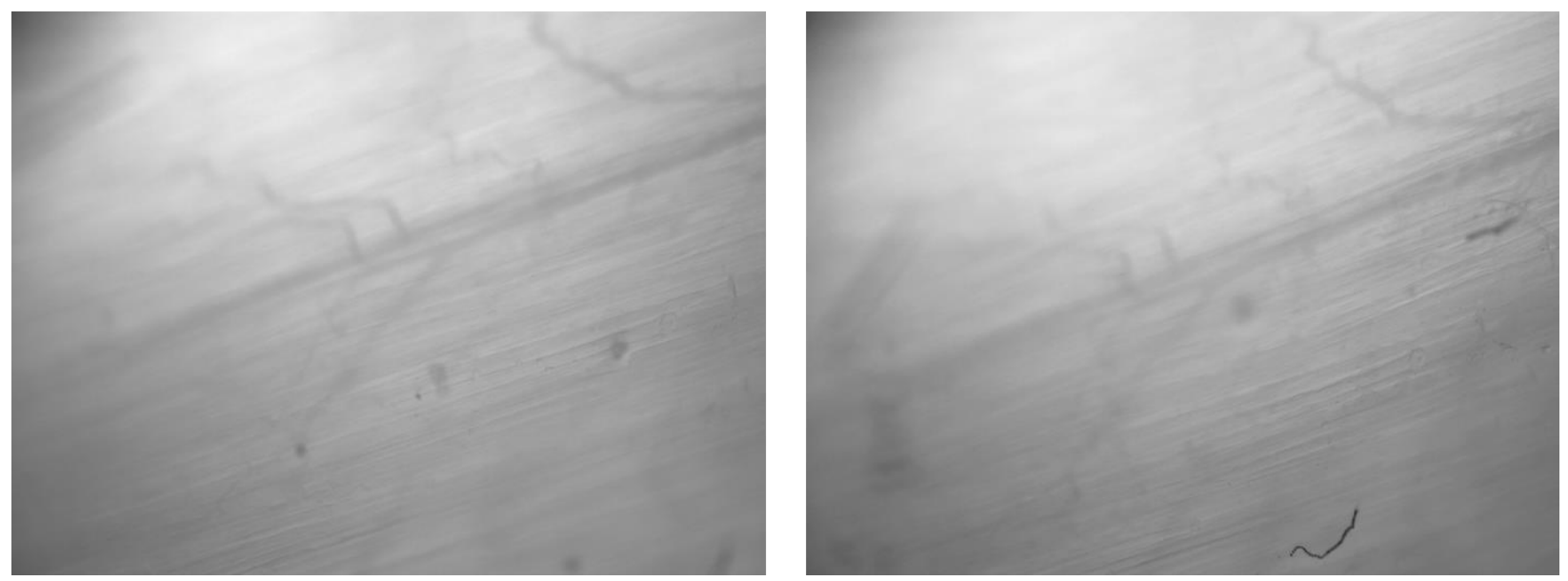

\section{Balb/c Male Sedentary Day 7 Operated}
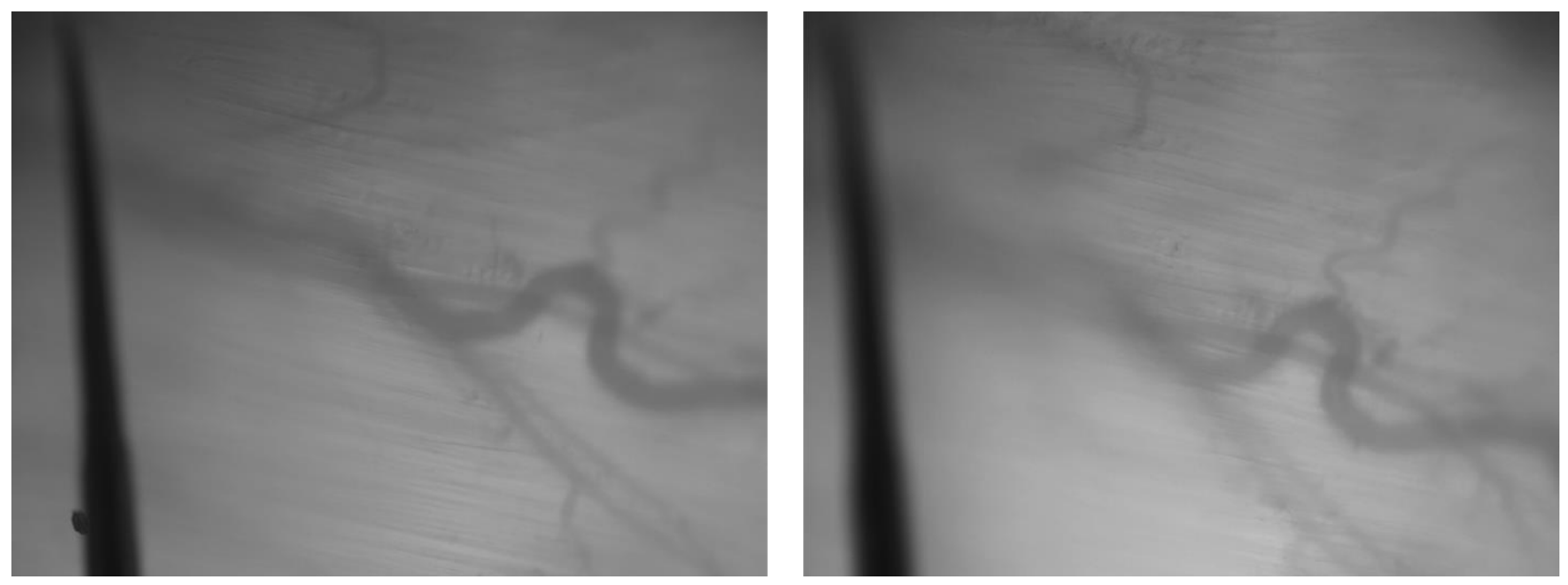

Balb/c Male Sedentary Day 7 Sham
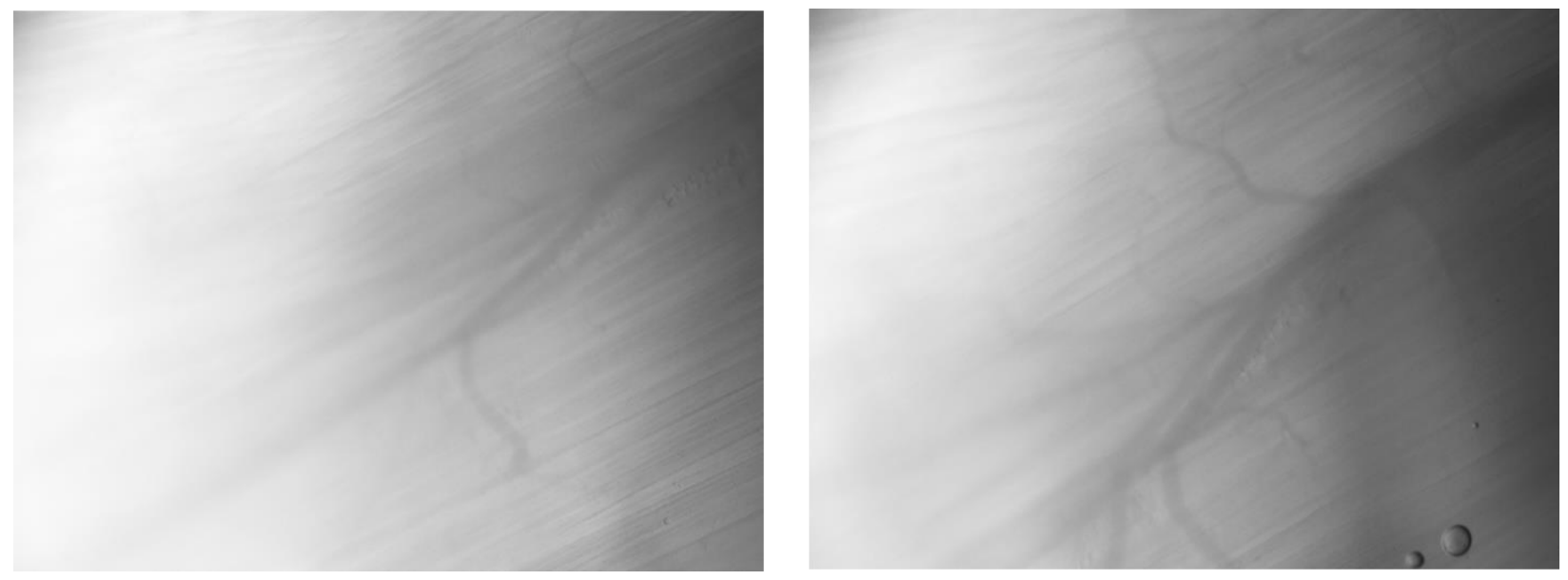
Balb/c Male Exercise-Trained Day 7 Operated
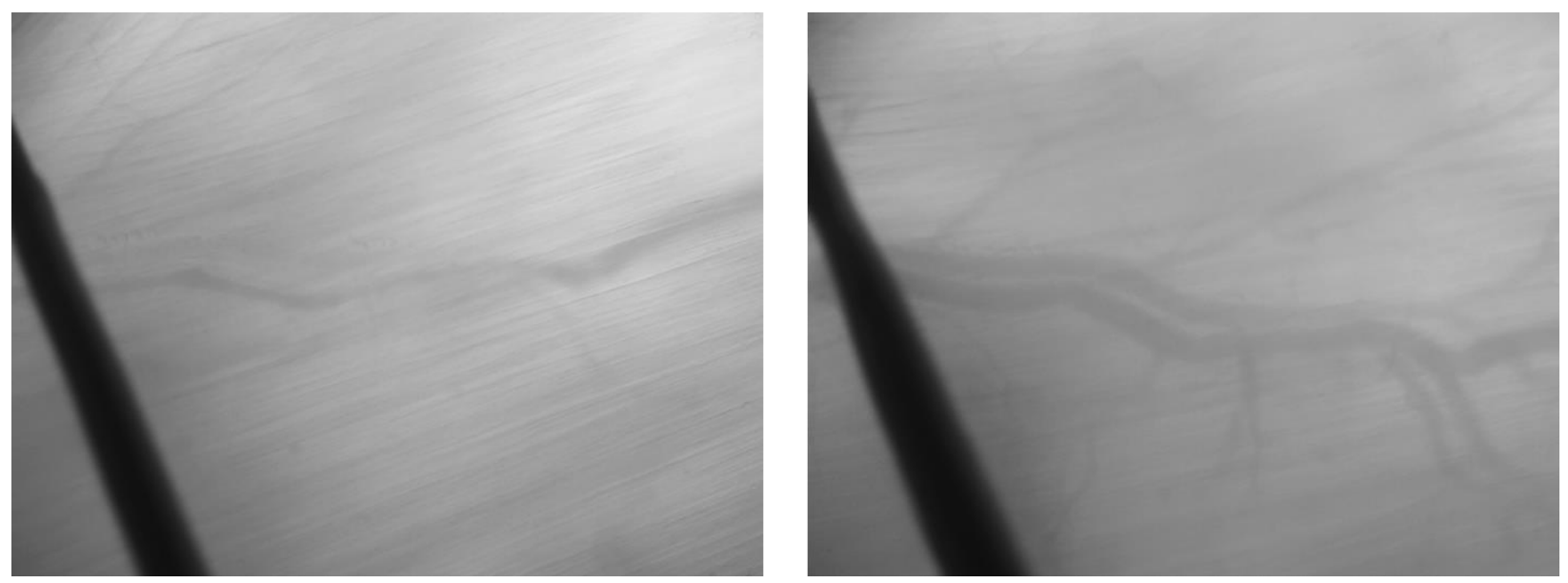

Balb/c Male Exercise-Trained Day 7 Sham
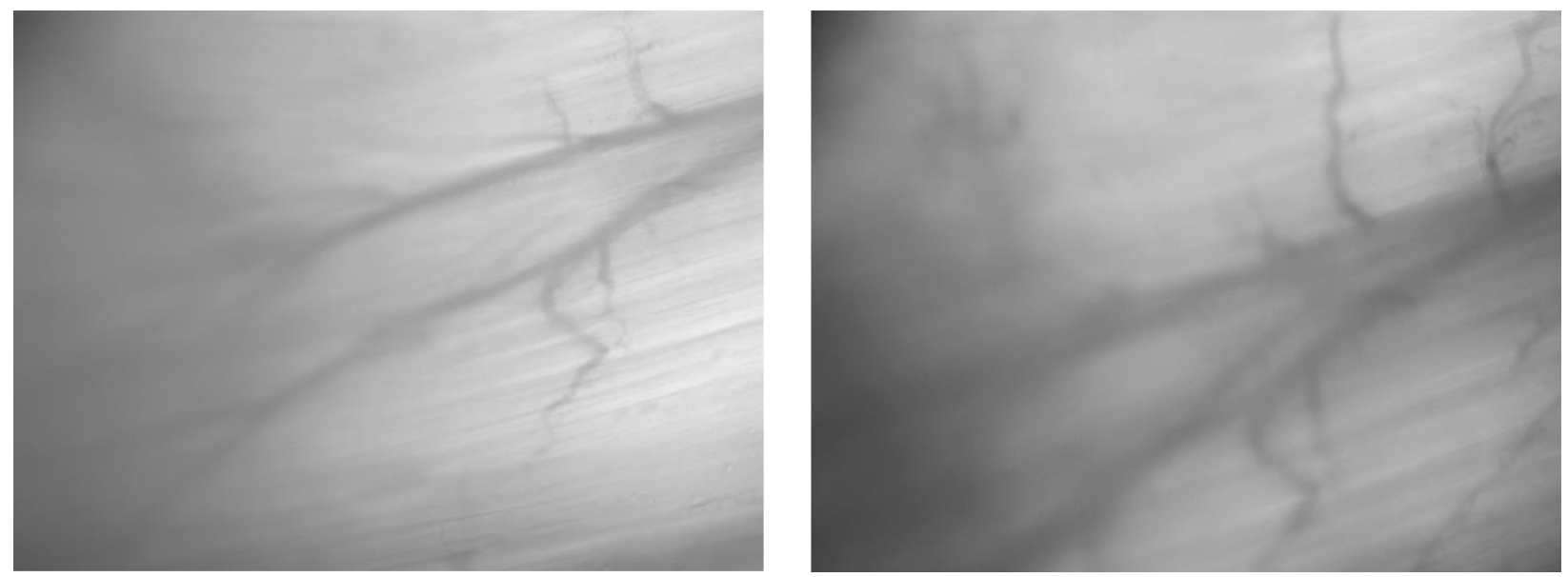


\section{Appendix C: Raw Data}

C57B1/6 Functional Vasodilation Data

\begin{tabular}{|c|c|c|c|c|c|c|c|c|}
\hline Sex & Treatment & Limb & $\begin{array}{l}\text { Time } \\
\text { Point }\end{array}$ & Replicate & $\begin{array}{c}\text { Cage } \\
\#\end{array}$ & $\begin{array}{c}\text { Resting } \\
(\mu \mathrm{m})\end{array}$ & $\begin{array}{c}\text { Dilated } \\
(\mu \mathrm{m})\end{array}$ & $\begin{array}{c}\text { Percent } \\
\text { change }(\%)\end{array}$ \\
\hline $\mathrm{M}$ & Sedentary & Operated & Day 7 & 1 & 4 & 77.6 & 81.9 & 5.541237 \\
\hline $\mathrm{M}$ & Sedentary & Operated & Day 7 & 2 & 4 & 83.2 & 84.8 & 1.923077 \\
\hline $\mathrm{M}$ & Sedentary & Operated & Day 7 & 3 & 6 & 85.3 & 96 & 12.54396 \\
\hline $\mathrm{M}$ & Sedentary & Operated & Day 7 & 4 & 6 & 60.6 & 75.4 & 24.42244 \\
\hline $\mathrm{M}$ & Sedentary & Operated & Day 7 & 5 & 3 & 54.2 & 68.8 & 26.93727 \\
\hline $\mathrm{M}$ & Sedentary & Operated & Day 7 & 6 & 3 & 75.3 & 83.3 & 10.62417 \\
\hline $\mathrm{M}$ & Sedentary & Operated & Day 7 & 7 & 18 & 60.6 & 84.2 & 38.94389 \\
\hline $\mathrm{M}$ & Sedentary & Operated & Day 7 & 8 & 5 & 103.4 & 108.5 & 4.932302 \\
\hline $\mathrm{M}$ & Sedentary & Operated & Day 7 & 9 & & 71.1 & 81.6 & 14.76793 \\
\hline $\mathrm{M}$ & Sedentary & Operated & Day 28 & 1 & 4 & 85.1 & 104.1 & 22.32667 \\
\hline $\mathrm{M}$ & Sedentary & Operated & Day 28 & 2 & 4 & 63.1 & 75 & 18.85895 \\
\hline $\mathrm{M}$ & Sedentary & Operated & Day 28 & 3 & 6 & 52.7 & 72.1 & 36.81214 \\
\hline $\mathrm{M}$ & Sedentary & Operated & Day 28 & 4 & 6 & 64.9 & 107.2 & 65.1772 \\
\hline $\mathrm{M}$ & Sedentary & Operated & Day 28 & 5 & 3 & 35.4 & 81.6 & 130.5085 \\
\hline $\mathrm{M}$ & Sedentary & Operated & Day 28 & 6 & 3 & 34.7 & 82.5 & 137.7522 \\
\hline $\mathrm{M}$ & Sedentary & Operated & Day 28 & 7 & 18 & 50 & 92.5 & 85 \\
\hline $\mathrm{M}$ & Sedentary & Operated & Day 28 & 8 & 5 & 52.8 & 91.8 & 73.86364 \\
\hline $\mathrm{M}$ & Sedentary & Sham & Day 7 & 1 & $3 a \rightarrow 3 b$ & & & \\
\hline $\mathrm{M}$ & Sedentary & Sham & Day 7 & 2 & $3 a$ & 35.3 & 53 & 50.14164 \\
\hline $\mathrm{M}$ & Sedentary & Sham & Day 7 & 3 & 3 & 35.5 & 52.6 & 48.16901 \\
\hline $\mathrm{M}$ & Sedentary & Sham & Day 7 & 4 & 3 & 42.4 & 59.6 & 40.56604 \\
\hline $\mathrm{M}$ & Sedentary & Sham & Day 7 & 5 & 1 & 57.1 & 80.9 & 41.68126 \\
\hline $\mathrm{M}$ & Sedentary & Sham & Day 7 & 6 & 1 & 41 & 57.9 & 41.21951 \\
\hline $\mathrm{M}$ & Sedentary & Sham & Day 7 & 7 & 1 & & & \\
\hline $\mathrm{M}$ & Sedentary & Sham & Day 7 & 8 & 1 & 33.5 & 69.7 & 108.0597 \\
\hline $\mathrm{M}$ & Sedentary & Sham & Day 28 & 1 & $3 a \rightarrow 3 b$ & 39 & 62 & 58.97436 \\
\hline $\mathrm{M}$ & Sedentary & Sham & Day 28 & 2 & $3 a$ & 26.7 & 38.8 & 45.31835 \\
\hline $\mathrm{M}$ & Sedentary & Sham & Day 28 & 3 & 3 & & & \\
\hline $\mathrm{M}$ & Sedentary & Sham & Day 28 & 4 & 3 & 25.6 & 51.7 & 101.9531 \\
\hline $\mathrm{M}$ & Sedentary & Sham & Day 28 & 5 & 1 & 32.9 & 52.6 & 59.87842 \\
\hline $\mathrm{M}$ & Sedentary & Sham & Day 28 & 6 & 1 & 22.2 & 55.4 & 149.5495 \\
\hline $\mathrm{M}$ & Sedentary & Sham & Day 28 & 7 & 1 & 39.7 & 56.6 & 42.56927 \\
\hline $\mathrm{M}$ & Sedentary & Sham & Day 28 & 8 & 1 & 41.9 & 70 & 67.06444 \\
\hline $\mathrm{M}$ & Exercised & Operated & Day 7 & 1 & 1 & 90.8 & 114.2 & 25.77093 \\
\hline $\mathrm{M}$ & Exercised & Operated & Day 7 & 2 & 1 & 32 & 52.7 & 64.6875 \\
\hline $\mathrm{M}$ & Exercised & Operated & Day 7 & 3 & 15 & 39.2 & 81.4 & 107.6531 \\
\hline $\mathrm{M}$ & Exercised & Operated & Day 7 & 4 & 15 & 70.8 & 84.1 & 18.78531 \\
\hline $\mathrm{M}$ & Exercised & Operated & Day 7 & 5 & 1 & 76.4 & 80.6 & 5.497382 \\
\hline
\end{tabular}




\begin{tabular}{|c|c|c|c|c|c|c|c|c|}
\hline $\mathrm{M}$ & Exercised & Operated & Day 7 & 6 & 1 & 49.8 & 70.4 & 41.36546 \\
\hline $\mathrm{M}$ & Exercised & Operated & Day 7 & 7 & 2 & 54.1 & 91.5 & 69.13124 \\
\hline $\mathrm{M}$ & Exercised & Operated & Day 7 & 8 & 2 & 78.5 & 93.7 & 19.36306 \\
\hline $\mathrm{M}$ & Exercised & Operated & Day 28 & 1 & 1 & 46.3 & 105.7 & 128.2937 \\
\hline $\mathrm{M}$ & Exercised & Operated & Day 28 & 2 & 1 & 48.4 & 69.7 & 44.00826 \\
\hline $\mathrm{M}$ & Exercised & Operated & Day 28 & 3 & 15 & 26.2 & 87.3 & 233.2061 \\
\hline $\mathrm{M}$ & Exercised & Operated & Day 28 & 4 & 15 & 34.9 & 87.7 & 151.2894 \\
\hline $\mathrm{M}$ & Exercised & Operated & Day 28 & 5 & 1 & 28.5 & 75.6 & 165.2632 \\
\hline $\mathrm{M}$ & Exercised & Operated & Day 28 & 6 & 1 & 88 & 88.6 & 0.681818 \\
\hline M & Exercised & Operated & Day 28 & 7 & 2 & 47.1 & 49.5 & 5.095541 \\
\hline $\mathrm{M}$ & Exercised & Operated & Day 28 & 8 & 2 & 37.7 & 69.1 & 83.28912 \\
\hline $\mathrm{M}$ & Exercised & Sham & Day 7 & 1 & 1 & 19.2 & 30.1 & 56.77083 \\
\hline $\mathrm{M}$ & Exercised & Sham & Day 7 & 2 & 1 & 23.5 & 46.2 & 96.59574 \\
\hline $\mathrm{M}$ & Exercised & Sham & Day 7 & 3 & 2 & 31.2 & 42.9 & 37.5 \\
\hline $\mathrm{M}$ & Exercised & Sham & Day 7 & 4 & 2 & 31.7 & 56.8 & 79.17981 \\
\hline $\mathrm{M}$ & Exercised & Sham & Day 7 & 5 & 6 & 33.3 & 47.1 & 41.44144 \\
\hline $\mathrm{M}$ & Exercised & Sham & Day 7 & 6 & 6 & 47.1 & 65.4 & 38.8535 \\
\hline $\mathrm{M}$ & Exercised & Sham & Day 7 & 7 & 25 & 29 & 43.8 & 51.03448 \\
\hline $\mathrm{M}$ & Exercised & Sham & Day 7 & 8 & 25 & 37.6 & 61.6 & 63.82979 \\
\hline $\mathrm{M}$ & Exercised & Sham & Day 28 & 1 & 1 & 23.8 & 57.3 & 140.7563 \\
\hline $\mathrm{M}$ & Exercised & Sham & Day 28 & 2 & 1 & 35.1 & 57.9 & 64.95726 \\
\hline $\mathrm{M}$ & Exercised & Sham & Day 28 & 3 & 2 & 23.8 & 44.5 & 86.97479 \\
\hline $\mathrm{M}$ & Exercised & Sham & Day 28 & 4 & 2 & 29.7 & 50.3 & 69.36027 \\
\hline $\mathrm{M}$ & Exercised & Sham & Day 28 & 5 & 6 & & & \\
\hline $\mathrm{M}$ & Exercised & Sham & Day 28 & 6 & 6 & 31.7 & 43.4 & 36.90852 \\
\hline $\mathrm{M}$ & Exercised & Sham & Day 28 & 7 & 25 & 32.9 & 46.6 & 41.64134 \\
\hline $\mathrm{M}$ & Exercised & Sham & Day 28 & 8 & 25 & 25.5 & 49.2 & 92.94118 \\
\hline $\mathrm{F}$ & Sedentary & Operated & Day 7 & 1 & $5 \mathrm{a}$ & 61.2 & 72.6 & 18.62745 \\
\hline $\mathrm{F}$ & Sedentary & Operated & Day 7 & 2 & $5 a$ & 77 & 90 & 16.88312 \\
\hline $\mathrm{F}$ & Sedentary & Operated & Day 7 & 3 & $4 a$ & 48.5 & 59.5 & 22.68041 \\
\hline $\mathrm{F}$ & Sedentary & Operated & Day 7 & 4 & $4 a$ & 97.1 & 104 & 7.106076 \\
\hline $\mathrm{F}$ & Sedentary & Operated & Day 7 & 5 & $4 \mathrm{a}$ & 53 & 76.4 & 44.15094 \\
\hline $\mathrm{F}$ & Sedentary & Operated & Day 7 & 6 & 21 & 90.6 & 100 & 10.37528 \\
\hline $\mathrm{F}$ & Sedentary & Operated & Day 7 & 7 & 21 & 66.4 & 78.5 & 18.22289 \\
\hline $\mathrm{F}$ & Sedentary & Operated & Day 7 & 8 & 21 & 75.9 & 80.3 & 5.797101 \\
\hline $\mathrm{F}$ & Sedentary & Operated & Day 28 & 1 & $5 a$ & 31.3 & 91 & 190.7348 \\
\hline $\mathrm{F}$ & Sedentary & Operated & Day 28 & 2 & $5 a$ & 26 & 79.2 & 204.6154 \\
\hline $\mathrm{F}$ & Sedentary & Operated & Day 28 & 3 & $4 a$ & 28.2 & 76.5 & 171.2766 \\
\hline $\mathrm{F}$ & Sedentary & Operated & Day 28 & 4 & $4 a$ & 33.5 & 79 & 135.8209 \\
\hline $\mathrm{F}$ & Sedentary & Operated & Day 28 & 5 & $4 a$ & 37 & 74.1 & 100.2703 \\
\hline $\mathrm{F}$ & Sedentary & Operated & Day 28 & 6 & 21 & 35.6 & 65 & 82.58427 \\
\hline $\mathrm{F}$ & Sedentary & Operated & Day 28 & 7 & 21 & 50 & 108.5 & 117 \\
\hline $\mathrm{F}$ & Sedentary & Operated & Day 28 & 8 & 21 & 33.1 & 97.7 & 195.1662 \\
\hline
\end{tabular}




\begin{tabular}{|c|c|c|c|c|c|c|c|c|}
\hline $\mathrm{F}$ & Sedentary & Sham & Day 7 & 1 & 24 & 25 & 54.7 & 118.8 \\
\hline $\mathrm{F}$ & Sedentary & Sham & Day 7 & 2 & 24 & 27.7 & 50 & 80.50542 \\
\hline $\mathrm{F}$ & Sedentary & Sham & Day 7 & 3 & 24 & 32.9 & 49.3 & 49.84802 \\
\hline $\mathrm{F}$ & Sedentary & Sham & Day 7 & 4 & 24 & 46.5 & 66.1 & 42.15054 \\
\hline $\mathrm{F}$ & Sedentary & Sham & Day 7 & 5 & 9 & & 50.3 & \\
\hline $\mathrm{F}$ & Sedentary & Sham & Day 7 & 6 & 9 & 23.7 & 36.4 & 53.5865 \\
\hline $\mathrm{F}$ & Sedentary & Sham & Day 7 & 7 & 9 & 26.6 & 45.8 & 72.18045 \\
\hline $\mathrm{F}$ & Sedentary & Sham & Day 7 & 8 & 9 & 44.2 & 58.9 & 33.25792 \\
\hline $\mathrm{F}$ & Sedentary & Sham & Day 28 & 1 & 24 & 33 & 47.2 & 43.0303 \\
\hline $\mathrm{F}$ & Sedentary & Sham & Day 28 & 2 & 24 & 30.8 & 53.2 & 72.72727 \\
\hline $\mathrm{F}$ & Sedentary & Sham & Day 28 & 3 & 24 & & & \\
\hline $\mathrm{F}$ & Sedentary & Sham & Day 28 & 4 & 24 & 47.6 & 56.2 & 18.06723 \\
\hline $\mathrm{F}$ & Sedentary & Sham & Day 28 & 5 & 9 & 35.2 & 56.9 & 61.64773 \\
\hline $\mathrm{F}$ & Sedentary & Sham & Day 28 & 6 & 9 & 26.3 & 60.6 & 130.4183 \\
\hline $\mathrm{F}$ & Sedentary & Sham & Day 28 & 7 & 9 & 35.8 & 54.2 & 51.39665 \\
\hline $\mathrm{F}$ & Sedentary & Sham & Day 28 & 8 & 9 & 26.4 & 76.7 & 190.5303 \\
\hline $\mathrm{F}$ & Exercised & Operated & Day 7 & 1 & $6 a$ & 45.5 & 63.5 & 39.56044 \\
\hline $\mathrm{F}$ & Exercised & Operated & Day 7 & 2 & $6 a$ & 26.7 & 65.8 & 146.4419 \\
\hline $\mathrm{F}$ & Exercised & Operated & Day 7 & 3 & 22 & 51.5 & 69.5 & 34.95146 \\
\hline $\mathrm{F}$ & Exercised & Operated & Day 7 & 4 & 22 & 63.6 & 87.6 & 37.73585 \\
\hline $\mathrm{F}$ & Exercised & Operated & Day 7 & 5 & 8 & 76.4 & 80.4 & 5.235602 \\
\hline $\mathrm{F}$ & Exercised & Operated & Day 7 & 6 & 8 & 37.9 & 94.9 & 150.3958 \\
\hline $\mathrm{F}$ & Exercised & Operated & Day 7 & 7 & 8 & 29.6 & 78.5 & 165.2027 \\
\hline $\mathrm{F}$ & Exercised & Operated & Day 7 & 8 & 8 & 29.3 & 75.1 & 156.314 \\
\hline $\mathrm{F}$ & Exercised & Operated & Day 28 & 1 & $6 a$ & 28.5 & 59.7 & 109.4737 \\
\hline $\mathrm{F}$ & Exercised & Operated & Day 28 & 2 & $6 a$ & 80.3 & 91.4 & 13.82316 \\
\hline $\mathrm{F}$ & Exercised & Operated & Day 28 & 3 & 22 & 45.1 & 94.9 & 110.4213 \\
\hline $\mathrm{F}$ & Exercised & Operated & Day 28 & 4 & 22 & 43.1 & 68.6 & 59.16473 \\
\hline $\mathrm{F}$ & Exercised & Operated & Day 28 & 5 & 8 & 35.2 & 67.3 & 91.19318 \\
\hline $\mathrm{F}$ & Exercised & Operated & Day 28 & 6 & 8 & 42.1 & 95.6 & 127.0784 \\
\hline $\mathrm{F}$ & Exercised & Operated & Day 28 & 7 & 8 & 41.8 & 91.9 & 119.8565 \\
\hline $\mathrm{F}$ & Exercised & Operated & Day 28 & 8 & 8 & 38 & 88.3 & 132.3684 \\
\hline $\mathrm{F}$ & Exercised & Sham & Day 7 & 1 & 7 & 22.3 & 54.1 & 142.6009 \\
\hline $\mathrm{F}$ & Exercised & Sham & Day 7 & 2 & 7 & 22.7 & 46.2 & 103.5242 \\
\hline $\mathrm{F}$ & Exercised & Sham & Day 7 & 3 & 7 & 35.8 & 55.2 & 54.18994 \\
\hline $\mathrm{F}$ & Exercised & Sham & Day 7 & 4 & 7 & 31 & 54.1 & 74.51613 \\
\hline $\mathrm{F}$ & Exercised & Sham & Day 7 & 5 & 2 & 27.8 & 54.5 & 96.04317 \\
\hline $\mathrm{F}$ & Exercised & Sham & Day 7 & 6 & 2 & 33.7 & 49.8 & 47.77448 \\
\hline $\mathrm{F}$ & Exercised & Sham & Day 7 & 7 & 2 & 42.1 & 62.1 & 47.50594 \\
\hline $\mathrm{F}$ & Exercised & Sham & Day 7 & 8 & 2 & 23.6 & 48.9 & 107.2034 \\
\hline $\mathrm{F}$ & Exercised & Sham & Day 28 & 1 & 7 & 33.9 & 49.4 & 45.72271 \\
\hline $\mathrm{F}$ & Exercised & Sham & Day 28 & 2 & 7 & 26.3 & 57.5 & 118.6312 \\
\hline $\mathrm{F}$ & Exercised & Sham & Day 28 & 3 & 7 & 23.7 & 40.5 & 70.88608 \\
\hline
\end{tabular}




\begin{tabular}{|c|c|c|c|c|c|c|c|c|}
\hline F & Exercised & Sham & Day 28 & 4 & 7 & 35.4 & 45.3 & 27.9661 \\
\hline F & Exercised & Sham & Day 28 & 5 & 2 & & & \\
\hline F & Exercised & Sham & Day 28 & 6 & 2 & 25.7 & 47.9 & 86.38132 \\
\hline F & Exercised & Sham & Day 28 & 7 & 2 & 27.7 & 49 & 76.89531 \\
\hline F & Exercised & Sham & Day 28 & 8 & 2 & & & \\
\hline
\end{tabular}

C57B1/6 Exercise Data

\begin{tabular}{|c|c|c|c|c|c|c|c|c|c|}
\hline Sex & Treatment & Limb & $\begin{array}{l}\text { Time } \\
\text { Point }\end{array}$ & Replicate & $\begin{array}{c}\text { Cage } \\
\#\end{array}$ & $\begin{array}{c}\text { Mice } \\
\text { per } \\
\text { cage }\end{array}$ & $\begin{array}{c}\text { Total } \\
\text { revolutions }\end{array}$ & $\begin{array}{c}\text { Total } \\
\text { distance } \\
(\mathbf{k m})\end{array}$ & $\begin{array}{c}\text { Avg } \\
\text { distance } \\
\text { per day } \\
(\mathbf{k m}) \\
\end{array}$ \\
\hline $\mathrm{M}$ & Exercised & Operated & Day 7 & 1 & 1 & 2 & 1190.5 & 0.344086 & 0.049155 \\
\hline $\mathrm{M}$ & Exercised & Operated & Day 7 & 2 & 1 & 2 & 6283.5 & 1.816098 & 0.259443 \\
\hline $\mathrm{M}$ & Exercised & Operated & Day 7 & 3 & 15 & 3 & 18572 & 5.367801 & 0.766829 \\
\hline $\mathrm{M}$ & Exercised & Operated & Day 7 & 4 & 15 & 3 & 24599 & 7.109763 & 1.01568 \\
\hline $\mathrm{M}$ & Exercised & Operated & Day 7 & 5 & 1 & 3 & 24599 & 7.109763 & 1.01568 \\
\hline $\mathrm{M}$ & Exercised & Operated & Day 7 & 6 & 1 & 3 & 14369 & 4.152829 & 0.593261 \\
\hline $\mathrm{M}$ & Exercised & Operated & Day 7 & 7 & 2 & 3 & 18181 & 5.254599 & 0.750657 \\
\hline $\mathrm{M}$ & Exercised & Operated & Day 7 & 8 & 2 & 3 & 18181 & 5.254599 & 0.750657 \\
\hline $\mathrm{M}$ & Exercised & Operated & Day 28 & 1 & 1 & 2 & 1190.5 & 0.344086 & 0.049155 \\
\hline $\mathrm{M}$ & Exercised & Operated & Day 28 & 2 & 1 & 2 & 6283.5 & 1.816098 & 0.259443 \\
\hline $\mathrm{M}$ & Exercised & Operated & Day 28 & 3 & 15 & 3 & 18572 & 5.367801 & 0.766829 \\
\hline $\mathrm{M}$ & Exercised & Operated & Day 28 & 4 & 15 & 3 & 24599 & 7.109763 & 1.01568 \\
\hline $\mathrm{M}$ & Exercised & Operated & Day 28 & 5 & 1 & 3 & 24599 & 7.109763 & 1.01568 \\
\hline $\mathrm{M}$ & Exercised & Operated & Day 28 & 6 & 1 & 3 & 14369 & 4.152829 & 0.593261 \\
\hline $\mathrm{M}$ & Exercised & Operated & Day 28 & 7 & 2 & 3 & 18181 & 5.254599 & 0.750657 \\
\hline $\mathrm{M}$ & Exercised & Operated & Day 28 & 8 & 2 & 3 & 18181 & 5.254599 & 0.750657 \\
\hline $\mathrm{M}$ & Exercised & Sham & Day 7 & 1 & 1 & 4 & 299376 & 86.5276 & 3.090272 \\
\hline $\mathrm{M}$ & Exercised & Sham & Day 7 & 2 & 1 & 4 & 299376 & 86.5276 & 3.090272 \\
\hline $\mathrm{M}$ & Exercised & Sham & Day 7 & 3 & 2 & 4 & 311248.5 & 89.95907 & 3.212824 \\
\hline $\mathrm{M}$ & Exercised & Sham & Day 7 & 4 & 2 & 4 & 311248.5 & 89.95907 & 3.212824 \\
\hline $\mathrm{M}$ & Exercised & Sham & Day 7 & 5 & 6 & 4 & 207080 & 59.85161 & 3.150085 \\
\hline $\mathrm{M}$ & Exercised & Sham & Day 7 & 6 & 6 & 4 & 207080 & 59.85161 & 3.150085 \\
\hline $\mathrm{M}$ & Exercised & Sham & Day 7 & 7 & 25 & 4 & 207080 & 59.85161 & 3.150085 \\
\hline $\mathrm{M}$ & Exercised & Sham & Day 7 & 8 & 25 & 4 & 207080 & 59.85161 & 3.150085 \\
\hline $\mathrm{M}$ & Exercised & Sham & Day 28 & 1 & 1 & 4 & 299376 & 86.5276 & 3.090272 \\
\hline $\mathrm{M}$ & Exercised & Sham & Day 28 & 2 & 1 & 4 & 299376 & 86.5276 & 3.090272 \\
\hline $\mathrm{M}$ & Exercised & Sham & Day 28 & 3 & 2 & 4 & 311248.5 & 89.95907 & 3.212824 \\
\hline $\mathrm{M}$ & Exercised & Sham & Day 28 & 4 & 2 & 4 & 311248.5 & 89.95907 & 3.212824 \\
\hline $\mathrm{M}$ & Exercised & Sham & Day 28 & 5 & 6 & 4 & 207080 & 59.85161 & 3.150085 \\
\hline $\mathrm{M}$ & Exercised & Sham & Day 28 & 6 & 6 & 4 & 207080 & 59.85161 & 3.150085 \\
\hline $\mathrm{M}$ & Exercised & Sham & Day 28 & 7 & 25 & 4 & 207080 & 59.85161 & 3.150085 \\
\hline
\end{tabular}




\begin{tabular}{|c|c|c|c|c|c|c|c|c|c|}
\hline $\mathrm{M}$ & Exercised & Sham & Day 28 & 8 & 25 & 4 & 207080 & 59.85161 & 3.150085 \\
\hline $\mathrm{F}$ & Exercised & Operated & Day 7 & 1 & $6 a$ & 2 & 93005 & 26.88091 & 3.84013 \\
\hline $\mathrm{F}$ & Exercised & Operated & Day 7 & 2 & $6 a$ & 2 & 93005 & 26.88091 & 3.84013 \\
\hline $\mathrm{F}$ & Exercised & Operated & Day 7 & 3 & 22 & 2 & 93804 & 13.55592 & 1.93656 \\
\hline $\mathrm{F}$ & Exercised & Operated & Day 7 & 4 & 22 & 2 & 93804 & 13.55592 & 1.93656 \\
\hline $\mathrm{F}$ & Exercised & Operated & Day 7 & 5 & 8 & 4 & 76665 & 31.0908 & 4.441543 \\
\hline $\mathrm{F}$ & Exercised & Operated & Day 7 & 6 & 8 & 4 & 76665 & 31.0908 & 4.441543 \\
\hline $\mathrm{F}$ & Exercised & Operated & Day 7 & 7 & 8 & 4 & 76665 & 31.0908 & 4.441543 \\
\hline $\mathrm{F}$ & Exercised & Operated & Day 7 & 8 & 8 & 4 & 76665 & 31.0908 & 4.441543 \\
\hline $\mathrm{F}$ & Exercised & Operated & Day 28 & 1 & $6 a$ & 2 & 93005 & 26.88091 & 3.84013 \\
\hline $\mathrm{F}$ & Exercised & Operated & Day 28 & 2 & $6 a$ & 2 & 93005 & 26.88091 & 3.84013 \\
\hline $\mathrm{F}$ & Exercised & Operated & Day 28 & 3 & 22 & 2 & 93804 & 13.55592 & 1.93656 \\
\hline $\mathrm{F}$ & Exercised & Operated & Day 28 & 4 & 22 & 2 & 93804 & 13.55592 & 1.93656 \\
\hline $\mathrm{F}$ & Exercised & Operated & Day 28 & 5 & 8 & 4 & 76665 & 31.0908 & 4.441543 \\
\hline $\mathrm{F}$ & Exercised & Operated & Day 28 & 6 & 8 & 4 & 76665 & 31.0908 & 4.441543 \\
\hline $\mathrm{F}$ & Exercised & Operated & Day 28 & 7 & 8 & 4 & 76665 & 31.0908 & 4.441543 \\
\hline $\mathrm{F}$ & Exercised & Operated & Day 28 & 8 & 8 & 4 & 76665 & 31.0908 & 4.441543 \\
\hline $\mathrm{F}$ & Exercised & Sham & Day 7 & 1 & 7 & 4 & 146466.25 & 42.33263 & 3.527719 \\
\hline $\mathrm{F}$ & Exercised & Sham & Day 7 & 2 & 7 & 4 & 146466.25 & 42.33263 & 3.527719 \\
\hline $\mathrm{F}$ & Exercised & Sham & Day 7 & 3 & 7 & 4 & 146466.25 & 42.33263 & 3.527719 \\
\hline $\mathrm{F}$ & Exercised & Sham & Day 7 & 4 & 7 & 4 & 146466.25 & 42.33263 & 3.527719 \\
\hline $\mathrm{F}$ & Exercised & Sham & Day 7 & 5 & 2 & 4 & 209607.125 & 60.58202 & 3.786376 \\
\hline $\mathrm{F}$ & Exercised & Sham & Day 7 & 6 & 2 & 4 & 209607.125 & 60.58202 & 3.786376 \\
\hline $\mathrm{F}$ & Exercised & Sham & Day 7 & 7 & 2 & 4 & 209607.125 & 60.58202 & 3.786376 \\
\hline $\mathrm{F}$ & Exercised & Sham & Day 7 & 8 & 2 & 4 & 209607.125 & 60.58202 & 3.786376 \\
\hline $\mathrm{F}$ & Exercised & Sham & Day 28 & 1 & 7 & 4 & 146466.25 & 42.33263 & 3.527719 \\
\hline $\mathrm{F}$ & Exercised & Sham & Day 28 & 2 & 7 & 4 & 146466.25 & 42.33263 & 3.527719 \\
\hline $\mathrm{F}$ & Exercised & Sham & Day 28 & 3 & 7 & 4 & 146466.25 & 42.33263 & 3.527719 \\
\hline $\mathrm{F}$ & Exercised & Sham & Day 28 & 4 & 7 & 4 & 146466.25 & 42.33263 & 3.527719 \\
\hline $\mathrm{F}$ & Exercised & Sham & Day 28 & 5 & 2 & 4 & 209607.125 & 60.58202 & 3.786376 \\
\hline $\mathrm{F}$ & Exercised & Sham & Day 28 & 6 & 2 & 4 & 209607.125 & 60.58202 & 3.786376 \\
\hline $\mathrm{F}$ & Exercised & Sham & Day 28 & 7 & 2 & 4 & 209607.125 & 60.58202 & 3.786376 \\
\hline $\mathrm{F}$ & Exercised & Sham & Day 28 & 8 & 2 & 4 & 209607.125 & 60.58202 & 3.786376 \\
\hline
\end{tabular}

Balb/c Functional Vasodilation Data

\begin{tabular}{|c|c|c|c|c|c|c|c|c|}
\hline Sex & Treatment & Limb & $\begin{array}{c}\text { Time } \\
\text { Point }\end{array}$ & Replicate & $\begin{array}{c}\text { Cage } \\
\#\end{array}$ & $\begin{array}{c}\text { Resting } \\
(\boldsymbol{\mu m})\end{array}$ & $\begin{array}{c}\text { Dilated } \\
(\boldsymbol{\mu m})\end{array}$ & $\begin{array}{c}\text { Percent } \\
\text { change (\%) }\end{array}$ \\
\hline M & Sedentary & Operated & Day 7 & 1 & 16 & 73.2 & 76.8 & 4.918033 \\
\hline M & Sedentary & Operated & Day 7 & 2 & 16 & 64.8 & 69.4 & 7.098765 \\
\hline M & Sedentary & Operated & Day 7 & 3 & 16 & 77.1 & 81.1 & 5.188067 \\
\hline M & Sedentary & Operated & Day 7 & 4 & 16 & 50.2 & 64.4 & 28.28685 \\
\hline
\end{tabular}




\begin{tabular}{|c|c|c|c|c|c|c|c|c|}
\hline M & Sedentary & Operated & Day 7 & 5 & 14 & 64.8 & 68 & 4.938272 \\
\hline M & Sedentary & Operated & Day 7 & 6 & 15 & 56.9 & 59.7 & 4.920914 \\
\hline M & Sedentary & Sham & Day 7 & 1 & 16 & 21.6 & 32.5 & 50.46296 \\
\hline M & Sedentary & Sham & Day 7 & 2 & 16 & 33.3 & 48.3 & 45.04505 \\
\hline M & Sedentary & Sham & Day 7 & 3 & 16 & 47.5 & 68.8 & 44.84211 \\
\hline M & Sedentary & Sham & Day 7 & 4 & 16 & 20.9 & 46.6 & 122.9665 \\
\hline M & Sedentary & Sham & Day 7 & 5 & 14 & 38.1 & 53.4 & 40.15748 \\
\hline M & Sedentary & Sham & Day 7 & 6 & 15 & 36.5 & 56.7 & 55.34247 \\
\hline M & Exercised & Operated & Day 7 & 1 & 13 & 73.9 & 98.3 & 33.01759 \\
\hline M & Exercised & Operated & Day 7 & 2 & 13 & 56 & 69 & 23.21429 \\
\hline M & Exercised & Operated & Day 7 & 3 & 12 & 61.3 & 66.2 & 7.993475 \\
\hline M & Exercised & Operated & Day 7 & 4 & 12 & 58.7 & 70 & 19.25043 \\
\hline M & Exercised & Operated & Day 7 & 5 & 12 & 27.2 & 74.2 & 172.7941 \\
\hline M & Exercised & Operated & Day 7 & 6 & 12 & 38.8 & 54.3 & 39.94845 \\
\hline M & Exercised & Sham & Day 7 & 1 & 13 & 21.2 & 35 & 65.09434 \\
\hline M & Exercised & Sham & Day 7 & 2 & 13 & 29.2 & 39.5 & 35.27397 \\
\hline M & Exercised & Sham & Day 7 & 3 & 12 & 21.5 & 37.3 & 73.48837 \\
\hline M & Exercised & Sham & Day 7 & 4 & 12 & 30.8 & 42.2 & 37.01299 \\
\hline M & Exercised & Sham & Day 7 & 5 & 12 & 27.2 & 45.8 & 68.38235 \\
\hline M & Exercised & Sham & Day 7 & 6 & 12 & 29 & 47.5 & 63.7931 \\
\hline
\end{tabular}

Balb/c Exercise Data

\begin{tabular}{|c|c|c|c|c|c|c|c|c|c|}
\hline Sex & Treatment & Limb & $\begin{array}{c}\text { Time } \\
\text { Point }\end{array}$ & Replicate & $\begin{array}{c}\text { Cage } \\
\#\end{array}$ & $\begin{array}{c}\text { Mice } \\
\text { per } \\
\text { cage }\end{array}$ & $\begin{array}{c}\text { Total } \\
\text { revolutions }\end{array}$ & $\begin{array}{c}\text { Total } \\
\text { distance } \\
\text { (km) }\end{array}$ & $\begin{array}{c}\text { Avg } \\
\text { distance } \\
\text { per day } \\
\text { (km) }\end{array}$ \\
\hline M & Exercised & Operated & Day 7 & 1 & 13 & 2 & 31333.5 & 9.056213 & 1.293745 \\
\hline M & Exercised & Operated & Day 7 & 2 & 13 & 2 & 31333.5 & 9.056213 & 1.293745 \\
\hline M & Exercised & Operated & Day 7 & 3 & 12 & 4 & 47035.75 & 13.59458 & 1.942083 \\
\hline M & Exercised & Operated & Day 7 & 4 & 12 & 4 & 47035.75 & 13.59458 & 1.942083 \\
\hline M & Exercised & Operated & Day 7 & 5 & 12 & 4 & 47035.75 & 13.59458 & 1.942083 \\
\hline M & Exercised & Operated & Day 7 & 6 & 12 & 4 & 47035.75 & 13.59458 & 1.942083 \\
\hline M & Exercised & Sham & Day 7 & 1 & 13 & 2 & 31333.5 & 9.056213 & 1.293745 \\
\hline M & Exercised & Sham & Day 7 & 2 & 13 & 2 & 31333.5 & 9.056213 & 1.293745 \\
\hline M & Exercised & Sham & Day 7 & 3 & 12 & 4 & 47035.75 & 13.59458 & 1.942083 \\
\hline M & Exercised & Sham & Day 7 & 4 & 12 & 4 & 47035.75 & 13.59458 & 1.942083 \\
\hline M & Exercised & Sham & Day 7 & 5 & 12 & 4 & 47035.75 & 13.59458 & 1.942083 \\
\hline M & Exercised & Sham & Day 7 & 6 & 12 & 4 & 47035.75 & 13.59458 & 1.942083 \\
\hline
\end{tabular}


Reliability Measurements - Collateral Diameter $(\mu \mathrm{m})$

\begin{tabular}{|c|c|c|c|c|c|c|c|}
\hline Day & Measurement & Image 1 & Image 2 & Image 3 & Image 4 & Image 5 & Image 6 \\
\hline 1 & 1 & 33.3 & 21.4 & 54.1 & 27.3 & 99.8 & 33.4 \\
\hline 1 & 2 & 37.5 & 28.5 & 60.2 & 28.9 & 105 & 29.9 \\
\hline 1 & 3 & 35.3 & 30.4 & 56.1 & 28.9 & 106.4 & 39.9 \\
\hline 2 & 1 & 34.6 & 28 & 58.1 & 27.2 & 98.4 & 31.5 \\
\hline 2 & 2 & 30.1 & 28.5 & 56.3 & 28 & 97.1 & 34.3 \\
\hline 2 & 3 & 36 & 28 & 55.4 & 28.9 & 100.1 & 36.2 \\
\hline
\end{tabular}

Image Quality Error Measurements - Collateral Diameter $(\mu \mathrm{m})$

\begin{tabular}{|c|c|c|c|}
\hline Image & Minimum & Maximum & Range \\
\hline 1 & 16.4 & 22.9 & 6.5 \\
\hline 2 & 23.5 & 35.2 & 11.7 \\
\hline 3 & 16.6 & 28 & 11.4 \\
\hline 4 & 21.9 & 31.9 & 10 \\
\hline 5 & 33.3 & 42.2 & 8.9 \\
\hline 6 & 20.1 & 30.9 & 10.8 \\
\hline 7 & 37.6 & 52.5 & 14.9 \\
\hline 8 & 31.9 & 41.6 & 9.7 \\
\hline 9 & 18.8 & 25.6 & 6.8 \\
\hline 10 & 19.6 & 33.5 & 13.9 \\
\hline 11 & 20.6 & 30.8 & 10.2 \\
\hline 12 & 21.1 & 31.2 & 10.1 \\
\hline 13 & 29.8 & 42.9 & 13.1 \\
\hline 14 & 20.7 & 32.6 & 11.9 \\
\hline 15 & 22.3 & 34.2 & 11.9 \\
\hline 16 & 35.3 & 51.2 & 15.9 \\
\hline
\end{tabular}




\section{Appendix D: Statistics}

Intraclass Correlation Coefficient (ICC) Calculation

\section{General Linear Model: Diameter versus Image, Measurement}

Method

Factor coding $(-1,0,+1)$

Factor Information

Factor Type Levels Values

$\begin{array}{llll}\text { Image } & \text { Fixed } & 6 & 1,2,3,4,5,6 \\ \text { Measurement } & \text { Fixed } & 6 & \text { D1 M1, D1 M2, D1 M3, D2 M1, D2 M2, D2 M3 }\end{array}$

Analysis of Variance

$\begin{array}{lrrrrr}\text { Source } & \text { DF } & \text { Adj SS } & \text { Adj MS } & \text { F-Value } & \text { P-Value } \\ \quad \text { Image } & 5 & 24482.5 & 4896.50 & 813.20 & 0.000 \\ \quad \text { Measurement } & 5 & 89.0 & 17.79 & 2.96 & 0.031 \\ \text { Error } & 25 & 150.5 & 6.02 & & \\ \text { Total } & 35 & 24722.0 & & & \end{array}$

$F=F_{\text {image }}=813.20($ from ANOVA above $)$

$k=\frac{\# \text { observations }-\# \text { measurements }}{\# \text { images }-1}=\frac{36-6}{6-1}=6$

ICC $=\frac{F-1}{F+k-1}=\frac{813.20-1}{813.20+6-1}=0.99$

$\mathrm{ICC}=0.99$
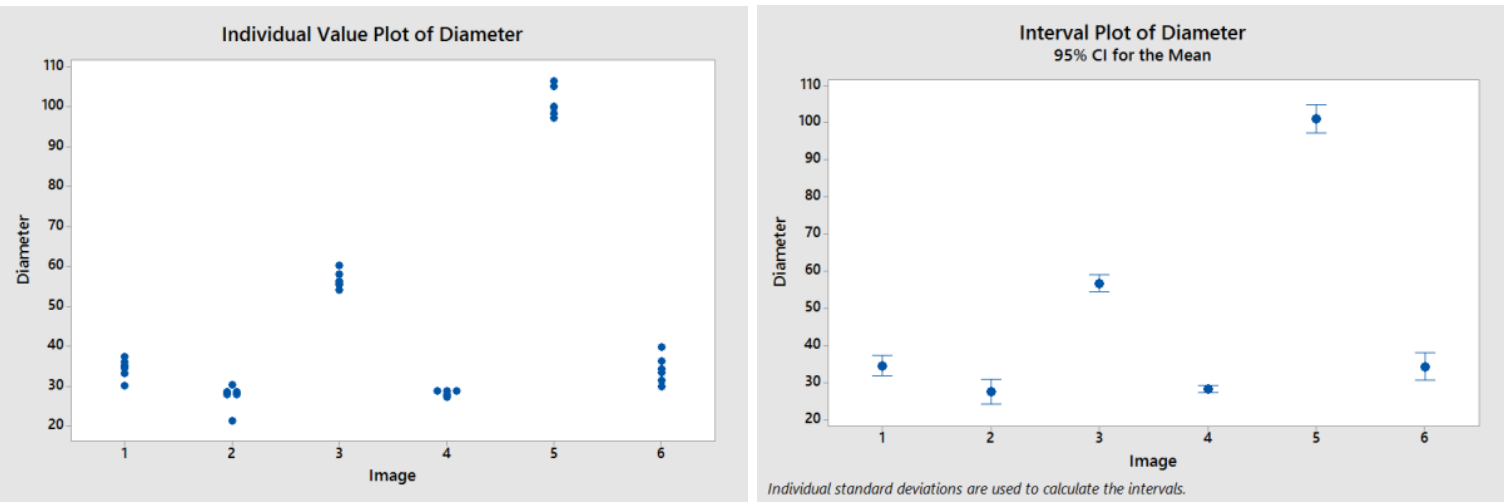
Sample Paired T-Tests

\section{Paired T-Test and Cl: Rest, Dilated}

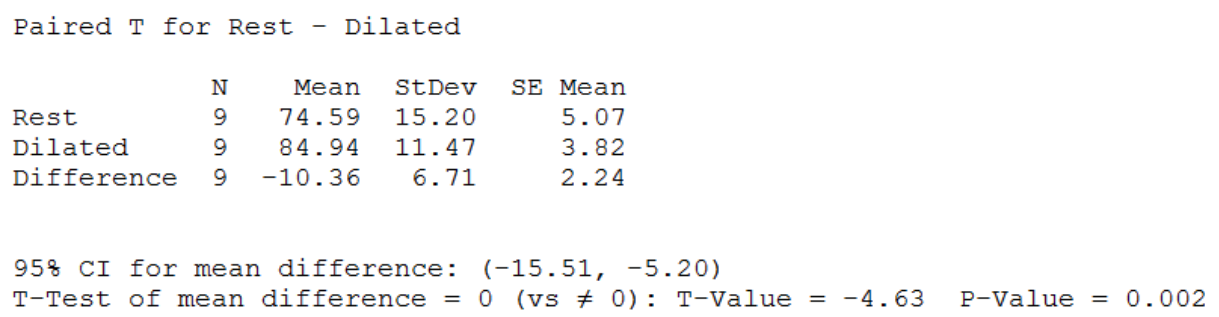

\section{Paired T-Test and Cl: Rest, Dilated}

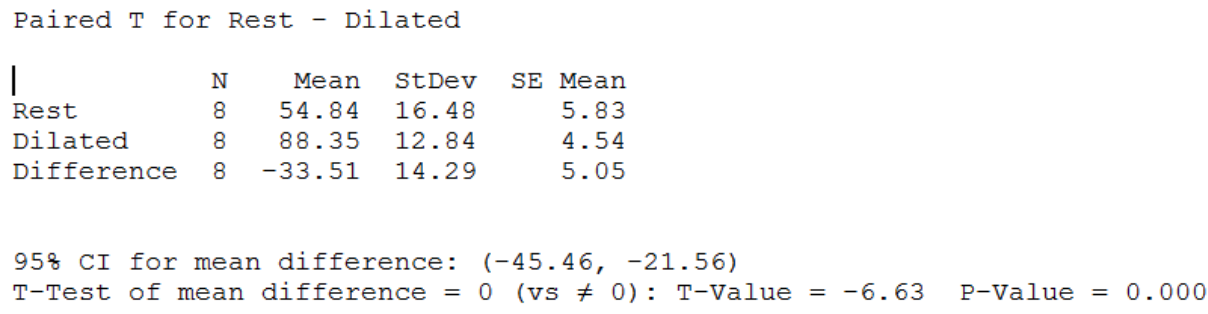


Anderson Darling Normality Test [Resting Diameter]

\begin{tabular}{|c|c|c|c|c|c|c|c|}
\hline Strain & Sex & Treatment & Limb & Time & Measurement & AD p-value & Normal? \\
\hline C57B1/6 & M & Sedentary & Operated & Day 7 & Resting Diameter & 0.763 & Yes \\
\hline C57B1/6 & M & Sedentary & Sham & Day 7 & Resting Diameter & 0.095 & Yes \\
\hline C57B1/6 & M & Sedentary & Operated & Day 28 & Resting Diameter & 0.519 & Yes \\
\hline C57B1/6 & M & Sedentary & Sham & Day 28 & Resting Diameter & 0.356 & Yes \\
\hline C57B1/6 & F & Sedentary & Operated & Day 7 & Resting Diameter & 0.876 & Yes \\
\hline C57B1/6 & F & Sedentary & Sham & Day 7 & Resting Diameter & 0.094 & Yes \\
\hline C57B1/6 & F & Sedentary & Operated & Day 28 & Resting Diameter & 0.18 & Yes \\
\hline C57B1/6 & F & Sedentary & Sham & Day 28 & Resting Diameter & 0.285 & Yes \\
\hline C57B1/6 & M & Exercised & Operated & Day 7 & Resting Diameter & 0.719 & Yes \\
\hline C57B1/6 & M & Exercised & Sham & Day 7 & Resting Diameter & 0.749 & Yes \\
\hline C57B1/6 & M & Exercised & Operated & Day 28 & Resting Diameter & 0.053 & Yes \\
\hline C57B1/6 & M & Exercised & Sham & Day 28 & Resting Diameter & 0.393 & Yes \\
\hline C57B1/6 & F & Exercised & Operated & Day 7 & Resting Diameter & 0.425 & Yes \\
\hline C57B1/6 & F & Exercised & Sham & Day 7 & Resting Diameter & 0.558 & Yes \\
\hline C57B1/6 & F & Exercised & Operated & Day 28 & Resting Diameter & 0.007 & No \\
\hline C57B1/6 & F & Exercised & Sham & Day 28 & Resting Diameter & 0.221 & Yes \\
\hline Balb/c & M & Sedentary & Operated & Day 7 & Resting Diameter & 0.782 & Yes \\
\hline Balb/c & M & Sedentary & Sham & Day 7 & Resting Diameter & 0.489 & Yes \\
\hline Balb/c & M & Exercised & Operated & Day 7 & Resting Diameter & 0.534 & Yes \\
\hline Balb/c & M & Exercised & Sham & Day 7 & Resting Diameter & 0.131 & Yes \\
\hline
\end{tabular}


Anderson Darling Normality Test [Dilated Diameter]

\begin{tabular}{|c|c|c|c|c|c|c|c|}
\hline Strain & Sex & Treatment & Limb & Time & Measurement & AD p-value & Normal? \\
\hline C57B1/6 & M & Sedentary & Operated & Day 7 & Dilated Diameter & 0.154 & Yes \\
\hline C57B1/6 & M & Sedentary & Sham & Day 7 & Dilated Diameter & 0.246 & Yes \\
\hline C57B1/6 & M & Sedentary & Operated & Day 28 & Dilated Diameter & 0.617 & Yes \\
\hline C57B1/6 & M & Sedentary & Sham & Day 28 & Dilated Diameter & 0.608 & Yes \\
\hline C57B1/6 & F & Sedentary & Operated & Day 7 & Dilated Diameter & 0.716 & Yes \\
\hline C57B1/6 & F & Sedentary & Sham & Day 7 & Dilated Diameter & 0.713 & Yes \\
\hline C57B1/6 & F & Sedentary & Operated & Day 28 & Dilated Diameter & 0.475 & Yes \\
\hline C57B1/6 & F & Sedentary & Sham & Day 28 & Dilated Diameter & 0.104 & Yes \\
\hline C57B1/6 & M & Exercised & Operated & Day 7 & Dilated Diameter & 0.657 & Yes \\
\hline C57B1/6 & M & Exercised & Sham & Day 7 & Dilated Diameter & 0.565 & Yes \\
\hline C57B1/6 & M & Exercised & Operated & Day 28 & Dilated Diameter & 0.57 & Yes \\
\hline C57B1/6 & M & Exercised & Sham & Day 28 & Dilated Diameter & 0.36 & Yes \\
\hline C57B1/6 & F & Exercised & Operated & Day 7 & Dilated Diameter & 0.891 & Yes \\
\hline C57B1/6 & F & Exercised & Sham & Day 7 & Dilated Diameter & 0.364 & Yes \\
\hline C57B1/6 & F & Exercised & Operated & Day 28 & Dilated Diameter & 0.04 & No \\
\hline C57B1/6 & F & Exercised & Sham & Day 28 & Dilated Diameter & 0.492 & Yes \\
\hline Balb/c & M & Sedentary & Operated & Day 7 & Dilated Diameter & 0.834 & Yes \\
\hline Balb/c & M & Sedentary & Sham & Day 7 & Dilated Diameter & 0.79 & Yes \\
\hline Balb/c & M & Exercised & Operated & Day 7 & Dilated Diameter & 0.176 & Yes \\
\hline Balb/c & M & Exercised & Sham & Day 7 & Dilated Diameter & 0.856 & Yes \\
\hline
\end{tabular}


Anderson Darling Normality Test [Percent Change in Diameter]

\begin{tabular}{|c|c|c|c|c|c|c|c|}
\hline Strain & Sex & Treatment & Limb & Time & Measurement & AD p-value & Normal? \\
\hline C57B1/6 & M & Sedentary & Operated & Day 7 & Percent Change & 0.408 & Yes \\
\hline C57B1/6 & M & Sedentary & Sham & Day 7 & Percent Change & $<0.005$ & No \\
\hline C57B1/6 & M & Sedentary & Operated & Day 28 & Percent Change & 0.508 & Yes \\
\hline C57B1/6 & M & Sedentary & Sham & Day 28 & Percent Change & 0.073 & Yes \\
\hline C57B1/6 & F & Sedentary & Operated & Day 7 & Percent Change & 0.121 & Yes \\
\hline C57B1/6 & F & Sedentary & Sham & Day 7 & Percent Change & 0.418 & Yes \\
\hline C57B1/6 & F & Sedentary & Operated & Day 28 & Percent Change & 0.431 & Yes \\
\hline C57B1/6 & F & Sedentary & Sham & Day 28 & Percent Change & 0.201 & Yes \\
\hline C57B1/6 & M & Exercised & Operated & Day 7 & Percent Change & 0.374 & Yes \\
\hline C57B1/6 & M & Exercised & Sham & Day 7 & Percent Change & 0.384 & Yes \\
\hline C57B1/6 & M & Exercised & Operated & Day 28 & Percent Change & 0.771 & Yes \\
\hline C57B1/6 & M & Exercised & Sham & Day 28 & Percent Change & 0.551 & Yes \\
\hline C57B1/6 & F & Exercised & Operated & Day 7 & Percent Change & 0.022 & No \\
\hline C57B1/6 & F & Exercised & Sham & Day 7 & Percent Change & 0.442 & Yes \\
\hline C57B1/6 & F & Exercised & Operated & Day 28 & Percent Change & 0.102 & Yes \\
\hline C57B1/6 & F & Exercised & Sham & Day 28 & Percent Change & 0.872 & Yes \\
\hline Balb/c & M & Sedentary & Operated & Day 7 & Percent Change & $<0.005$ & No \\
\hline Balb/c & M & Sedentary & Sham & Day 7 & Percent Change & $<0.005$ & No \\
\hline Balb/c & M & Exercised & Operated & Day 7 & Percent Change & $<0.005$ & No \\
\hline Balb/c & M & Exercised & Sham & Day 7 & Percent Change & 0.065 & Yes \\
\hline
\end{tabular}

Sample Normal Probability Plots
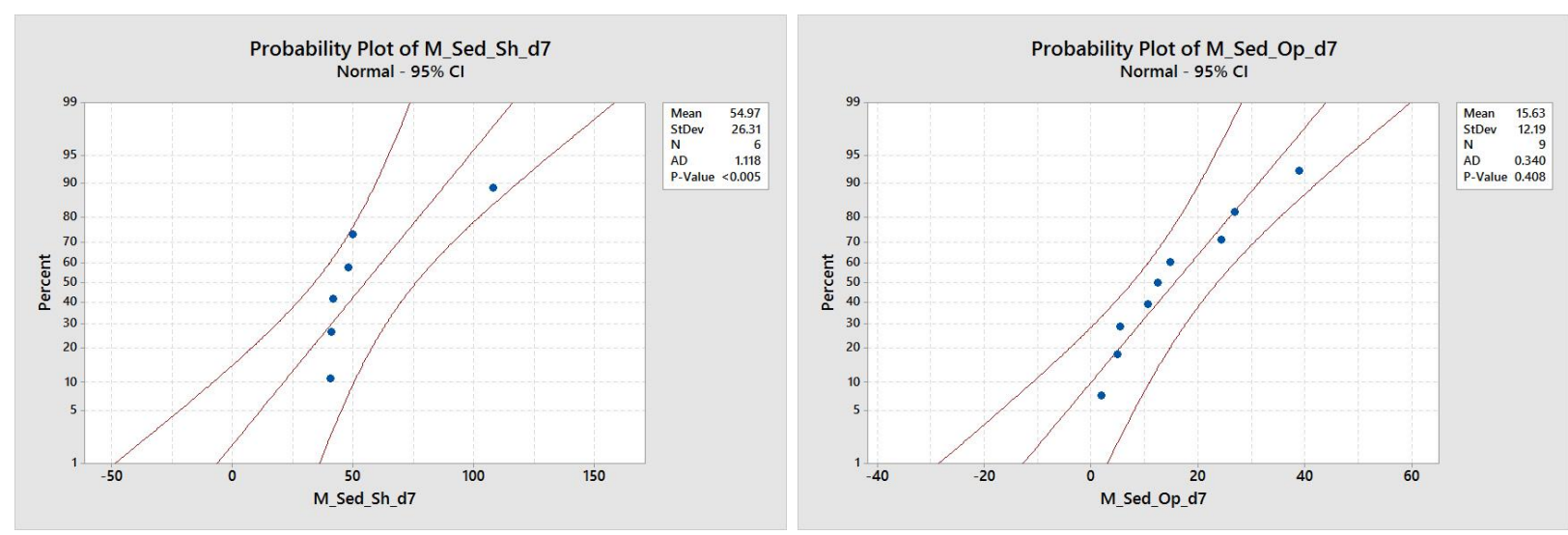
F-Test for Equal Variance and ANOVA [Resting Diameter]

\begin{tabular}{|c|c|c|c|c|c|c|c|}
\hline Group 1 & $\begin{array}{l}\text { Group } 1 \\
\text { normal? }\end{array}$ & Group 2 & $\begin{array}{c}\text { Group } 2 \\
\text { normal? }\end{array}$ & $\begin{array}{l}\text { F-Test } \\
\text { p-value }\end{array}$ & $\begin{array}{c}\text { Equal } \\
\text { variances? }\end{array}$ & $\begin{array}{l}\text { ANOVA } \\
\text { p-value }\end{array}$ & $\begin{array}{c}\text { Different } \\
\text { means? }\end{array}$ \\
\hline M_Sed_Op_d7 & Yes & M_Sed_Sh_d7 & Yes & 0.236 & Yes & 0 & Yes \\
\hline F_Sed_Sh_d7 & Yes & M_Sed_Sh_d7 & Yes & 0.897 & Yes & 0.123 & No \\
\hline F_Sed_Op_d7 & Yes & F_Sed_Sh_d7 & Yes & 0.158 & Yes & 0 & Yes \\
\hline F_Sed_Op_d7 & Yes & M_Sed_Op_d7 & Yes & 0.73 & Yes & 0.673 & No \\
\hline M_Sed_Sh_d28 & Yes & M_Sed_Sh_d7 & Yes & 0.795 & Yes & 0.101 & No \\
\hline M_Sed_Op_d28 & Yes & M_Sed_Sh_d28 & Yes & 0.09 & Yes & 0.006 & Yes \\
\hline M_Sed_Op_d28 & Yes & M_Sed_Op_d7 & Yes & 0.818 & Yes & 0.021 & Yes \\
\hline F_Sed_Sh_d28 & Yes & M_Sed_Sh_d28 & Yes & 0.855 & Yes & 0.806 & No \\
\hline F_Sed_Sh_d28 & Yes & F_Sed_Sh_d7 & Yes & 0.555 & Yes & 0.791 & No \\
\hline F_Sed_Op_d28 & Yes & F_Sed_Sh_d28 & Yes & 0.992 & Yes & 0.845 & No \\
\hline F_Sed_Op_d28 & Yes & M_Sed_Op_d28 & Yes & 0.047 & No & 0.006 & Yes \\
\hline F_Sed_Op_d28 & Yes & F_Sed_Op_d7 & Yes & 0.038 & No & 0 & Yes \\
\hline M_Ex_Sh_d7 & Yes & M_Sed_Sh_d7 & Yes & 0.916 & Yes & 0.07 & No \\
\hline M_Ex_Op_d7 & Yes & M_Ex_Sh_d7 & Yes & 0.031 & No & 0.004 & Yes \\
\hline M_Ex_Op_d7 & Yes & M_Sed_Op_d7 & Yes & 0.401 & Yes & 0.154 & No \\
\hline F_Ex_Sh_d7 & Yes & M_Ex_Sh_d7 & Yes & 0.648 & Yes & 0.671 & No \\
\hline F_Ex_Sh_d7 & Yes & F_Sed_Sh_d7 & Yes & 0.488 & Yes & 0.567 & No \\
\hline F_Ex_Op_d7 & Yes & F_Ex_Sh_d7 & Yes & 0.026 & No & 0.052 & No \\
\hline F_Ex_Op_d7 & Yes & M_Ex_Op_d7 & Yes & 0.706 & Yes & 0.113 & No \\
\hline F_Ex_Op_d7 & Yes & F_Sed_Op_d7 & Yes & 0.919 & Yes & 0.01 & Yes \\
\hline M_Ex_Sh_d28 & Yes & M_Ex_Sh_d7 & Yes & 0.155 & Yes & 0.476 & No \\
\hline M_Ex_Sh_d28 & Yes & M_Sed_Sh_d28 & Yes & 0.217 & Yes & 0.31 & No \\
\hline M_Ex_Op_d28 & Yes & M_Ex_Sh_d28 & Yes & 0.003 & No & 0.058 & No \\
\hline M_Ex_Op_d28 & Yes & M_Ex_Op_d7 & Yes & 0.868 & Yes & 0.117 & No \\
\hline M_Ex_Op_d28 & Yes & M_Sed_Op_d28 & Yes & 0.673 & Yes & 0.277 & No \\
\hline F_Ex_Sh_d28 & Yes & M_Ex_Sh_d28 & Yes & 0.92 & Yes & 0.956 & No \\
\hline F_Ex_Sh_d28 & Yes & F_Ex_Sh_d7 & Yes & 0.392 & Yes & 0.751 & No \\
\hline F_Ex_Sh_d28 & Yes & F_Sed_Sh_d28 & Yes & 0.368 & Yes & 0.195 & No \\
\hline B_Sed_Sh_d7 & Yes & M_Sed_Sh_d7 & Yes & 0.731 & Yes & 0.185 & No \\
\hline B_Sed_Op_d7 & Yes & B_Sed_Sh_d7 & Yes & 0.953 & Yes & 0 & Yes \\
\hline B_Sed_Op_d7 & Yes & M_Sed_Op_d7 & Yes & 0.368 & Yes & 0.178 & No \\
\hline B_Ex_Sh_d7 & Yes & B_Sed_Sh_d7 & Yes & 0.068 & Yes & 0.18 & No \\
\hline B_Ex_Sh_d7 & Yes & M_Ex_Sh_d7 & Yes & 0.132 & Yes & 0.204 & No \\
\hline B_Ex_Op_d7 & Yes & B_Ex_Sh_d7 & Yes & 0.008 & No & 0.011 & Yes \\
\hline B_Ex_Op_d7 & Yes & B_Sed_Op_d7 & Yes & 0.276 & Yes & 0.168 & No \\
\hline B_Ex_Op_d7 & Yes & M_Ex_Op_d7 & Yes & 0.665 & Yes & 0.413 & No \\
\hline
\end{tabular}


Levene's Test for Equal Variance and Kruskal-Wallis [Resting Diameter]

\begin{tabular}{|c|c|c|c|c|c|c|c|}
\hline Group 1 & $\begin{array}{c}\text { Group 1 } \\
\text { normal? }\end{array}$ & Group 2 & $\begin{array}{c}\text { Group 2 } \\
\text { normal? }\end{array}$ & $\begin{array}{c}\text { Levene } \\
\text { Test } \\
\text { p-value }\end{array}$ & $\begin{array}{c}\text { Equal } \\
\text { variances? }\end{array}$ & $\begin{array}{c}\text { Kruskal- } \\
\text { Wallis } \\
\text { p-value }\end{array}$ & $\begin{array}{c}\text { Different } \\
\text { medians? }\end{array}$ \\
\hline F_Ex_Op_d28 & No & F_Ex_Sh_d28 & Yes & 0.391 & Yes & 0.007 & Yes \\
\hline F_Ex_Op_d28 & No & M_Ex_Op_d28 & Yes & 0.523 & Yes & 0.958 & No \\
\hline F_Ex_Op_d28 & No & F_Ex_Op_d7 & Yes & 0.334 & Yes & 1 & No \\
\hline F_Ex_Op_d28 & No & F_Sed_Op_d28 & Yes & 0.466 & Yes & 0.059 & No \\
\hline
\end{tabular}

Comparison of C57B1/6 Resting Diameter

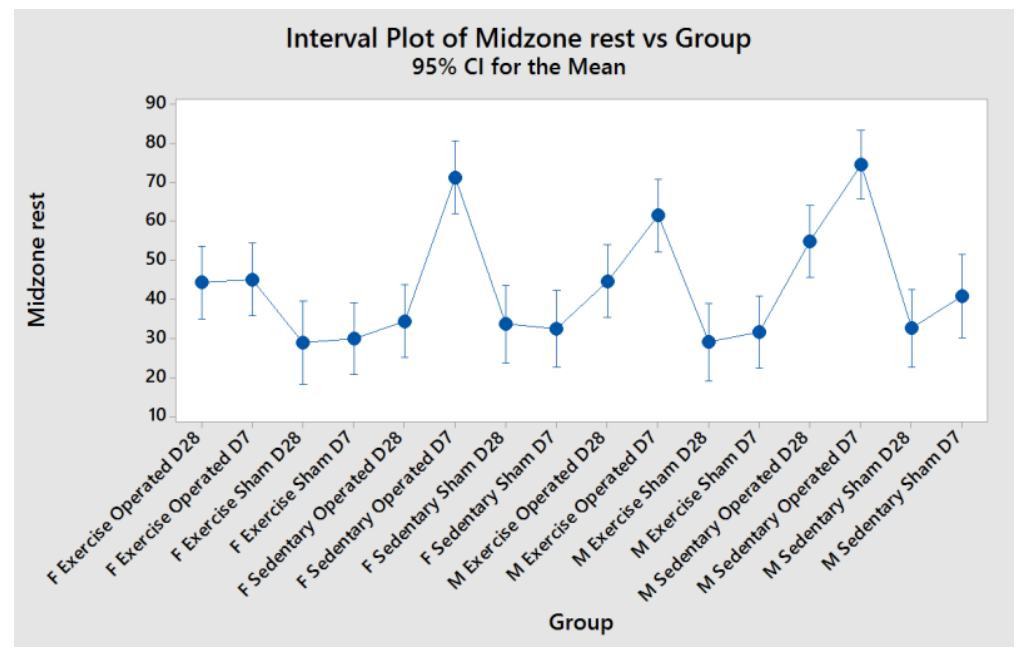

Comparison of Balb/c and C57Bl/6 Resting Diameter

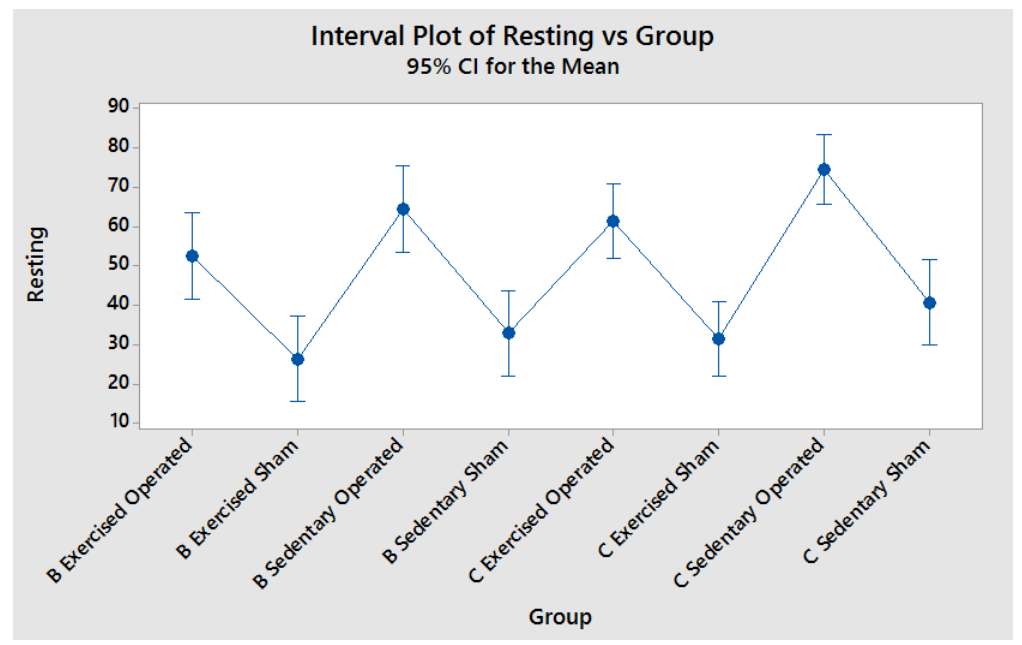


F-Test for Equal Variance and ANOVA [Dilated Diameter]

\begin{tabular}{|c|c|c|c|c|c|c|c|}
\hline Group 1 & $\begin{array}{l}\text { Group } 1 \\
\text { normal? }\end{array}$ & Group 2 & $\begin{array}{l}\text { Group } 2 \\
\text { normal? }\end{array}$ & $\begin{array}{l}\text { F-Test } \\
\text { p-value }\end{array}$ & $\begin{array}{c}\text { Equal } \\
\text { variances? }\end{array}$ & $\begin{array}{l}\text { ANOVA } \\
\text { p-value }\end{array}$ & $\begin{array}{c}\text { Different } \\
\text { means? }\end{array}$ \\
\hline M_Sed_Op_d7 & Yes & M_Sed_Sh_d7 & Yes & 0.976 & Yes & 0.002 & Yes \\
\hline F_Sed_Sh_d7 & Yes & M_Sed_Sh_d7 & Yes & 0.574 & Yes & 0.063 & No \\
\hline F_Sed_Op_d7 & Yes & F_Sed_Sh_d7 & Yes & 0.204 & Yes & 0 & Yes \\
\hline F_Sed_Op_d7 & Yes & M_Sed_Op_d7 & Yes & 0.503 & Yes & 0.724 & No \\
\hline M_Sed_Sh_d28 & Yes & M_Sed_Sh_d7 & Yes & 0.74 & Yes & 0.248 & No \\
\hline M_Sed_Op_d28 & Yes & M_Sed_Sh_d28 & Yes & 0.498 & Yes & 0 & Yes \\
\hline M_Sed_Op_d28 & Yes & M_Sed_Op_d7 & Yes & 0.752 & Yes & 0.572 & No \\
\hline F_Sed_Sh_d28 & Yes & M_Sed_Sh_d28 & Yes & 0.929 & Yes & 0.622 & No \\
\hline F_Sed_Sh_d28 & Yes & F_Sed_Sh_d7 & Yes & 0.893 & Yes & 0.193 & No \\
\hline F_Sed_Op_d28 & Yes & F_Sed_Sh_d28 & Yes & 0.322 & Yes & 0.001 & Yes \\
\hline F_Sed_Op_d28 & Yes & M_Sed_Op_d28 & Yes & 0.806 & Yes & 0.518 & No \\
\hline F_Sed_Op_d28 & Yes & F_Sed_Op_d7 & Yes & 0.923 & Yes & 0.869 & No \\
\hline M_Ex_Sh_d7 & Yes & M_Sed_Sh_d7 & Yes & 0.965 & Yes & 0.054 & No \\
\hline M_Ex_Op_d7 & Yes & M_Ex_Sh_d7 & Yes & 0.263 & Yes & 0 & Yes \\
\hline M_Ex_Op_d7 & Yes & M_Sed_Op_d7 & Yes & 0.235 & Yes & 0.852 & No \\
\hline F_Ex_Sh_d7 & Yes & M_Ex_Sh_d7 & Yes & 0.038 & No & 0.401 & No \\
\hline F_Ex_Sh_d7 & Yes & F_Sed_Sh_d7 & Yes & 0.137 & Yes & 0.646 & No \\
\hline F_Ex_Op_d7 & Yes & F_Ex_Sh_d7 & Yes & 0.052 & Yes & 0 & Yes \\
\hline F_Ex_Op_d7 & Yes & M_Ex_Op_d7 & Yes & 0.204 & Yes & 0.383 & No \\
\hline F_Ex_Op_d7 & Yes & F_Sed_Op_d7 & Yes & 0.434 & Yes & 0.387 & No \\
\hline M_Ex_Sh_d28 & Yes & M_Ex_Sh_d7 & Yes & 0.117 & Yes & 0.895 & No \\
\hline M_Ex_Sh_d28 & Yes & M_Sed_Sh_d28 & Yes & 0.243 & Yes & 0.226 & No \\
\hline M_Ex_Op_d28 & Yes & M_Ex_Sh_d28 & Yes & 0.018 & Yes & 0.001 & Yes \\
\hline M_Ex_Op_d28 & Yes & M_Ex_Op_d7 & Yes & 0.891 & Yes & 0.62 & No \\
\hline M_Ex_Op_d28 & Yes & M_Sed_Op_d28 & Yes & 0.48 & Yes & 0.242 & No \\
\hline F_Ex_Sh_d28 & Yes & M_Ex_Sh_d28 & Yes & 0.957 & Yes & 0.62 & No \\
\hline F_Ex_Sh_d28 & Yes & F_Ex_Sh_d7 & Yes & 0.71 & Yes & 0.109 & No \\
\hline F_Ex_Sh_d28 & Yes & F_Sed_Sh_d28 & Yes & 0.288 & Yes & $0.049 \rightarrow 0.05$ & No* \\
\hline B_Sed_Sh_d7 & Yes & M_Sed_Sh_d7 & Yes & 0.853 & Yes & 0.123 & No \\
\hline B_Sed_Op_d7 & Yes & B_Sed_Sh_d7 & Yes & 0.376 & Yes & 0.009 & Yes \\
\hline B_Sed_Op_d7 & Yes & M_Sed_Op_d7 & Yes & 0.425 & Yes & 0.015 & Yes \\
\hline B_Ex_Sh_d7 & Yes & B_Sed_Sh_d7 & Yes & 0.069 & Yes & 0.093 & No \\
\hline B_Ex_Sh_d7 & Yes & M_Ex_Sh_d7 & Yes & 0.077 & Yes & 0.137 & No \\
\hline B_Ex_Op_d7 & Yes & B_Ex_Sh_d7 & Yes & 0.031 & No & 0.003 & Yes \\
\hline B_Ex_Op_d7 & Yes & B_Sed_Op_d7 & Yes & 0.206 & Yes & 0.762 & No \\
\hline B_Ex_Op_d7 & Yes & M_Ex_Op_d7 & Yes & 0.668 & Yes & 0.221 & No \\
\hline
\end{tabular}


Levene's Test for Equal Variance and Kruskal-Wallis [Dilated Diameter]

\begin{tabular}{|c|c|c|c|c|c|c|c|}
\hline Group 1 & $\begin{array}{c}\text { Group 1 } \\
\text { normal? }\end{array}$ & Group 2 & $\begin{array}{c}\text { Group 2 } \\
\text { normal? }\end{array}$ & $\begin{array}{c}\text { Levene } \\
\text { Test } \\
\text { p-value }\end{array}$ & $\begin{array}{c}\text { Equal } \\
\text { variances? }\end{array}$ & $\begin{array}{c}\text { Kruskal- } \\
\text { Wallis } \\
\text { p-value }\end{array}$ & $\begin{array}{c}\text { Different } \\
\text { medians? }\end{array}$ \\
\hline F_Ex_Op_d28 & No & F_Ex_Sh_d28 & Yes & 0.152 & Yes & 0.002 & Yes \\
\hline F_Ex_Op_d28 & No & M_Ex_Op_d28 & Yes & 0.722 & Yes & 0.6 & No \\
\hline F_Ex_Op_d28 & No & F_Ex_Op_d7 & Yes & 0.55 & Yes & 0.372 & No \\
\hline F_Ex_Op_d28 & No & F_Sed_Op_d28 & Yes & 0.856 & Yes & 0.916 & No \\
\hline
\end{tabular}

Comparison of C57B1/6 Dilated Diameter

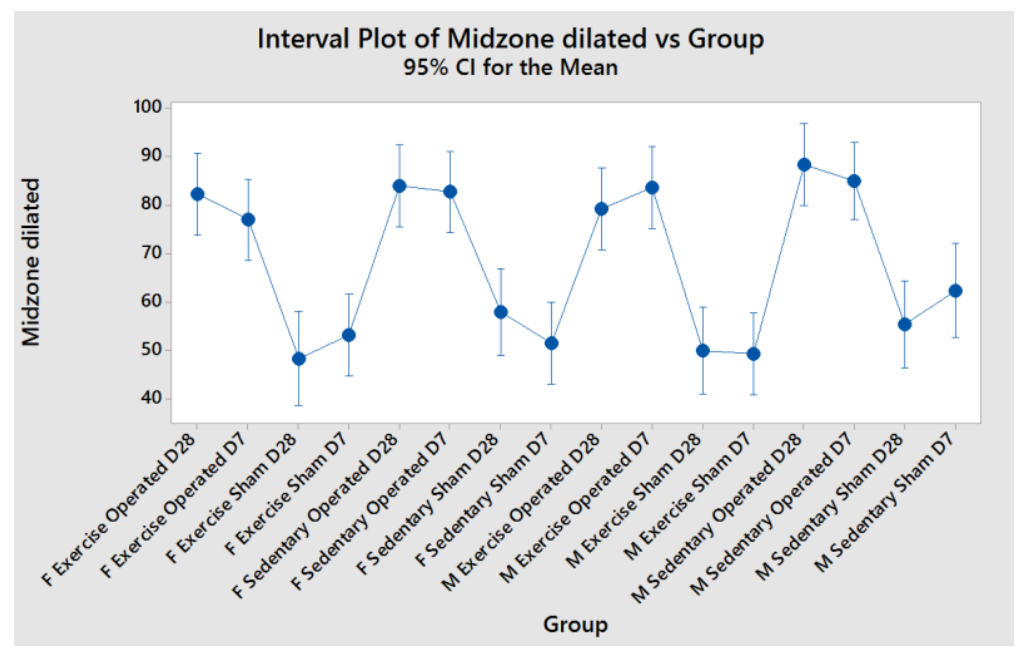

Comparison of Balb/c and C57B1/6 Dilated Diameter

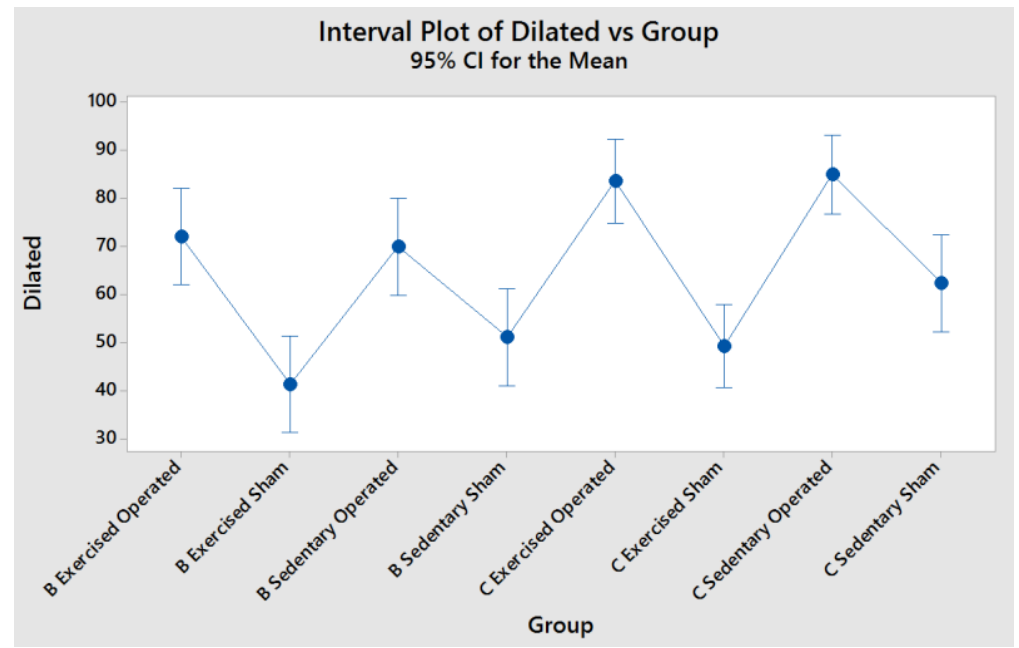


F-Test for Equal Variance and ANOVA [Percent Change in Diameter]

\begin{tabular}{|c|c|c|c|c|c|c|c|}
\hline Group 1 & $\begin{array}{l}\text { Group } 1 \\
\text { normal? }\end{array}$ & Group 2 & $\begin{array}{c}\text { Group } 2 \\
\text { normal? }\end{array}$ & $\begin{array}{l}\text { F-Test } \\
\text { p-value }\end{array}$ & $\begin{array}{c}\text { Equal } \\
\text { variances? }\end{array}$ & $\begin{array}{c}\text { ANOVA } \\
\text { p-value }\end{array}$ & $\begin{array}{c}\text { Different } \\
\text { means? }\end{array}$ \\
\hline F_Sed_Op_d7 & Yes & F_Sed_Sh_d7 & Yes & 0.037 & No & 0.005 & Yes \\
\hline F_Sed_Op_d7 & Yes & M_Sed_Op_d7 & Yes & 0.993 & Yes & 0.696 & No \\
\hline M_Sed_Op_d28 & Yes & M_Sed_Sh_d28 & Yes & 0.687 & Yes & 0.866 & No \\
\hline M_Sed_Op_d28 & Yes & M_Sed_Op_d7 & Yes & 0.001 & No & 0.01 & Yes \\
\hline F_Sed_Sh_d28 & Yes & M_Sed_Sh_d28 & Yes & 0.308 & Yes & 0.824 & No \\
\hline F_Sed_Sh_d28 & Yes & F_Sed_Sh_d7 & Yes & 0.106 & Yes & 0.515 & No \\
\hline F_Sed_Op_d28 & Yes & F_Sed_Sh_d28 & Yes & 0.552 & Yes & 0.027 & Yes \\
\hline F_Sed_Op_d28 & Yes & M_Sed_Op_d28 & Yes & 0.935 & Yes & 0.004 & Yes \\
\hline F_Sed_Op_d28 & Yes & F_Sed_Op_d7 & Yes & 0.002 & No & 0 & Yes \\
\hline M_Ex_Op_d7 & Yes & M_Ex_Sh_d7 & Yes & 0.222 & Yes & 0.336 & No \\
\hline M_Ex_Op_d7 & Yes & M_Sed_Op_d7 & Yes & 0.009 & No & 0.054 & No \\
\hline F_Ex_Sh_d7 & Yes & M_Ex_Sh_d7 & Yes & 0.225 & Yes & 0.087 & No \\
\hline F_Ex_Sh_d7 & Yes & F_Sed_Sh_d7 & Yes & 0.716 & Yes & 0.25 & No \\
\hline M_Ex_Sh_d28 & Yes & M_Ex_Sh_d7 & Yes & 0.2 & Yes & 0.242 & No \\
\hline M_Ex_Sh_d28 & Yes & M_Sed_Sh_d28 & Yes & 0.852 & Yes & 0.953 & No \\
\hline M_Ex_Op_d28 & Yes & M_Ex_Sh_d28 & Yes & 0.055 & Yes & 0.469 & No \\
\hline M_Ex_Op_d28 & Yes & M_Ex_Op_d7 & Yes & 0.033 & No & 0.102 & No \\
\hline M_Ex_Op_d28 & Yes & M_Sed_Op_d28 & Yes & 0.139 & Yes & 0.382 & No \\
\hline F_Ex_Sh_d28 & Yes & M_Ex_Sh_d28 & Yes & 0.833 & Yes & 0.789 & No \\
\hline F_Ex_Sh_d28 & Yes & F_Ex_Sh_d7 & Yes & 0.907 & Yes & 0.478 & No \\
\hline F_Ex_Sh_d28 & Yes & F_Sed_Sh_d28 & Yes & 0.19 & Yes & 0.719 & No \\
\hline F_Ex_Op_d28 & Yes & F_Ex_Sh_d28 & Yes & 0.618 & Yes & 0.246 & No \\
\hline F_Ex_Op_d28 & Yes & M_Ex_Op_d28 & Yes & 0.078 & Yes & 0.857 & No \\
\hline F_Ex_Op_d28 & Yes & F_Sed_Op_d28 & Yes & 0.697 & Yes & 0.026 & Yes \\
\hline B_Ex_Sh_d7 & Yes & M_Ex_Sh_d7 & Yes & 0.63 & Yes & 0.927 & No \\
\hline
\end{tabular}


Levene's Test for Equal Variance and Kruskal-Wallis [Percent Change in Diameter]

\begin{tabular}{|c|c|c|c|c|c|c|c|}
\hline Group 1 & $\begin{array}{c}\text { Group 1 } \\
\text { normal? }\end{array}$ & Group 2 & $\begin{array}{c}\text { Group 2 } \\
\text { normal? }\end{array}$ & $\begin{array}{c}\text { Levene } \\
\text { Test } \\
\text {-value }\end{array}$ & $\begin{array}{c}\text { Equal } \\
\text { variances? }\end{array}$ & $\begin{array}{c}\text { Kruskal- } \\
\text { Wallis } \\
\text { p-value }\end{array}$ & $\begin{array}{c}\text { Different } \\
\text { medians? }\end{array}$ \\
\hline B_Sed_Sh_d7 & No & M_Sed_Sh_d7 & Yes & 0.867 & Yes & 0.522 & No \\
\hline B_Sed_Op_d7 & No & B_Sed_Sh_d7 & No & 0.35 & Yes & 0.004 & Yes \\
\hline B_Sed_Op_d7 & No & M_Sed_Op_d7 & Yes & 0.306 & Yes & 0.239 & No \\
\hline B_Ex_Sh_d7 & Yes & B_Sed_Sh_d7 & No & 0.728 & Yes & 0.749 & No \\
\hline B_Ex_Op_d7 & No & B_Ex_Sh_d7 & Yes & 0.392 & Yes & 0.109 & No \\
\hline B_Ex_Op_d7 & No & B_Sed_Op_d7 & No & 0.245 & Yes & 0.016 & Yes \\
\hline B_Ex_Op_d7 & No & M_Ex_Op_d7 & Yes & 0.787 & Yes & 0.796 & No \\
\hline
\end{tabular}

Comparison of C57B1/6 Percent Change in Diameter

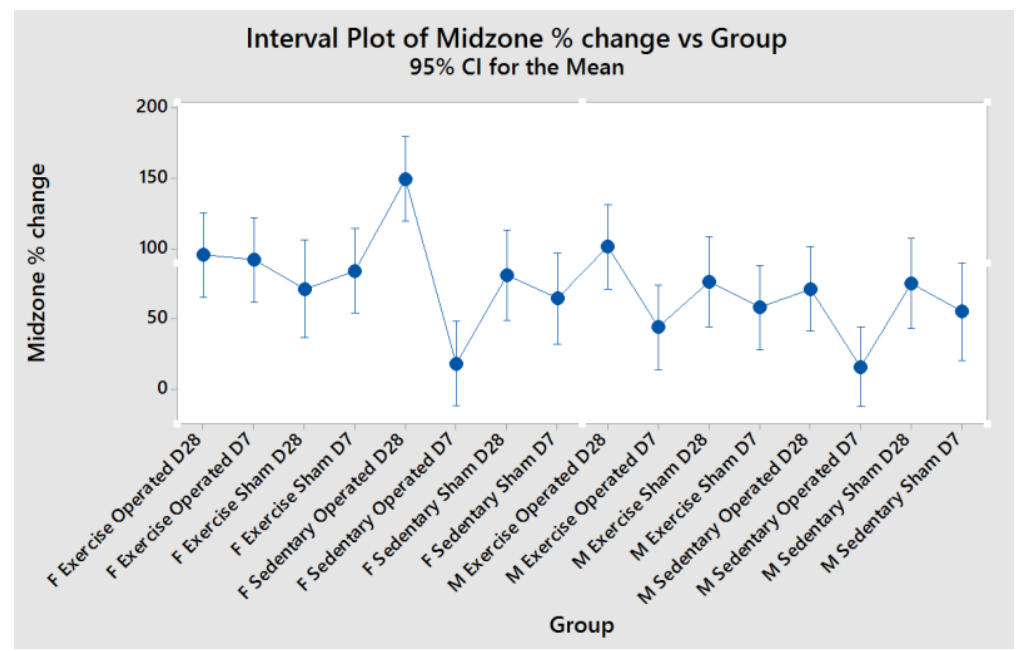

Comparison of Balb/c and C57B1/6 Percent Change in Diameter

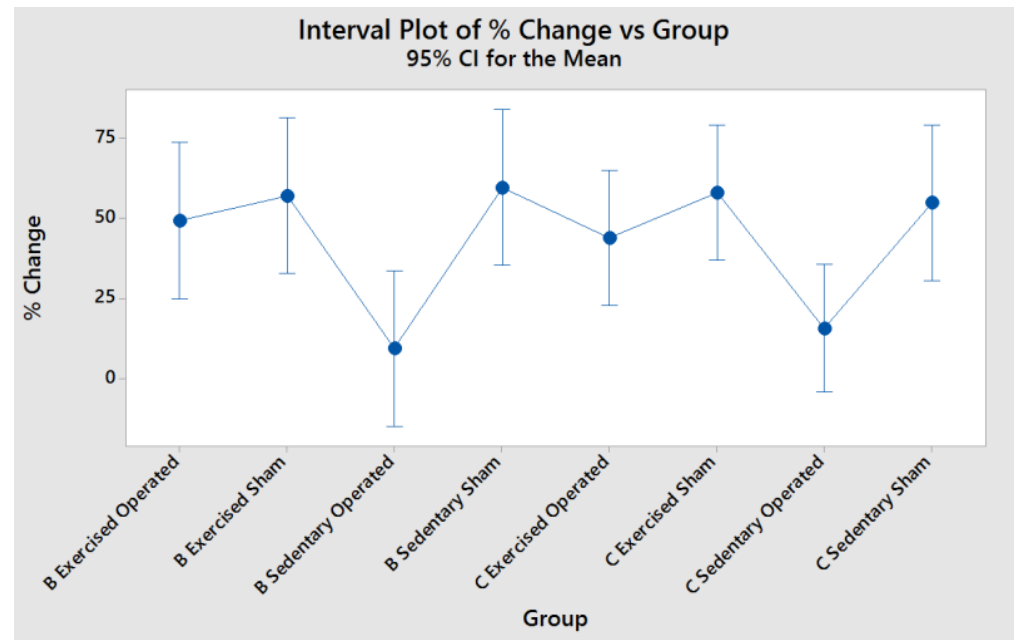


Sample F-Tests for Equal Variances, Interval Plots, and Tukey or Games-Howell Comparisons of Means
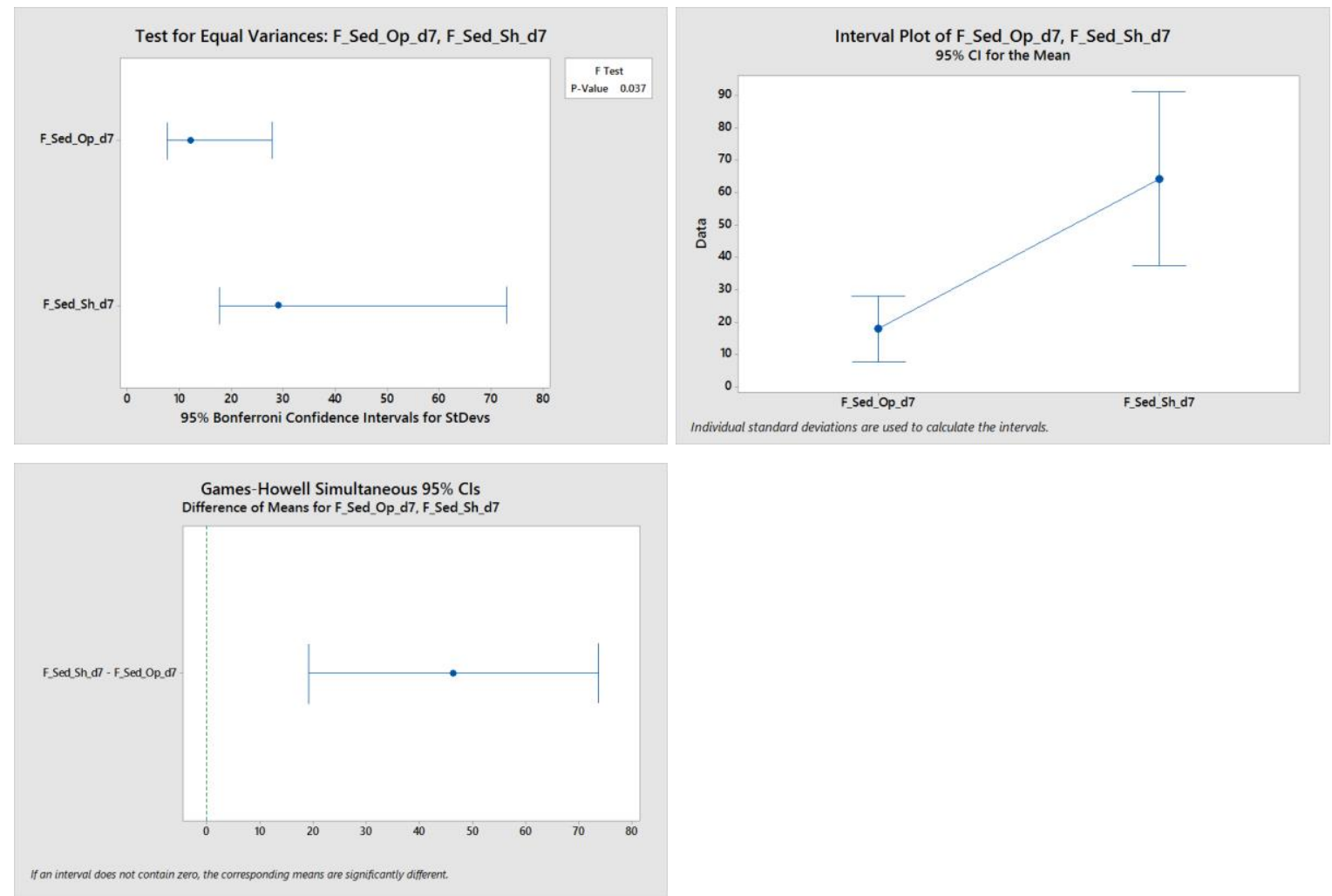

Individual standard deviations are used to calculate the intervals.
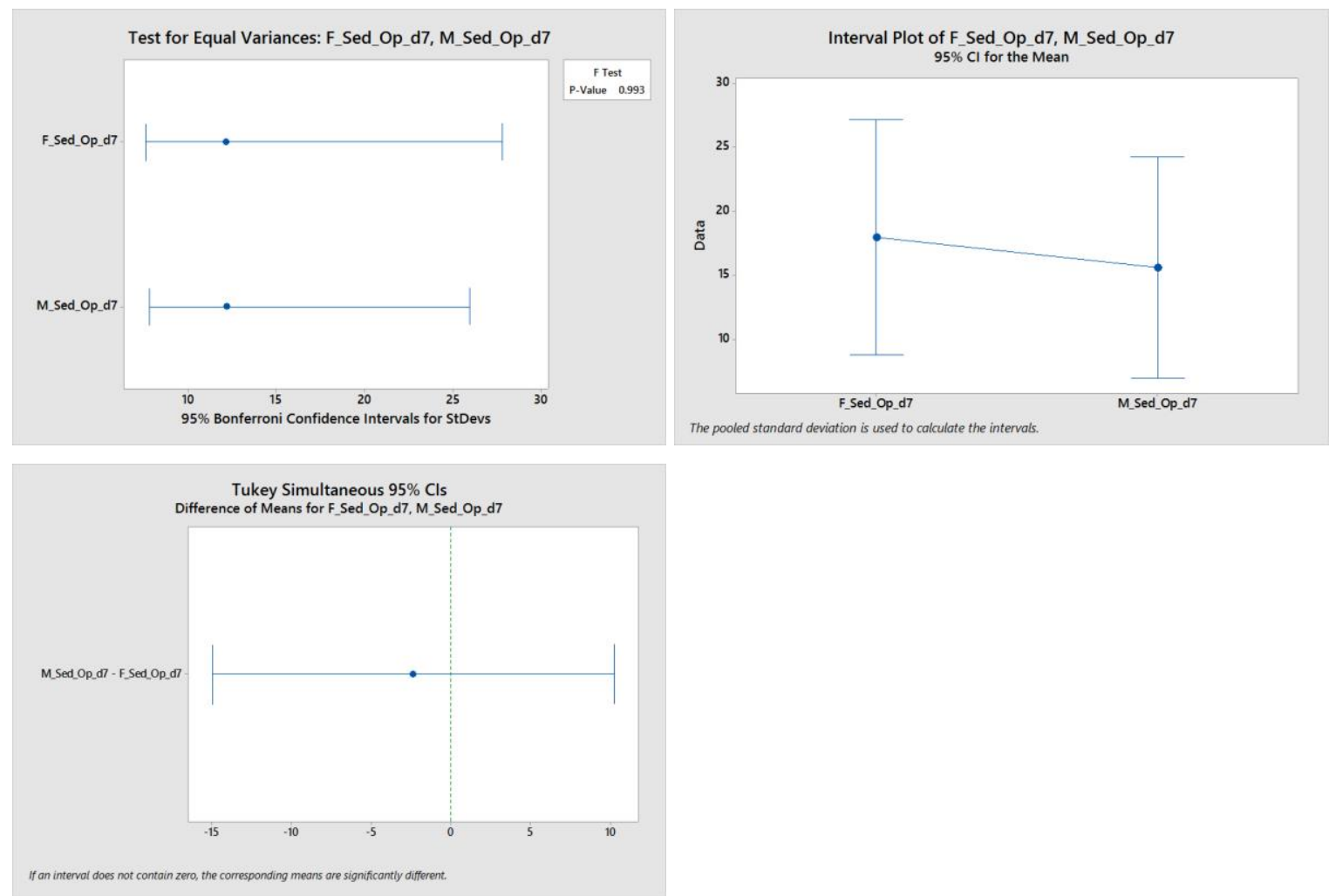
Sample Regression Plots of Resting Diameter, Dilated Diameter, and \% Change vs. Running Distance
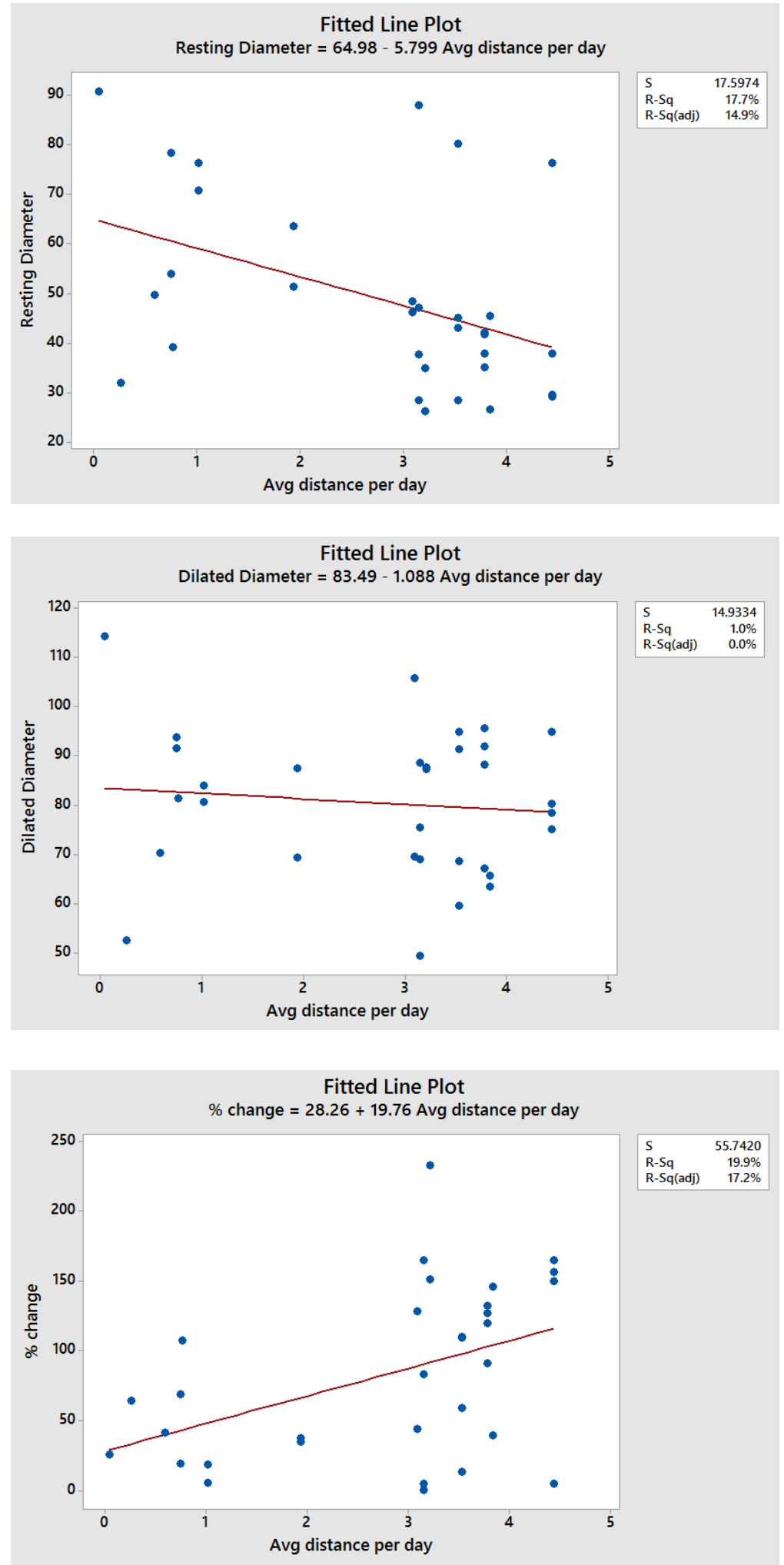